\title{
IV. MARKALAK CLAY
}

During field research, a particular type of clay appeared at different places along the Western Himalayas. It turned out to be commonly known as having a high quality for building purposes, and further appeared to have a long tradition with hard to understand roots. On the one hand it is presently a popular material used by locals and conservators; on the other hand we have evidence of its historical use. For now the research presented here extends from the very west of Ladakh to the most eastern finding of this material. It further stretches to a local building tradition in Purang located in West Tibet not far south of the Kailas region close to the Nepalese border (Map 1.4).

Partially the names given to this material are changing. In Ladakh it is commonly known as markalak clay. ${ }^{1}$ In Zangskar, Spiti, Lahaul, Kinnaur and Ngari (see Map 1.4) this term is also known although not necessarily commonly used (Feiglstorfer 2014: 378). For a markalak clay the expression "clay" is locally more common than "earth" (Interview Tsering Wangyal 2002; Feiglstorfer 2002: 36). South of Ladakh in the north east of Himachal Pradesh, in Spiti and Upper Kinnaur, it is known as tua clay. Moving further east to Purang in western Tibet, it is again known - similar to markalak clay-as narkalak clay. This obvious similarity of the names over a distance of approximately $700 \mathrm{~km}$ indicates a knowledge transfer of clay and invites deeper investigation.

During field research it was determined that places where this type of clay could be found were always related to a particular water transport close to a river, such as the Indus, the Spiti, the Sutlej or the Peacock River. However, these locations were not necessarily immediately adjacent to the water. In this relation it is of importance that vicinity to an aquiferous geological formation seems to be relevant for this type of clay. The author intends to question this relation within this chapter.

Common uses of this type of fine material are primarily for particular structural and decorative objects and building parts. One field of application is flat earth roofs, primarily used for the most upper constructive layer. For the roof, this material is used to fill cracks. In an interview, Mr. Dawa, the former director of LEDeG in Leh / Ladakh, described the method on the roof of the Ladakh Ecological Development Group (LEDeG) in Leh (Interview Sonam Dawa 2002). ${ }^{2}$ In the case of cracks, pieces of markalak clay of a size of up to one fist are sprinkled onto the roof along cracks. This is conducted during a dry period. As soon as rain falls the hard bricks of markalak clay are softened, and by turning into sludge the markalak clay fills and closes the cracks. After drying the cracks are filled without leaving any further cracks between the new filling material and the original clay on the roof. The mixture of this material, in particular of swellable and non

1 In the area of Basgo also a chukalak (Tib. chu ka lag: chu meaning water), i.e. clay-like silt on the ground of irrigation ponds and flood plains, is known (Feiglstorfer 2014: 374).

2 "Mr. Dawa presented some samples of markalak clay, which are characterised by a soft chalk fineness. In his youth - about 50 years ago, as he mentioned, he used this clay for writing on blackboards. The method of applying this material is very simple: fist-sized lumps of clay are crumbled into smaller pieces and scattered onto the leaking roof locations. No further addition of water is necessary. Only in the course of the next rain does the sprinkled clay combine with the underlying roof surface to form a homogeneous and moisture-proof layer of clay. Finally, the newly applied layer is about one centimetre thick. This is also a good method of refurbishment of the roof when previously a sufficient amount of clay was applied." (Feiglstorfer 2002: 36, translation from German)

https://doi.org/10.1515/9783110591330-006 


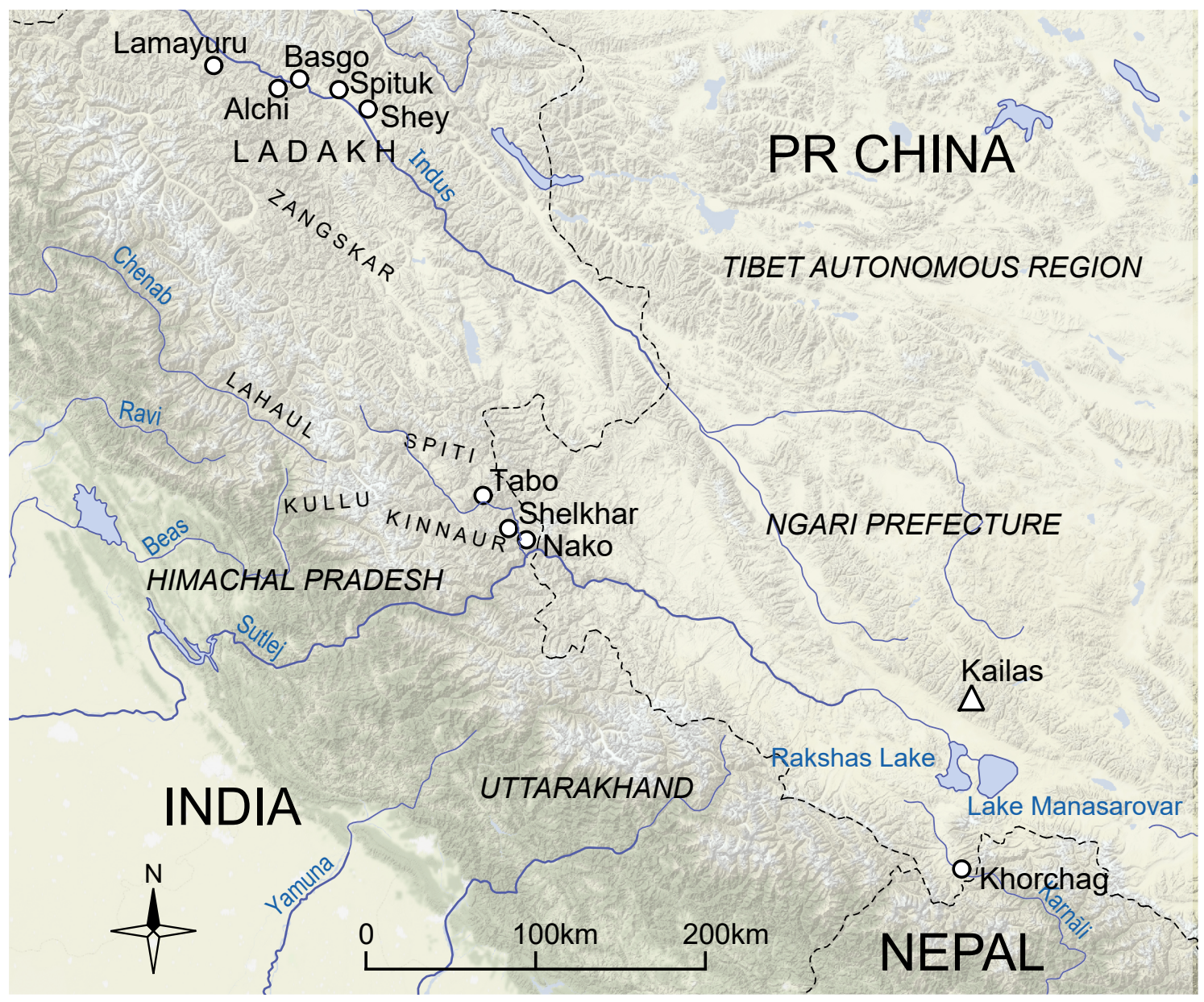

Map 1.4 Origin of the samples. GIS data based map: Jakob Gredler. Final graphics: author. Map based on data from VD and BM.

swellable clay minerals, and the amount of silt are ideal for this kind of purpose. ${ }^{3}$ For this reason such material is also popular for the restoration of cracks in walls, in particular of plasters and upper layers of plasters. As seen during examination of other kinds of clays in other regions, particularly in Nyarma (Chapter II) or at Basgo and Likir (cf. Feiglstorfer, forthcoming a), markalak clay is not a prime material for the preparation of plasters, although these would be areas close to markalak clay resources (Map 1.4). In Lamayuru in Ladakh on the other hand the markalak clay is mixed with sand for the preparation of plasters (Feiglstorfer 2014: 374).

While cracks in the exterior surface of an exterior wall, which was covered with a clay plaster, can easily be filled by pouring a slurry of clay over the cracks, the treatment of interior walls and of the roof is not particularly easy. After closing cracks on the inner surfaces of walls, their appearance should be even, especially in the case of walls covered by wall paintings, as we find in early Tibetan temples. For this purpose the clay does not have to be too coarse, as in this case it would not stick sufficiently to the surrounding existing material. Otherwise, too high content of clay would cause the filling-material to shrink and further cracks between the filling material and the surrounding existing parts of the wall would result.

3 See Chapter III for a detailed description of flat roof constructions. 
For this reason some types of markalak clays, which show a high content of silt, are popular for closing cracks. If the material does not have to be so fine, as is the case with the markalak clay, it is mixed with coarser clay. If the latter mentioned clay is of good quality according to the particular need, not much markalak clay or none at all has to be added. Mr. Wangchuk from the Archaeological Survey of India (ASI) in Leh mentions the former use of dark, black clay as the upper roof layer since this kind of clay stores a larger amount of water ${ }^{4}$ (Interview Wangchuk 2005). Interviews along the whole Western Himalayas have confirmed the wide dissemination of the knowledge about using markalak clay to fill cracks. In Dhankar in Spiti, for example, the owner of a local building showed his method of pouring a highly aqueous slurry of markalak clay with his watering can over the cracks along the facades. This is a method of maintenance which he practices every spring when cracks become visible. Such cracks are caused in the exterior surface of the wall by the freezing of precipitation.

In the case of bigger cracks (not hair cracks), which primarily are the result of static changes in the wall or much likelier in the subfloor or in the basement, these methods for filling cracks are not sufficient. For stitching big cracks, the filling itself has to be stressable by tension. Simply using clay is not enough in such a case. John Hurd explained a method for stitching structural cracks. ${ }^{5}$ After cutting a recess, the crack is filled with alternating layers of moistened bricks and a mixture of yagtsa (in the following given with the commonly used term "yakses") as well as twigs, branches and Hessian cloth (Interview Hurd 2008).

Markalak clay is also mentioned in relation to clay sculptures or as being used on painted surfaces before applying white wash. ${ }^{6}$ As seen in Nyarma (see Chapter II) for all ornaments - be it the modelled aureole in the assembly hall of the main temple or the piece of a frieze of the interior of a stupa - the characteristics of markalak clay can not be determined throughout the remains of the whole monastery. Also the material - which is used for building up the substructure of clay models, as practised at the CIBS (Central Institute of Buddhist Studies) in Choglamsar / Ladakh - is more related to what is commonly used for adobe bricks and has nothing to do with material qualities representative of markalak clays. On the other hand markalak clay was locally mentioned in relation to clay sculptures. For that reason, any relation to the markalak clay- most probably related to the fine (and most upper) layer of statues, which has yet to be examined - will be a challenge for further research.

4 The use of dark, black clay and the storage of water points towards an organic content. This description does not refer to a markalak clay but more to a tradition of using clay with an organic content as we know this from the neighbouring region of Kashmir.

5 The method of stitching structural cracks in earth walls is mentioned in an unpublished paper, which John Hurd gave to the author at the Terra Conference 2008 in Mali.

6 Cf. Feiglstorfer (2014: 379), according to Bielmeier et al. (Forthcoming). 
The haptic property of markalak clays is soft and greasy which may be an influence for the origin of its name (cf. Feiglstorfer 2014). The Tibetan term mar meaning "butter" seems well suited for widely understandable terminology to define a particular material property related to its haptic and visual qualities. The very fine types of markalak clays have a soft taste with minimal cracking sound between the teeth, and they 'melt' on the tongue but do not stick to it, indicating a particular amount of silt. In Pin Valley in North India the use of the term "kalak" for a tua clay mixed with water was recorded (see under 1.2.2 "Layers of clay" in Chapter III).

The visual effect is a monochromatic and smoothly broken surface without any clearly visible sand. The material breaks when in block form, and when dry it needs quite a lot of effort to be broken into small pieces by hand. When soaking in water, the water just slowly reaches the material's core - an indication of a dense and fine structure of the material. As soon as it is wet, it becomes sticky and easily malleable - indications for a content of clay minerals. After drying again, it remains without further cracks which makes it interesting for different kinds of building purposes, like filling cracks in wall plasters, flat earth roofs and clay sculptures.

\section{ORIGIN OF THE SAMPLES}

According to Table 1.4, clay from the following sites is examined (see Map 1.4):

- Spituk (Ladakh)

- Alchi (Ladakh)

- Lamayuru - Basgo (Ladakh)

- Shey (Ladakh)

- Nako - Shelkhar (Upper Kinnaur)

- Khorchag (Ngari)

The samples were collected at different sites according to which the following categorisation was defined. ${ }^{7}$ The markalak clay is an important raw material for conservators and builders. One research area concerns Ladakh where this material is widely known as a building material with good properties for building purposes. Dr. Christine Bläuer was kind enough to provide several samples of markalak clay for further research and comparisons with different other kinds of known types of markalak clay which were collected by the author. In particular this concerns the following samples:

- Sample 14874 from Lamayuru

- Sample 14875 from Spituk

- Sample 14876 from Alchi

Within discussions on markalak clay, which the author conducted with the Ladakh people, the most often mentioned type was the markalak clay from Spituk. Over more than ten years the author collected samples from the Spituk clay pit from different points of withdrawal at different

7 Several samples (numbers starting with 119.., 117.., 153.. and 154...) were collected and related field research was undertaken within the FWF Project P 21806 (Society, power and religion in pre-modern Western Tibet). 
Table 1.4 List of the samples.

\begin{tabular}{|c|c|c|c|c|c|c|}
\hline Sample & Country & Province & Valley & Settlement & Location & Local name \\
\hline \multicolumn{7}{|c|}{ Spituk } \\
\hline 6052 & India & Ladakh & Indus & Spituk & clay pit & markalak \\
\hline 8466 & India & Ladakh & Indus & Spituk & clay pit & markalak \\
\hline 8481 & India & Ladakh & Indus & Spituk & clay pit & markalak \\
\hline 14875 & India & Ladakh & Indus & Spituk & clay pit & markalak \\
\hline \multicolumn{7}{|c|}{ Alchi } \\
\hline 8526 & India & Ladakh & Indus & Alchi & clay pit & markalak \\
\hline 11934 & India & Ladakh & Indus & Alchi & clay pit & markalak \\
\hline 14876 & India & Ladakh & Indus & Alchi & clay pit & markalak \\
\hline \multicolumn{7}{|c|}{ Lamayuru } \\
\hline 11939 & India & Ladakh & Lamayuru & Lamayuru & clay pit & markalak \\
\hline 14874 & India & Ladakh & Lamayuru & Lamayuru & clay pit & markalak \\
\hline \multicolumn{7}{|c|}{ Basgo } \\
\hline 15518 & India & Ladakh & Indus & Basgo & clay pit & markalak \\
\hline \multicolumn{7}{|c|}{ Shey } \\
\hline 11913 & India & Ladakh & Indus & Shey & clay pit & markalak \\
\hline 15404 & India & Ladakh & Indus & Shey & clay pit & \\
\hline \multicolumn{7}{|c|}{ Nako } \\
\hline 15516 & India & Kinnaur & Spiti & Nako & building site & tua \\
\hline \multicolumn{7}{|c|}{ Shelkhar } \\
\hline 8504 & India & Spiti & Spiti & Shelkhar & clay pit & tua \\
\hline \multicolumn{7}{|c|}{ Khorchag } \\
\hline 15377 & China & Purang & Peacock & Khorchag & clay pit & narkalak \\
\hline
\end{tabular}

heights along the mining wall. Such a collection practice shows the stratigraphic layering very well. This concerns samples 6052, 8466 and 8481 . The clay pit itself is protected and digging is prohibited, as written on a big sign along the road. Nevertheless, during the author's visits a couple of people were digging which showed the renown and popularity of this material (Fig. 1.4 and Fig. 2.4). Further research led to Alchi where the author collected different types of clay used for different building purposes with the help of Morup Dorje, a local teacher. This concerns samples 8526 and 11934. Similar to the markalak clay from Spituk, the markalak clay from Lamayuru is well known within Ladakh. From this site the author collected sample 11939. In other regions of Ladakh, e.g. Basgo and the surrounding area, different species of clay are locally known (cf. Feiglstorfer, forthcoming a), and attributed to particular building purposes. Also a type of markalak clay is known. This concerns sample 15518. Also the markalak clay from Shey is widely known as a fine material for building purposes. Its location is a desertic area within a field of stupas. 11913 is the markalak clay sample from Shey. For comparison of different types of clay besides markalak clays, the author collected another clay material from Shey from a clay 


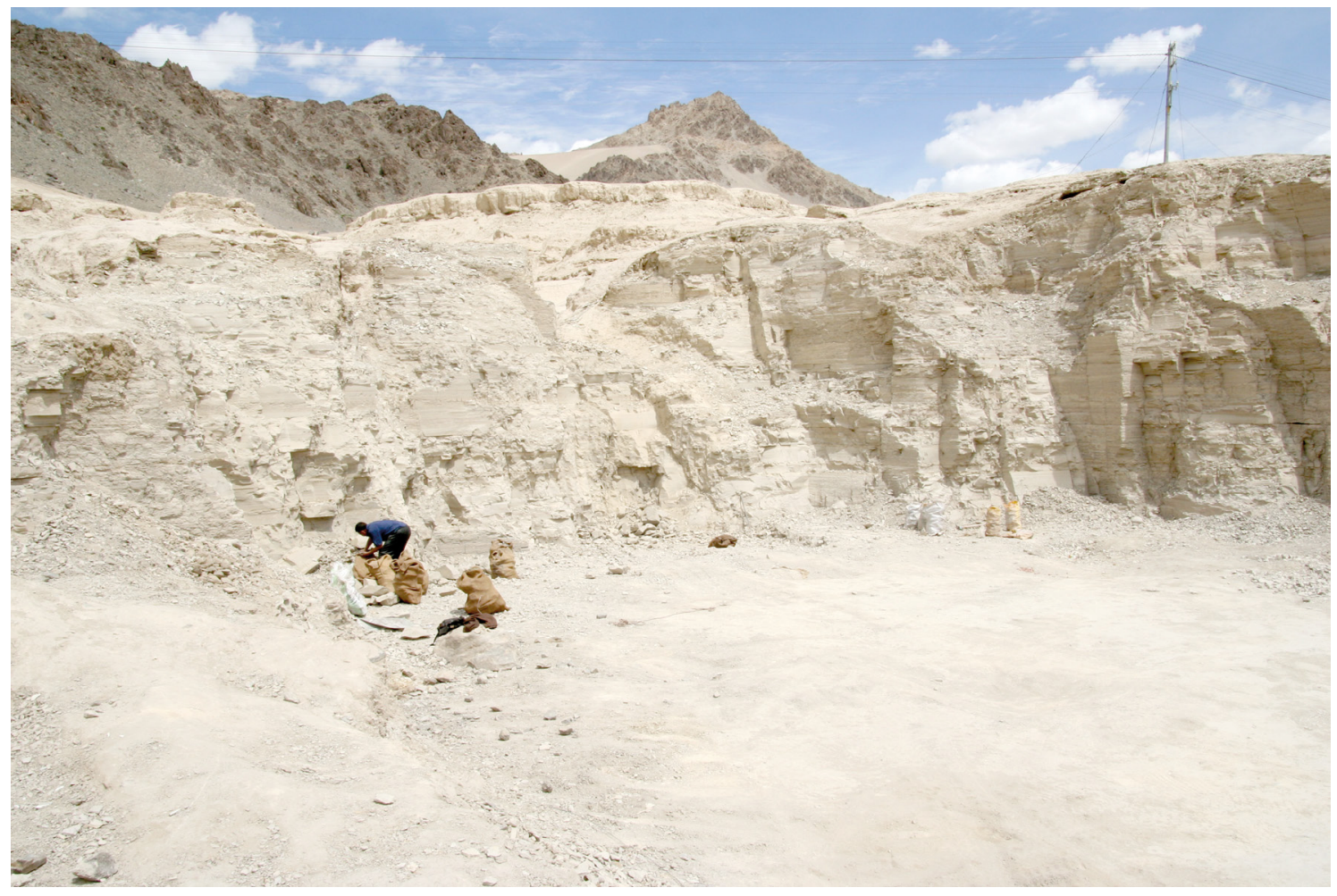

Fig. 1.4 (Top) Spituk. Ladakh. The clay is collected in big bags.

Fig. 2.4 (Bottom) Spituk. Remains of a lacustrine palaeolake in front. The Spituk Monastery is visible in the background.

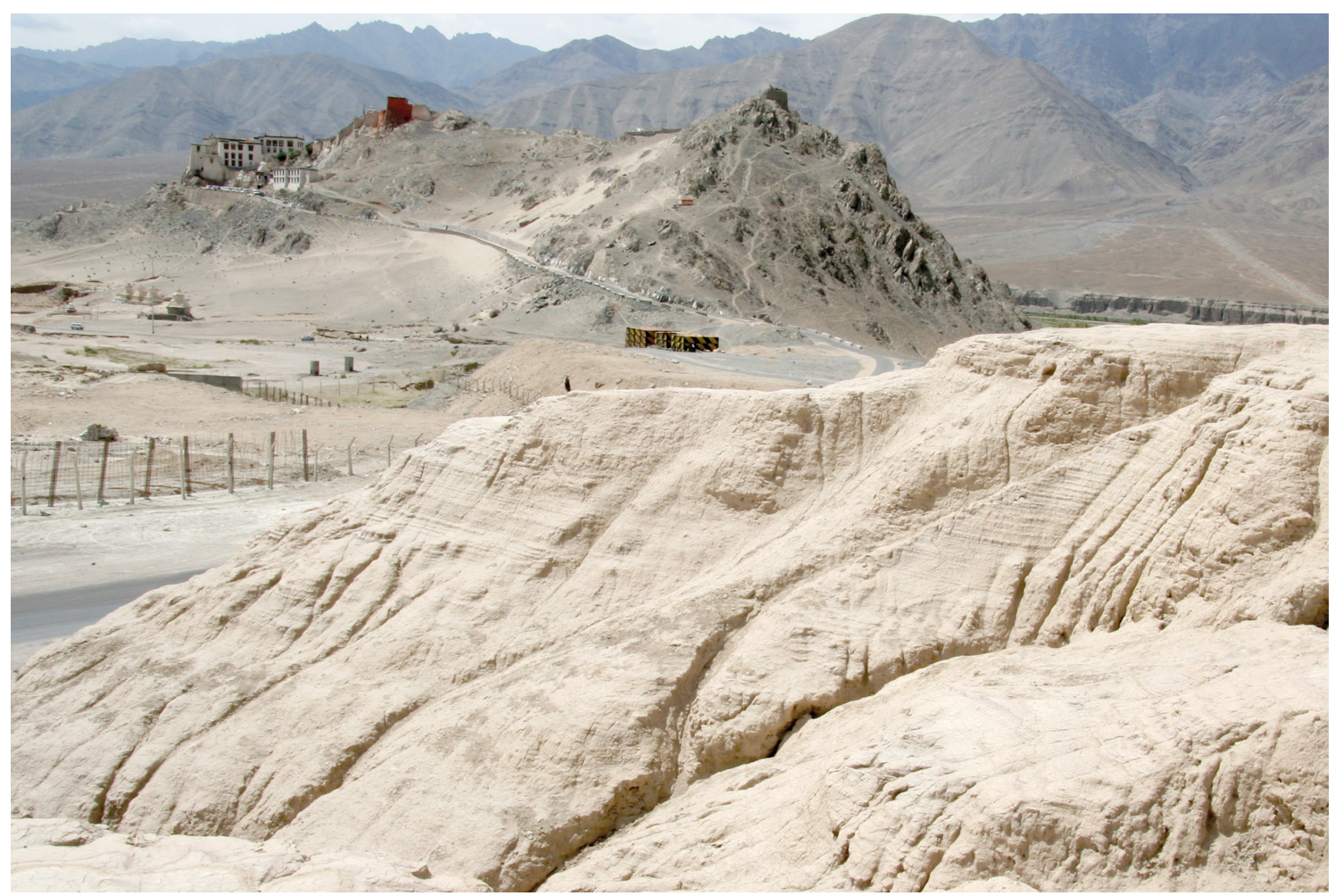


pit which is not a markalak clay and which is used for the production of bricks. This concerns sample 15404.

To enable comparison of the markalak clay types of Ladakh with markalak clay (-like) material from other Western Himalayan regions outside of Ladakh, particular material was collected in Himachal Pradesh at Shelkhar (sample 8504) and at Nako (sample 15516). Also in Tabo, from Nako upstream to Spiti, tua clay, which is said to be very similar to markalak clay, is still well known for its good material qualities. Further east in Purang in West Tibet (Ngari), moving along the Sutlej and close to the Kailas turning south along the Peacock River, another material as well known as narkalak clay was collected by a Lama from the Khorchag Monastery and provided to the author (see sample 15377).

According to present studies, the study on the markalak clay in Chapter IV will be subdivided into three geographic parts, i.e. Ladakh in Jammu and Kashmir, Spiti and Upper Kinnaur in Himachal Pradesh, and Purang in West Tibet. Although today the border between India and China is closed for a further understanding in the development of material traditions, these borders are not of striking relevance in the observation of former transport and related knowledge transfer. Much more, the whole research area within the Western Himalayas can be seen as one cultural zone specifically concerning building material traditions.

\section{RESEARCH QUESTIONS}

The generally posed research question as given in the Introduction of Chapter I are adjusted to the research topic of Chapter III and related to specific material properties and building traditions in the following way:

- Research question 1: Are there any particular material qualities to categorise a particular clay as markalak?

- Research question 2: Are the particular material qualities related to specific regions?

- Research question 3: What are the material qualities which support the markalak clay's use for the mentioned building purposes?

- Research question 4: Regarding places of finding, are there regional peculiarities for places where to find markalak clay?

- Research question 5: In which way can knowledge transfer concerning markalak clay be related to specific locally conventional terms?

- Research question 6: What are the geological parameters of markalak clays?

First the collected samples will be analysed according to their origin and local use, their grain size distribution and grain shapes, the related bulk and clay mineralogy, the content of calcite according to Scheibler, and based on simultaneous thermal analysis. Results of the analysis will be juxtaposed. Later, material properties will be examined regarding shrinkage according to DIN 18952, the liquid and plasticity limit, and the coefficient for the activity and the hardness of the surface with the Vickers needle test. 


\section{Properties of THE STUdied CLAY ${ }^{8}$}

\subsection{Spituk}

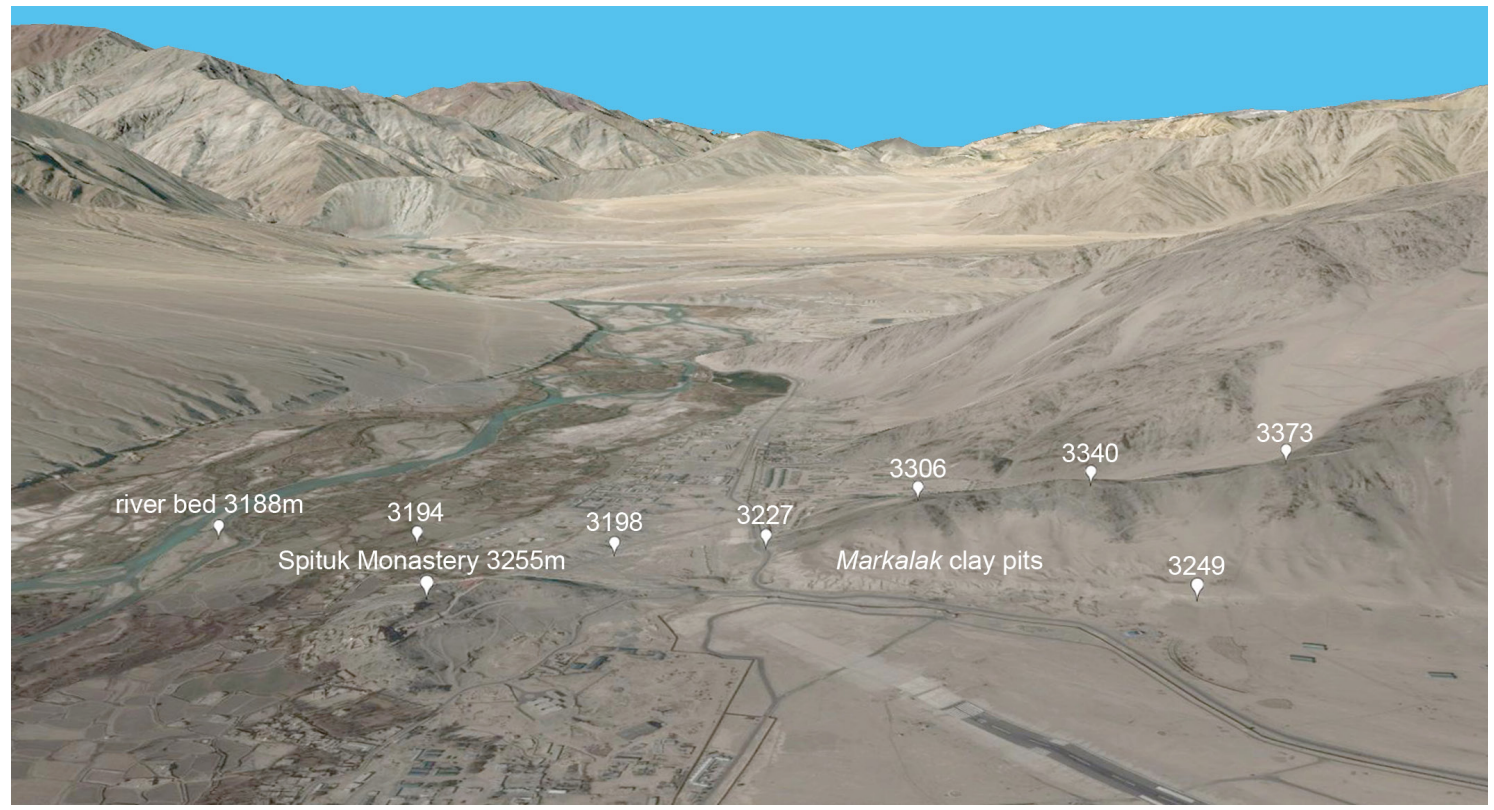

Fig. 3.4 Spituk. The level marks show the incline of the cross-country tread from the riverbed of the Indus on top of the remains of the lacustrine basin.

Source: Google Earth. Image (C) 2015 CNES / Astrium. Image Landsat. Image (C) 2015 Digital Globe.

Spituk. SAMPLE 6052

Sampling point

The Spituk clay pits (Fig. 3.4) are located in Ladakh at app. 34' $51.22^{\prime \prime} \mathrm{N}, 77^{\circ} 31^{\prime} 30.46^{\prime \prime} \mathrm{E}$. The area of the clay pits is located with a distance of app. $1 \mathrm{~km}$ from the Indus River and $61 \mathrm{~m}$ above the riverbed at a crossing with another valley in a northern direction. Fig. 3.4 shows a continuous increase of altitude from the Indus River towards the clay pits which points towards the direction of geological transport. Directly adjoining south to the Indus River, small inflows generate fluviatile forms and small alluvial fans. In a northerly direction along the glacial trough of the Indus River and the inflow, a lake may have resulted in impounding water and continuous piling up of layer by layer of fine alluvial sediments. A continuous repetition of this process caused the layering we find at several markalak clay pits. Constructive use: This material is locally reported as material for the most upper layer of earth roofs (Interview with Tsering Wangyal 2002; Feiglstorfer 2002: 36) (Fig. 4.4).

8 The documentation on which this analysis is based is collected as graphics and tables in Appendix IV. This concerns tables, grain size classes, bulk mineral analysis, clay mineral analysis, simultane thermo analysis, infrared spectroscopy and Vickers needle tests. In the appendix these data are collected by method of documentation according to the list of objects. 


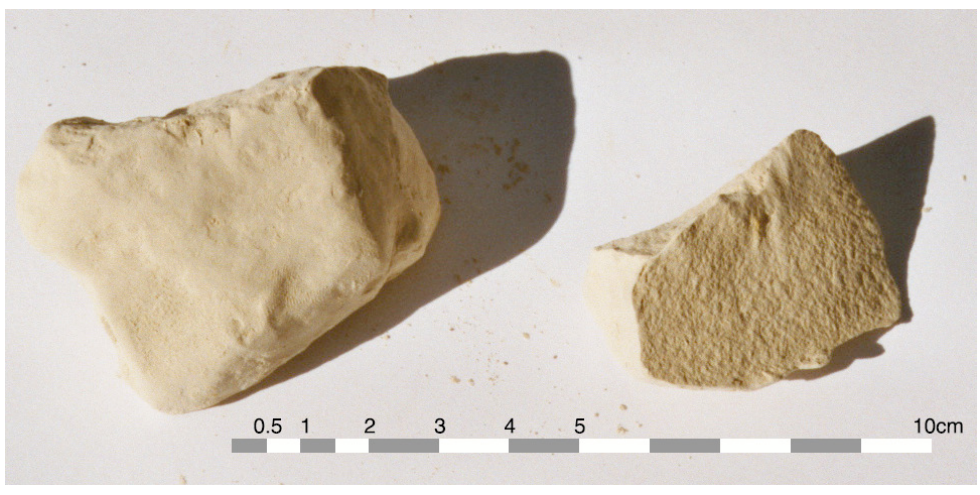

Fig. 4.4 Spituk. Sample 6052.

Sample colour (after Munsell): Dry 2.5Y6/2 light brownish grey.

Semi-dry 2.5 Y 6/3 light yellow grey.

\section{Grain size distribution}

The material is very fine. Biggest fraction: coarse silt (not regarding contents of $0.2 \%$ in the sand fraction and $0.1 \%$ in the gravel fraction). The median is located at app. $7.5 \mu \mathrm{m}$; the $<2 \mu \mathrm{m}$ fraction contains app. $16 \%$ of the whole sample. At $84.6 \%$, the amount of silt is high. The maximum peak lies at $39.5 \%$ for medium silt. In the distribution curve, no bimodal distribution is evident. A mixture of the material with sand or another type of clay is excluded since this sample was directly taken from the pit. The cumulative curve shows a soft break from fine silt to coarse clay and emphasises the clear dominance of silt. The high amount of silt is responsible for counteracting against too strong shrinkage and avoiding cracks.

6052

$\begin{array}{llll}\text { Gravel } & \text { Sand } & \text { Silt } & \text { Clay [\%] } \\ 0.1 & 0.2 & 84.6 & 15.1\end{array}$

\section{Grain shapes}

An average shape can be given as "angular" (Fig. 5.4).
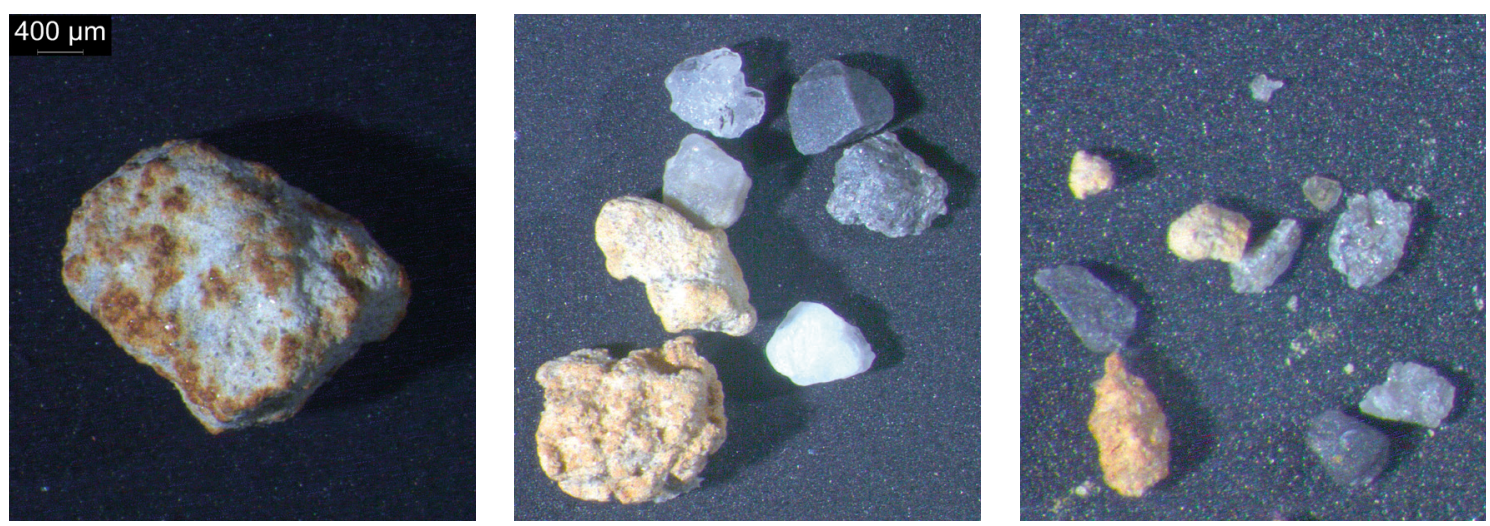

Fig. 5.4 Shapes of grains in sample 6052. Same scale (see upper left corner of the left picture).

Shape of fraction $>2,000 \mu \mathrm{m}$ (Left), 630-2,000 $\mu \mathrm{m}$ (Centre), 200-630 $\mu \mathrm{m}$ (Right). 
Bulk mineral analysis

This material matches with the main features of the Spituk samples: Mica, phyllosilicates, quartz and plagioclase are available in small amounts; $14 \AA$ minerals, $7 \AA$ minerals and $\mathrm{K}$-feldspar are found as traces. Amphiboles could not be traced. At $69 \%$ the content of calcite reaches its maximum within the markalak clay samples. At $5 \%$ the content of dolomite is similar to the value compared with samples containing dolomite, in particular sample 14875 from Spituk; the other samples from Spituk, i.e. 8466 and 8481 , do not show any dolomite. The sample appears as rather bright. A small amount of goethite explains the soft changing of the colour towards brownish/ yellowish.

Anticipating the analysis of the further markalak clay samples, a content of calcite starting with traces up to about $42 \%$ seems to be a kind of marker for markalak clay. ${ }^{9}$ In this sample a goethite in the X-ray diffraction is not clearly traceable but would explain the partially yellowish colouring. A small amount of mica, quartz and on average also a small amount of plagioclase - in some samples also a medium or high amount but at least a small amount (marked with (*) in Table 3.4) - are markers for a markalak clay. A potash feldspar (here mentioned as K-feldspar) also occurs at least as a trace in each markalak clay sample.

\section{Results measured with STA}

- The content of calcite was measured at $69 \%$, the content of dolomite at $5 \%$.

- The residual mass at $1,000^{\circ} \mathrm{C}$ is $65.69 \%$.

Clay mineral analysis

The CMA shows a small amount of $6 \%$ of swellable clay minerals, and in particular no vermiculite, only smectite. The content of illite at $70 \%$ is rather high. The amount of kaolinite at $6 \%$ is rather low. A cracking of the material during the drying process after its application is avoided by the high and non swellable content of silt and the low content of swellable clay minerals. Values below are given in $\%$ of the clay fraction.

6052

$\begin{array}{llll}\text { Smectite } & \text { Illite } & \text { Kaolinite } & \text { Chlorite } \\ 6 & 70 & 6 & 18\end{array}$

\section{SPituk. SAMPle 8466}

\section{Sampling point}

Ladakh, Spituk, clay pit. Like sample 6052, this sample was also taken from the bright layers within the bright and dark layered wall of the clay pit. Sample number in the field: 14 SP/MARK. Constructive use: Today this material is known as being used for the most upper layer of earth roofs. Sample colour: The sample appears as rather bright but without a yellowish content like sample 6052. The picture shows the red colouring of the sample, which emphasises the content of haematite (Fig. 6.4).

9 The sediments from the Indus Valley are locally mentioned as fine grained material like chalk or glacial flour. Their origin is the bedrock ground as a result of glacial erosion (Feiglstorfer 2014: 365). 


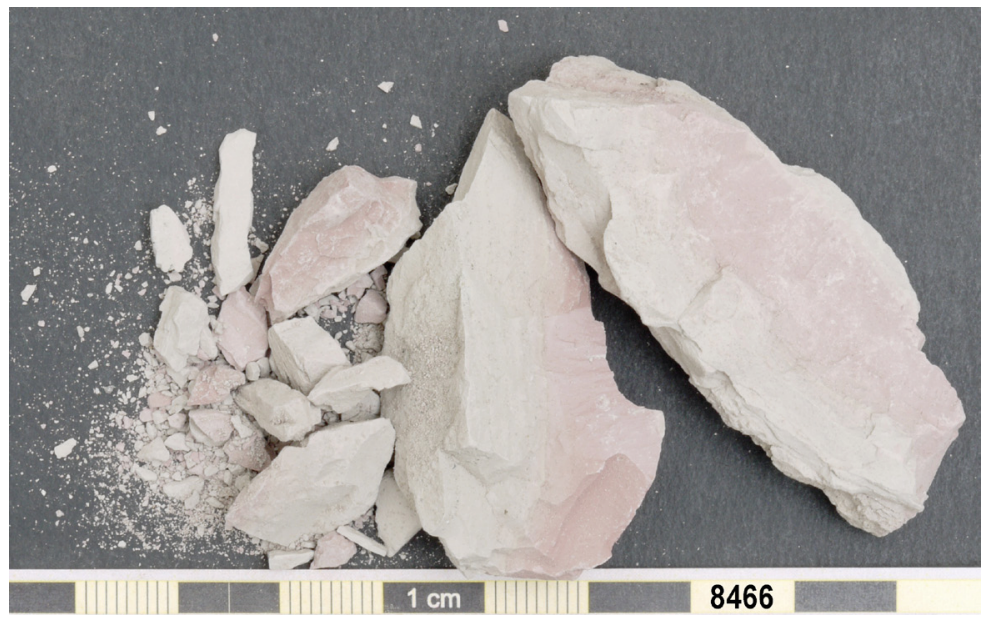

Fig. 6.4 Spituk. Sample 8466. Sample colour (after Munsell): Dry 10YR 7/1 light grey. Semi-dry 10 YR 5/2 greyish brown.

\section{Grain size distribution}

The material is very fine. Biggest fraction: medium sand. The median is located at app. $0.9 \mu \mathrm{m}$; the $<2 \mu \mathrm{m}$ fraction contains app. $80 \%$ of the whole sample. Compared to the previous sample, i.e. sample 6052, this sample contains less silt and has a much higher content of clay (vs. sample 6052 with $15.1 \%$ ) but also a very small content of medium and fine sand. The maximum peaks lie at $43.9 \%$ for coarse clay and at $24.1 \%$ for medium clay. In the distribution curve, no bimodal distribution is evident. A mixture of the material with sand or another type of clay is excluded since this sample was directly taken from the clay pit. The cumulative curve shows a break from fine silt to coarse clay but contrary to sample 6052, this break goes in the other direction, and emphasises a clear dominance of clay.

$\begin{array}{lllll} & \text { Gravel } & \text { Sand } & \text { Silt } & \text { Clay [\%] } \\ 8466 & 0 & 0.3 & 20 & 79.7 \\ 6052 & 0.1 & 0.2 & 84.6 & 15.1\end{array}$

Conversely to sample 6052, sample 8466 shows a high amount of clay and not of silt. Interestingly, the tests of this material showed that the small amount of silt and sand can be enough to keep the material crack free during drying. Shrinkage tests with this material showed a drying process without any cracks. The rounding can be mentioned as "angular shaped".

\section{Bulk mineral analysis}

This material matches with the main features of the Spituk samples: Mica, quartz and plagioclase, in this case also $14 \AA$ minerals and $7 \AA$ minerals, are available in small amounts; just amphiboles and $\mathrm{K}$-feldspar occur as traces. In this sample a goethite in the diffractogram is not clearly identified but can not be excluded. Contrary, traces of haematite are visible in the X-ray diffraction and also for the sample colour itself. This explains the partially reddish colouring. At $5 \%$ the content of calcite ranges below the average of the measured markalak clay samples. No dolomite is available. 
Clay mineral analysis

In general, the clay mineral distribution accords with the other examined samples from Spituk. The CMA shows a small amount of $8 \%$ of swellable clay minerals of the clay fraction; in particular, no vermiculite but only smectite. The small amount of smectite must be important for the strong cohesiveness of this type of fine markalak clays so as to make it hard in a dry state. The content of illite at $65 \%$ is smaller than for sample 6052 but still rather high. The amount of kaolinite is rather low. Cracking during the drying process seems to also be avoided by the high and non swellable content of silt. In the following list, juxtaposition with sample 6052 is given.

$\begin{array}{lllll} & \text { Smectite } & \text { Illite } & \text { Kaolinite } & \text { Chlorite [\%] } \\ 8466 & 8 & 65 & 4 & 23 \\ 6052 & 6 & 70 & 6 & 18\end{array}$

\section{Spituk. SAMple 8481}

\section{Sampling point}

Ladakh, Spituk, clay pit. Contrary to samples 6052 and 8466, sample 8481 (Fig. 7.4) was not taken from the bright layers within the bright and dark layered wall of the clay pit but from one of the dark layers, in close vicinity to the layer of sample 8466. Constructive use: Today this material is locally mentioned as used for the most upper layer of the earth roofs, and in general used for building structures. Sample number in the field: 16 SP/MARK II.

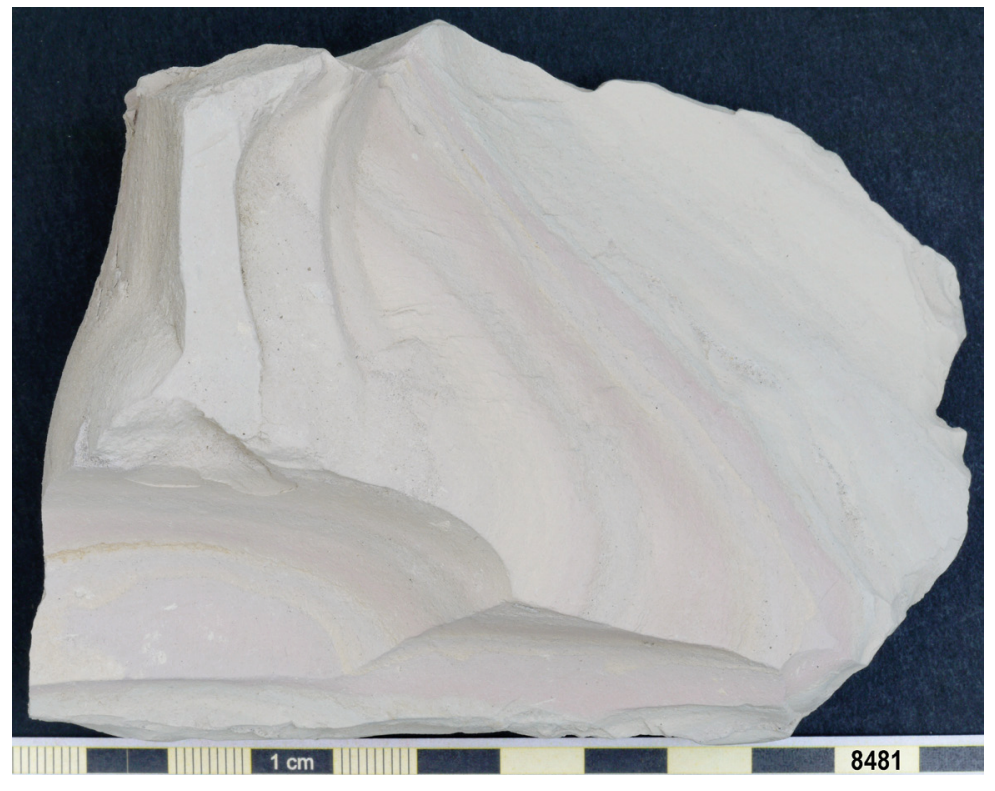

Fig. 7.4 Spituk. Sample 8481. Sample colour (after Munsell): Dry 10YR 6/1 grey. Semi-dry 10YR 4/2-5/2 dark greyish brown to greyish brown.

\section{Grain size distribution}

Generally speaking the grain size distribution of this sample shows a similarity to bright sample 8466. The material is very fine. Biggest fraction: fine sand. The median is located at app. $0.6 \mu \mathrm{m}$ (same as sample 8466 ); the $<2 \mu \mathrm{m}$ fraction contains app. $82 \%$ of the whole sample (vs. sample 8466 with app. $80 \%$ ) and can be described as extremely high. Compared to sample 8466 this 
sample contains a similar small amount of silt and only traces of sand. The maximum peaks lie at $29.1 \%$ for coarse clay and at $29 \%$ for medium clay. In the distribution curve, no bimodal distribution is evident. A mixture of the material with sand or another type of clay is excluded since this sample was directly taken from the pit. The cumulative curve shows a break from fine silt to coarse clay but contrary to sample 6052, it goes in the other direction and emphasises a clear dominance of clay. This material - similar to sample 8466 - can be mentioned as close to pure clay and as an extremely fine material. Compared to sample 6052 with a dominance of silt, this dichotomy is striking. Conversely to sample 6052 but similar to sample 8466 , sample 8481 shows a high amount of clay and not of silt.

$\begin{array}{lllll} & \text { Gravel } & \text { Sand } & \text { Silt } & \text { Clay [\%] } \\ 8481 & 0 & 1 & 17.5 & 81.5 \\ 6052 & 0.1 & 0.2 & 84.6 & 15.1 \\ 8466 & 0 & 0.3 & 20 & 79.7\end{array}$

Bulk mineral analysis

This material matches with the main features of the Spituk samples, most in regard to the brighter layer of sample 8481: Mica, quartz and plagioclase, and in this case also $7 \AA$ minerals, are available in small amounts; only $14 \AA$ minerals, amphiboles and $\mathrm{K}$-feldspar occur as traces as well as the content of some haematite. At $3 \%$ the content of calcite ranges below the average of the measured markalak clay samples. No dolomite is available - this also matches with sample 8466 . Yellowish, red and blue stripes point towards a content of goethite, respectively haematite representing a reduced iron compound. In the dry state the difference between samples 8466 (10YR 7/1 - light grey) and 8481 (10YR 6/1 - grey) become slightly evident. In the field within the in-situ conditions the stripes become more evident than on small pieces in the laboratory. Fig. 7.4 shows the striped layering in which this sample is embedded.

Clay mineral analysis

In general the clay mineral distribution accords with the other examined samples from Spituk, again with a high accordance to the brighter layer shown by sample 8466 . The CMA shows a small amount of $12 \%$ of swellable clay minerals of the clay fraction, in particular no vermiculite but only smectite, although this rate is the highest within the samples collected at the Spituk clay pit. At $64 \%$ the content of illite of the clay fraction is smaller than for sample 6052 but nearly identical to sample 8466 . With $65 \%$ of the clay fraction, the content is still rather high. The amount of kaolinite is again rather low.

$\begin{array}{lllll} & \text { Smectite } & \text { Illite } & \text { Kaolinite } & \text { Chlorite [\%] } \\ 8481 & 12 & 64 & 5 & 19 \\ 6052 & 6 & 70 & 6 & 18 \\ 8466 & 0 & 0.3 & 20 & 79.7\end{array}$


Spituk. SAMPLE 14875

Sampling point

Sample (Fig. 8.4) was also taken from the Spituk clay pit and provided to the author by Dr. Christine Bläuer. ${ }^{10}$ Dr. Martina Oeter ${ }^{11}$ explained its origin and use. Both work as professional conservators in Ladakh related to the ACHI association. Sample number in the field: Collected on behalf of Achi Association. ${ }^{12}$ Constructive use: According to Martina Oeter this material's use is described in various forms. For conservation work, which goes deeper into the wall, the markalak clay is mixed with fine river sand with a grain size of up to about $2 \mathrm{~mm}$. The proportion of mixing is about 2:1. For finer corrections up to the painting level, the markalak clay is used purely without being mixed with sand. Martina Oeter also explains that for the un-mixed (pure) application, the oatmeal material is best suited since the yellowish and grey materials shrink and crack after compression. ${ }^{13}$

These statements would mean that sample 6052 with a light brownish grey colour $(2.5 \mathrm{Y} 6 / 2)$ shows a much higher content of silt and would give a much better result concerning less shrinkage than the light grey and grey samples, e.g. sample 8466, which shows a much higher content of clay than of silt. However, despite the shrinkage behaviour of sample 8466 - which can be classified as light grey - showing no cracks, the proportion of clay to silt is still not ideal due to a rather high content of clay. In this regard sample 6052, which shows the mentioned oatmeal colour, has a controversial proportion of clay to silt due to a much higher content of silt. Sample 14875 is somewhere in between. On the one hand it still has a relatively high amount of clay, but on the other hand it still has a relatively high amount of silt which seems to be the prime reason for its proper use, according to Martina Oeter.

Grain size distribution

Generally speaking the grain size distribution of this sample shows similar features to samples 8466 and 8481. In detail, this sample shows a kind of merging of the features of samples 6052 (with a higher content of silt) and 8466 or 8481 (both with a higher content of clay). In the case of sample 14875, the amount of silt is much higher than for samples 8466 or 8481 but still less than for sample 6052. Further the amount of clay is still relatively high and versus sample 6052 the dominant fraction. The material is very fine. Biggest fraction: fine sand. The median is located at app. $0.8 \mu \mathrm{m}$ (vs. $7.5 \mu \mathrm{m}$ for sample 6052 and similar to samples 8466 and 8481 both with $0.9 \mu \mathrm{m}$ and $0.55 \mu \mathrm{m}$, respectively); the $<2 \mu \mathrm{m}$ fraction contains app. $70 \%$ of the whole sample (vs. sample 6052 with $16 \%$, sample 8466 with $80 \%$ and sample 8481 with $82 \%$ ). The maximum peaks lie at $23 \%, 23.5 \%$ and $21.3 \%$, respectively, for coarse, medium and fine clay. In the distribution curve, no bimodal distribution is evident. The grain size distribution curve does not show a break from fine silt to coarse clay as found for samples 6052,8466 and 8481.

10 Dr. Christine Bläuer is a conservation scientist at Conservation Science Consulting Sàrl BIO.

11 Dr. Martina Oeter works as a freelance conservator and head conservator of the Achi Association, and teaches at Regensburg Technical University in the Faculty of Architecture.

12 "The Achi Association is a NGO based in Europe which has been working in Ladakh since 1999 on earthen architectural heritage endangered through climate change related effects" (cf. Bertagnin et al. 2015: 43).

13 E-Mail message by Martina Oeter on October 11 in 2014. 


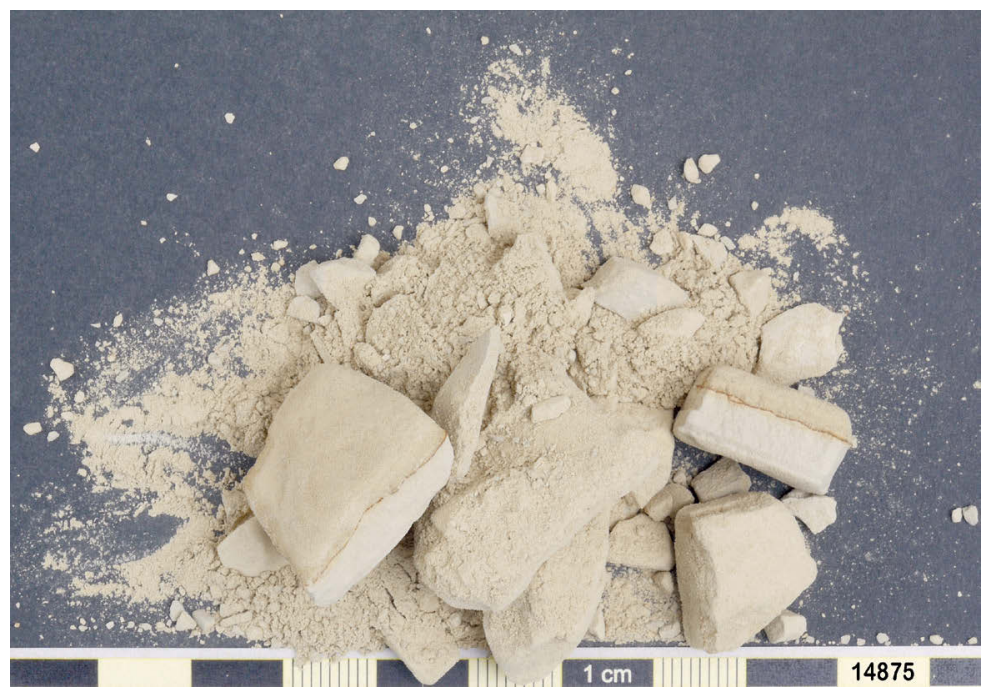

Fig. 8.4 Spituk. Sample 14875. Sample colour (after Munsell): Dry 10YR 8/1-10YR 7/1 partially white - light grey - yellowish. Semi-dry 10YR 6/2 light brownish grey.

$\begin{array}{lllll} & \text { Gravel } & \text { Sand } & \text { Silt } & \text { Clay [\%] } \\ 14875 & 0 & 0.9 & 31.3 & 67.8 \\ 6052 & 0.1 & 0.2 & 84.6 & 15.1 \\ 8466 & 0 & 0.3 & 20 & 79.7 \\ 8481 & 0 & 1 & 17.5 & 81.5\end{array}$

With a proportion of app. 1:2.1, this sample shows a more balanced proportion between silt and clay than sample 6052 with a proportion of app. 1:0.18 (or 5.6:1), sample 8466 with a proportion of 1:4 and sample 8481 with a proportion of 1:4.7.

Bulk mineral analysis

This material matches with the main features of the Spituk samples, though mostly with sample 6052 which shows a high content of silt: Mica, $7 \AA \AA$ minerals, phyllo silicates, quartz and plagioclase are available in small amounts; just $14 \AA$ minerals, amphiboles and K-feldspar occur as traces. Traces of haematite are visible in the X-ray diffraction. The content of calcite at $42 \%$ again shows similarities to sample 6052 at $69 \%$ and exceeds the average content of calcite within the markalak clay samples. Dolomite being available at $4 \%$ is also similar to sample 6052 . In comparing the colours of the Spituk samples, they are obviously marked by some reddish content due to traces of haematite. In samples 6052,8466 and 8481 , this is probably also due to possible traces of goethite. Compared to the other samples collected in Spituk (6052, 8466 and 8481), sample 14875 appears as relatively bright giving the following comparison:

$\begin{array}{llll}14875 & \text { Dry } & \text { 10YR 8/1-10YR 7/1 } & \text { partially white }- \text { light grey }- \text { yellowish } \\ & \text { Semi-dry } & 10 \text { YR 6/2 } & \text { light brownish grey } \\ 6052 & \text { Dry } & 2.5 \text { Y 6/2 } & \text { light brownish grey } \\ & \text { Semi-dry } & 2.5 \text { Y 6/3 } & \text { light yellowish grey } \\ 8466 & \text { Dry } & \text { 10YR } 7 / 1 & \text { light grey } \\ & \text { Semi-dry } & \text { 10YR 5/2 } & \text { greyish brown } \\ 8481 & \text { Dry } & \text { 10YR 6/1 } & \text { grey } \\ & \text { Semi-dry } & \text { 10YR 4/2-5/2 } & \text { dark greyish brown-greyish brown }\end{array}$


Results measured with STA

- The content of calcite was measured at $69 \%$, the content of dolomite at $5 \%$.

- The residual mass at $1,000^{\circ} \mathrm{C}$ is $75.65 \%$.

Clay mineral analysis

In general the clay mineral distribution accords with the other examined samples from Spituk, again with a high accordance to sample 6052 . At $3 \%$ of the clay fraction, the CMA shows - compared to the other samples of Spituk - the smallest amount of swellable clay minerals, again containing no vermiculite but only smectite. The content of illite at $64 \%$ of the clay fraction is within an average range of the samples from Spituk. The amount of kaolinite at $6 \%$ is also the same for the clay fraction. The content of chlorite is the highest within the samples of Spituk.

$\begin{array}{lllll} & \text { Smectite } & \text { Illite } & \text { Kaolinite } & \text { Chlorite [\%] } \\ 14875 & 3 & 64 & 6 & 27 \\ 6052 & 6 & 70 & 6 & 18 \\ 8466 & 8 & 65 & 4 & 23 \\ 8481 & 12 & 64 & 5 & 19\end{array}$

\subsection{Analyses of Spituk samples}

Sample 8466 from Spituk, which the author collected himself, was one of the brighter striped layers within this locally well-known varve clay pit and was locally recommended as "the best quality clay" (see Fig. 6.4). For its characteristics as building material and also in particular for very fine and detailed work, tests were conducted at the IAG / BOKU to determine its material properties related to standardised values.

3.2.1 Shrinkage tests and determining the drying shrinkage according to DIN 18952

Three samples of the same size from same sample 8466 were tested (Fig. 9.4 and Fig. 10.4).

Shrinkage during drying: Final length after drying in the oven $\left(70 \mathrm{C}^{\circ}\right)$

$18.65 \mathrm{~cm}$ at Sample I

$18.65 \mathrm{~cm}$ at Sample II

$18.60 \mathrm{~cm}$ at Sample III

Within this period in the oven, no further shrinkage could be observed, i.e. the shrinkage process was already finished after four days drying at room temperature. Finally, shrinkage during drying could be stated at about 7\%. According to DIN 18952, B1. 2, four types of clay are categorised by their behaviour during their shrinkage process: "Loose clay", "Nearly loose clay", "Soft clay" and "Very soft clay". Markalak clay sample 8466 ranges in the category of "Very soft clay". 


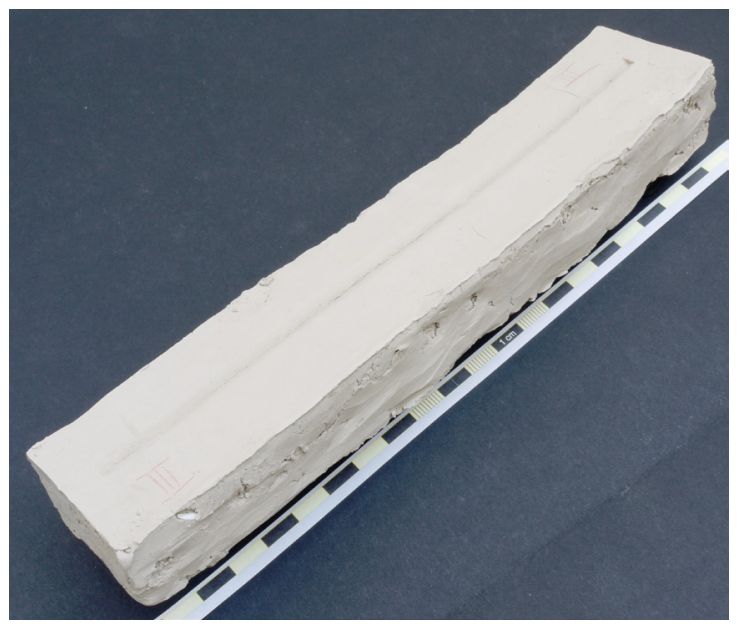

Fig. 9.4 (Left) Sample 8466 from Spituk.

Sample used for shrinkage test.

$\begin{array}{lll}\text { Type of clay } & \text { shrinkage in \% } & \text { [in mm] } \\ \text { Loose clay (Ger. Magerer Lehm) } & 1 \text { to } 2.5 & \text { [2 to 5] } \\ \text { Nearly loose clay (Ger. Fast fetter Lehm) } & 2 \text { to } 2.5 & \text { [4 to 7] } \\ \text { Soft clay (Ger. Fetter Lehm) } & 3 \text { to } 5 & \text { [6 to 10] } \\ \text { Very soft clay (Ger. Sehr fetter Lehm) } & 4 \text { to } 10 & \text { [8 to 20] }\end{array}$

Result of the Shrinkage tests and determining the drying shrinkage: According to DIN 18952, the standard stiffness of markalak clay sample 8466 had a water content of $121 \%$ (giving the geotechnical value for humidity).

3.2.2 Testing the plasticity according to DIN 18122, part 1: (a) Determination of the liquid limit $\left(\mathrm{W}_{\mathrm{L}}\right)$; (b) the plasticity limit $\left(\mathrm{W}_{\mathrm{P}}\right)$ ('Atterberg limits'); (c) number for plasticity $\left(I_{p}\right)$.

The liquid limit $\left(\mathrm{W}_{\mathrm{L}}\right)$ marks the transformation point from liquid to plastic; the plasticity limit $\left(\mathrm{W}_{\mathrm{P}}\right)$ marks the transformation point from plastic to semi-hard (Fig. 11.4).

(a) Determination of the liquid limit $\left(\mathrm{W}_{\mathrm{L}}\right)$ according to A. Casagrande (Calculation, see Appendix of Chapter IV). According to DIN 18122, the liquid limit $\left(\mathrm{W}_{\mathrm{L}}\right)$ for markalak clay sample 8466 shows a water content of $133.7 \%$ on a scale of 25 beats (giving the geotechnical value for humidity; see Fig. 11.4).

(b) Determination of the plasticity limit $\left(\mathrm{W}_{\mathrm{p}}\right)$ (Calculation, see Appendix of Chapter IV). Result: According to DIN 18122, the plasticity limit $\left(\mathrm{W}_{\mathrm{P}}\right)$ had a water content of $121 \%$ on average (giving the geotechnical value for humidity). 
(c) Classification number for the plasticity $\left(\mathrm{I}_{\mathrm{P}}\right)$ of clays according to Voth 1978 (Minke 1995: 43).

$\mathrm{I}_{\mathrm{P}}[\%]=\mathrm{W}_{\mathrm{L}}[\%]-\mathrm{W}_{\mathrm{P}}[\%]$

$I_{P}[\%]=133.75 \%-121 \%=12.75 \%$

The values for the water content are given according to geotechnical standards (versus geological standards):

$\begin{array}{llll}\text { Type of clay } & \mathrm{W}_{\mathrm{L}}[\%] & \mathrm{W}_{\mathrm{p}}[\%] & \mathrm{I}_{\mathrm{p}}[\%] \\ \text { Very sandy } & 110-123 & 105-120 & <5 \\ \text { Very silty } & 115-135 & 110-125 & \underline{5-15} \\ \text { Very clayey } & \underline{128-250} & \underline{120-150} & 15-95 \\ \text { Bentonite } & 140 & 108 & 32\end{array}$

Regarding the result for liquid limit $\left(\mathrm{W}_{\mathrm{L}}\right)$ and plasticity limit $\left(\mathrm{W}_{\mathrm{P}}\right)$, the plasticity number $\mathrm{I}_{\mathrm{p}}$ is given as $12.75 \%$. With the measured liquid limit $\left(\mathrm{W}_{\mathrm{L}}\right)$, the plasticity limit $\left(\mathrm{W}_{\mathrm{P}}\right)$ and number for the plasticity $\left(\mathrm{I}_{\mathrm{p}}\right)$ of this sample can be classified as "very clayey" with a tendency towards "very silty".

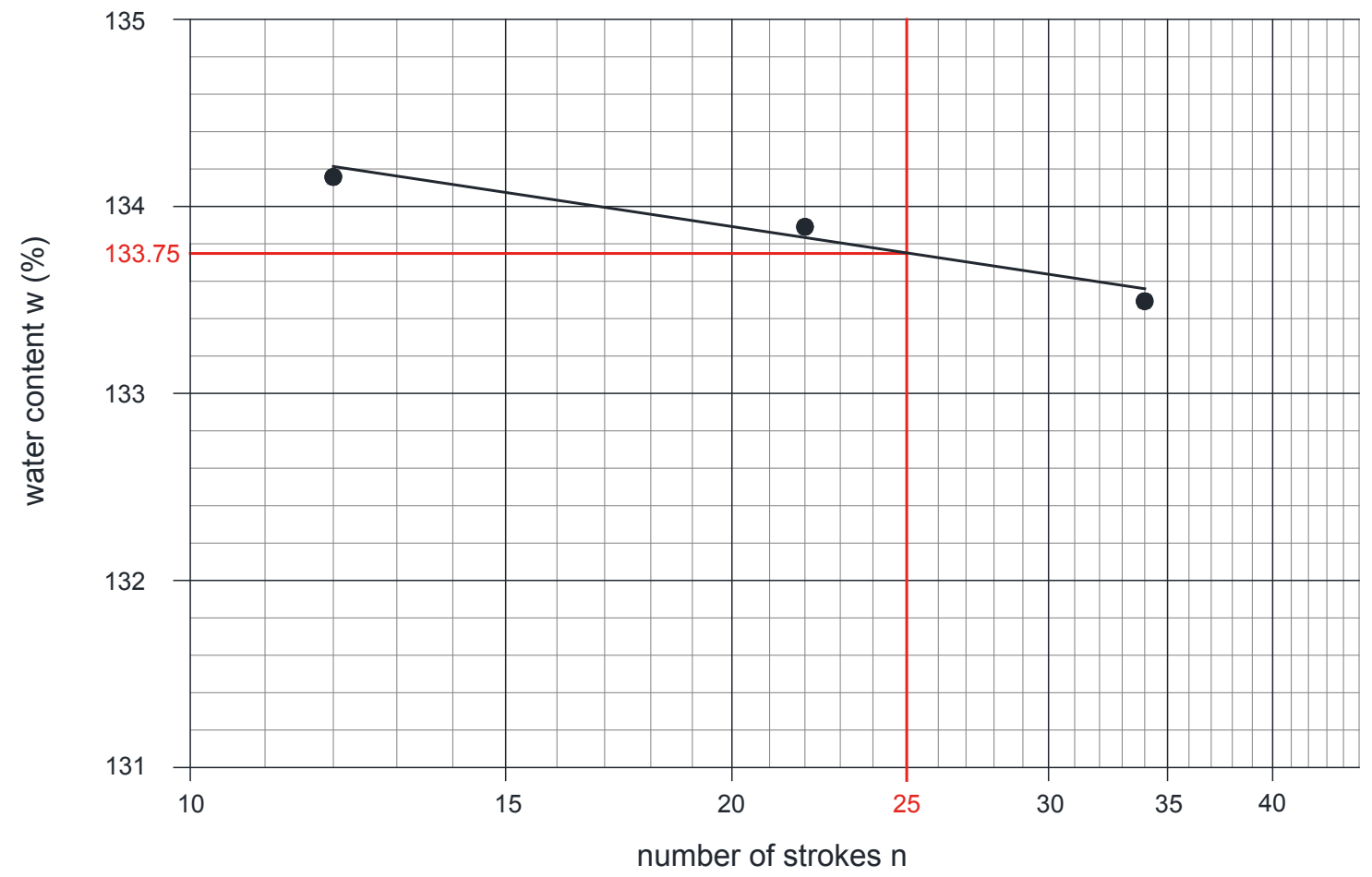

Fig. 11.4 Sample 8466 from Spituk. Atterberg limits. 


\subsubsection{Coefficient for the activity}

$$
\mathrm{I}_{\mathrm{A}}=\frac{\mathrm{W}_{\mathrm{L}}-\mathrm{W}_{\mathrm{P}} \text { [percent by mass] }}{\text { Content of clay [percent by mass] }}
$$

$I_{A}=(133.75 \%-121 \%) / 84.7=12.75 / 84.7=0.15$

$\mathrm{I}_{\mathrm{A}}<0.75 \quad$ points towards a very little activity

$\mathrm{I}_{\mathrm{A}}>0.75$ and $<1.25$ points towards a normal activity

$\mathrm{I}_{\mathrm{A}}>0.75 \quad$ points towards a high activity

The coefficient for the activity $\mathrm{I}_{\mathrm{A}}$ with 0.15 is below 0.75 , and according to Houben and Guillaud (1984: 59), regarding content of clay, it compares with the plasticity $\left(\mathrm{I}_{\mathrm{p}}\right)$ according to Voth 1978. Despite a relatively high content of clay, a determined $\mathrm{I}_{\mathrm{A}}$ value of 0.15 points towards 'very little activity'.

\subsubsection{Hardness of the sample according to Vickers}

$\mathrm{HV}\left[\mathrm{kg} / \mathrm{mm}^{2}\right]=\frac{\mathrm{F}^{*} 1.854}{\mathrm{~d}^{2}} \quad \mathrm{~d}=\underline{\mathrm{d}}_{\underline{1}}+\frac{\mathrm{d}_{2}}{2}$

The hardness of several plasters was examined in Chapter II (5.1.1 "Quality of surfaces"). For comparison, this test shows the relation between the hardness of those samples particularly chosen as plasters and a type of markalak clay, which appears as relatively hard when dry (Fig. 12.4). The result matches with the result after scratching the surface of the sample with a fingernail. The surface is easily scratched, and with a hardness of $1.39 \mathrm{~kg} / \mathrm{mm}^{2}$.

Result of the hardness test according to Vickers:

Tested sample: 8466 unburnished

Applied force $0.5 \mathrm{kgf}$;

Diagonals: $848 \mu \mathrm{m}$ and $783 \mu \mathrm{m}$;

$1.39 \operatorname{HD} 0.5\left(1.39 \mathrm{~kg} / \mathrm{mm}^{2}\right)$.

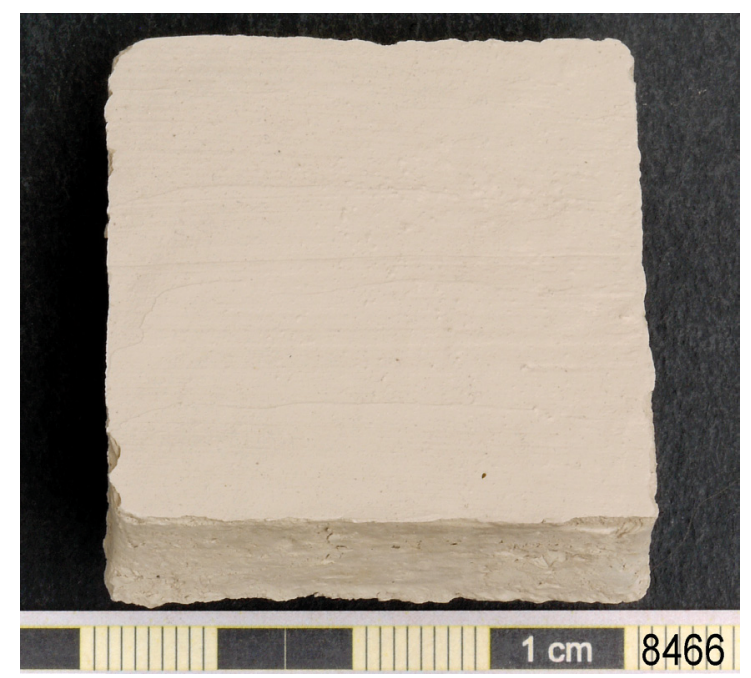

Fig. 12.4 Sample 8466 from Spituk. Specimen used for the hardness test according to Vickers. 


\subsection{Alchi}

\section{Alchi. Sample 8526}

\section{Sampling point}

This sample was collected along the road leaving the village of Alchi towards the bridge crossing the Indus (Fig. 13.4). It was collected by Morup Dorje, a teacher from Alchi. Sample number in the field: $70 \mathrm{AL} / \mathrm{LG}$. Constructive use: Today this material is known for making earth roofs. It is used without any further additives and without sieving. It is known to be of similar consistency as the mentioned markalak clay from Spituk (Interview Morup Dorjay 2002; Feiglstorfer 2002: 11).

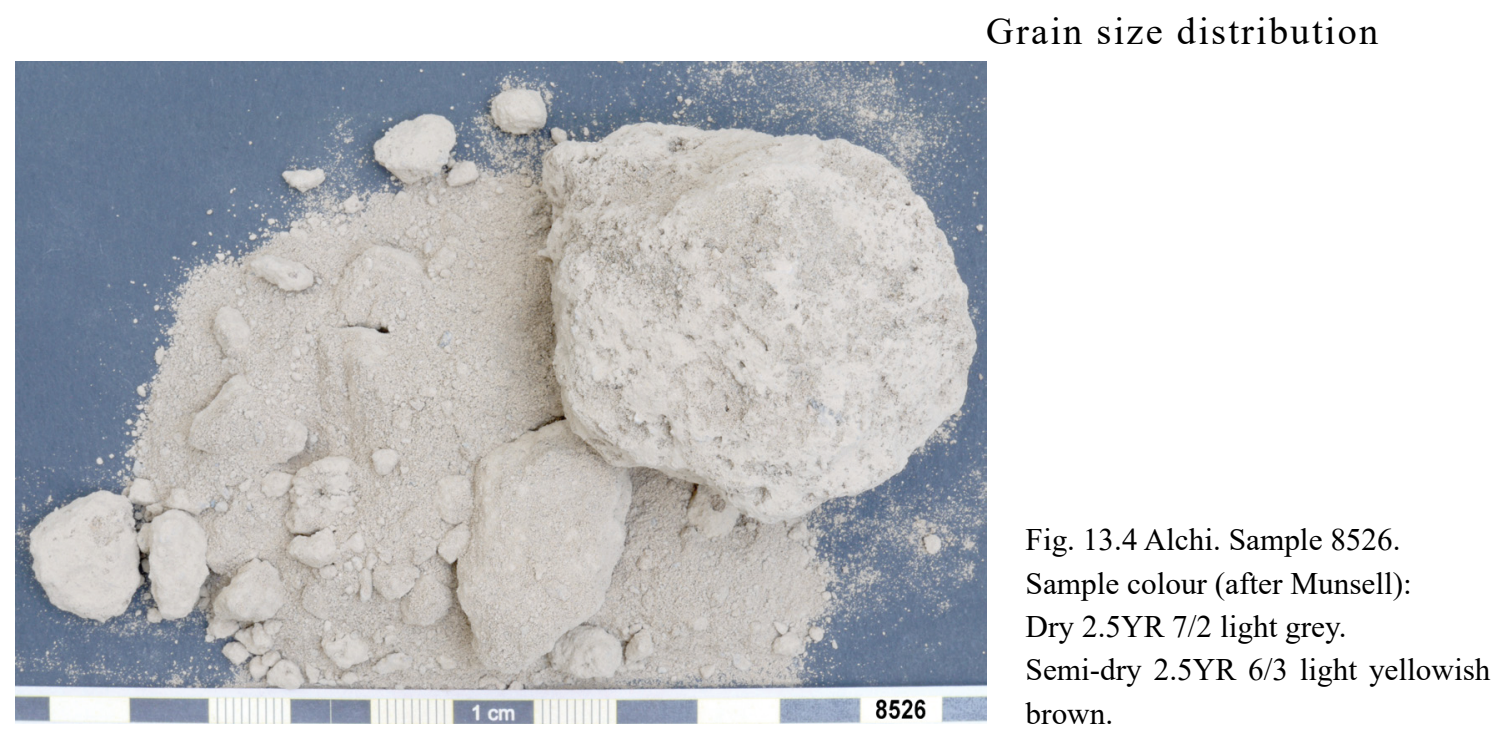

Generally speaking the grain size distribution of this sample shows no similarity to the samples from Spituk. It appears as much coarser with a very different course of the grain size distribution curve. Biggest fractions: coarse, medium and fine gravel. The median is located at app. $95 \mu \mathrm{m}$; the $<2 \mu \mathrm{m}$ fraction contains app. $13 \%$ of the whole sample. The maximum peak lies at $32.6 \%$ for fine sand. In the distribution curve a bimodal distribution with a soft valley between coarse silt and fine silt is evident. The grain size distribution curve shows a break on both sides of the fine sand fraction. The distribution of the single fractions is relatively linear. The sample was handed over right after its collection, a mixture with sand or another type of clay is excluded. Compared with any of the Spituk samples, a main difference is certainly the large amount of coarse material.

$\begin{array}{lllll} & \text { Gravel } & \text { Sand } & \text { Silt } & \text { Clay [\%] } \\ 8526 \text { (Alchi) } & 8.1 & 53.7 & 24.4 & 13.8 \\ 14875 \text { (Spituk) } & 0 & 0.9 & 31.3 & 67.8\end{array}$

Evidence of not having been mixed with sand or another type of clay is supported by the result given by the examination of the grain shapes, which show no difference between the single fractions. Also within the markalak clay samples the examined shape follows for evident continuity 
when comparing to other markalak clay samples such as 8466 or 6052 . The grain shape is given according to Tucker (1985: 17f.).

\begin{tabular}{c|c|c|c|c|c}
$>6,300 \mu \mathrm{m}$ & $>2,000 \mu \mathrm{m}$ & $>630 \mu \mathrm{m}$ & $>200 \mu \mathrm{m}$ & $>63 \mu \mathrm{m}$ & on average \\
\hline nonexistent & $0(1)$ & 1 & 1 & notmeasured & 1
\end{tabular}

Bulk mineral analysis

The BMA shows great similarity to samples from Spituk. Mica, $7 \AA$ minerals, phyllo silicates, and K-feldspar are available in small amounts; just $14 \AA$ minerals and amphiboles occur as traces while quartz and plagioclase occur in a medium amount (in the Table 3.4 marked with $(* *)$ ). Similar to samples 6052 and 14875 , a small amount of dolomite at $3 \%$ is also available. The content of calcite at $15 \%$ is about the average amount for the samples from Spituk but below the average amount of the samples of Spituk. The sample shows no evidence of the content of ferric oxides.

Clay mineral analysis

In general the clay mineral distribution is also similar with the samples from Spituk, in particular with sample 6052. The following list shows a comparison with sample 6052 from Spituk.

$\begin{array}{lllll} & \text { Smectite } & \text { Illite } & \text { Kaolinite } & \text { Chlorite [\%] } \\ 8526 & 6 & 63 & 5 & 26 \\ 6052 & 6 & 70 & 6 & 18\end{array}$

Primarily regarding the grain size distribution, this sample's properties do not follow the properties of the markalak clay samples, which were examined in Spituk, and also not the other samples, which were collected at Alchi, i.e. samples 14876 and 8526. Morup Dorje knew about the markalak clay's approximate location close to the bridge and mentions this material as suitable for making roofs, bringing it in relation with the term "markalak".

In this case a hypothesis for using the term "markalak" for this material is its relation to its general use for construction of a roof (which markalak clays is general known to be used for). In this context we can not exclude that Morup Dorje took a coarse material from near the site where markalak clay is found in regard to his knowledge about the material's use. In this relation the markalak clay is not necessarily a highly fine material, as was examined for the samples from Spituk, but related to a particular use, place and commonly known properties.

Use and place are clear in this context while the common traditionally accepted properties are not that clearly defined. Since this material still shows the same content of swellable material as the fine markalak clay, this may be one of the prime properties of this material. The grain size distribution shows the availability of all the fine fractions (silt and clay), still with an amount of $38.2 \%$. Morup Dorje mentions that this type of markalak clay is not needed to be mixed with sand but that it is used in a kind of already 'mixed' natural state. 
Alchi. SAmple 11934

\section{Sampling point}

This sample was collected along the road leaving the village of Alchi towards the bridge crossing the Indus. Deldan Angmo, who at the time was working at INTACH, ${ }^{14}$ collected the sample (Fig. 14.4). Sample number in the field: 49. Constructive use: Today this material is known for making earth roofs. It is used without any further additives and without sieving. Further use was not reported but refers to the description given under sample 14875 .

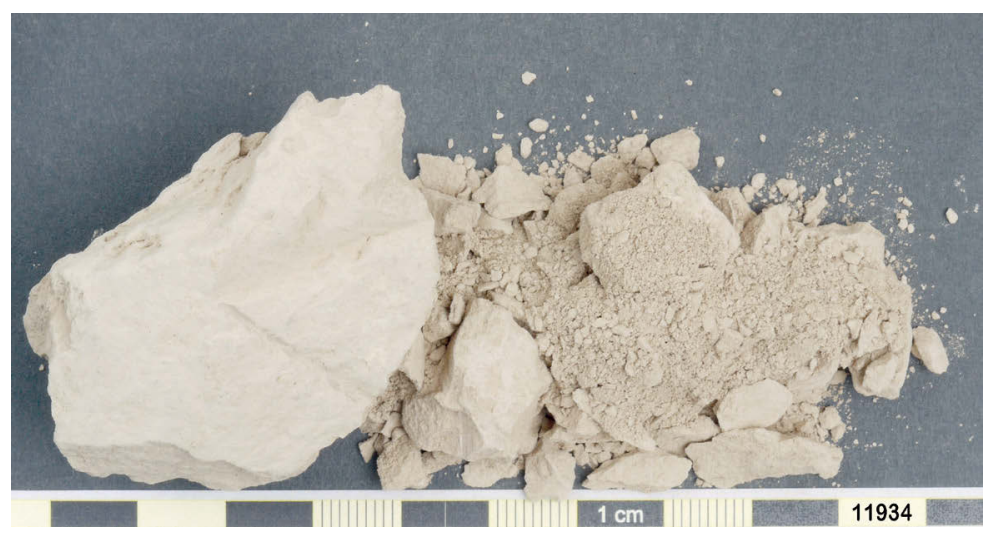

Fig. 14.4 Alchi. Sample 11934. Sample colour (after Munsell): Dry 10 YR $8 / 2$ very pale brown. Semi-dry 10 YR 5/3 brown.

\section{Grain size distribution}

Generally speaking the grain size distribution of this sample shows a difference (i.e. less clay and more silt) to samples from Spituk, in particular samples 8466 and 8481 or sample 14875 collected by ACHI Association in Spituk. The material is very fine. Biggest fraction: fine sand. The median is located at app. $2.6 \mu \mathrm{m}$ (vs. $0.9 \mu \mathrm{m}$ at sample 8466 and $0.6 \mu \mathrm{m}$ at sample $8481 ; 0.8 \mu \mathrm{m}$ at sample 14875); the $<2 \mu \mathrm{m}$ fraction contains app. $43 \%$ of the whole sample (vs. sample 8481 with $82 \%$ and sample 8466 with $80 \%$; sample 14875 with $70 \%$ ) and can be described as high. Contrary to samples 8466 and 8481 , which contain just between $17.5 \%$ and $20 \%$ of silt, this sample contains a higher amount of silt than clay. A mixture of the material with sand or another type of clay is excluded since this sample was directly taken from the pit. The depositional environment is similar to the samples from Spituk. For comparison, samples 8466, 8481 and 14875 from Spituk are listed below:

$\begin{array}{lllll} & \text { Gravel } & \text { Sand } & \text { Silt } & \text { Clay [\%] } \\ 11934 \text { (Alchi) } & 0 & 1.3 & 56.2 & 42.5 \\ 8466 \text { (Spituk) } & 0 & 0.3 & 20 & 79.7 \\ 8481 \text { (Spituk) } & 0 & 1 & 17.5 & 81.5 \\ 14875 \text { (Spituk) } & 0 & 0.9 & 31.3 & 67.8\end{array}$

14 INTACH: Indian National Trust for Art and Cultural Heritage; ww.intach.org: In 1984, the Indian National Trust for Art and Cultural Heritage (INTACH) was registered as a society and founded with the vision to create a membership organisation to stimulate and spearhead heritage awareness and conservation in India. 
Bulk mineral analysis

The BMA shows great similarity to samples from Spituk and also within the whole range of markalak clay samples collected in Alchi. $14 \AA$ minerals, mica, $7 \AA$ minerals, phyllo silicates, quartz, and plagioclase are available in small amounts; only amphiboles and K-feldspar occur as traces. Dolomite is not available in this sample. The content of calcite at $14 \%$ is about the average amount for the samples from Alchi but below the average amount of the samples of Spituk. The sample shows no evidence of the content of ferric oxides. Similarities are given with the greyish/ brown layers of sample 8466 from Spituk or the brown portion of sample 14785 but not with the more greyish portions of these samples or sample 8526, also from Alchi.

Clay mineral analysis

In general the clay mineral distribution is also similar with the samples from Spituk. The following list shows comparison with samples 6052 and 14875 from Spituk.

$\begin{array}{lllll} & \text { Smectite } & \text { Illite } & \text { Kaolinite } & \text { Chlorite [\%] } \\ 11934 \text { (Alchi) } & 7 & 55 & 4 & 33 \\ 6052 \text { (Spituk) } & 6 & 70 & 6 & 18 \\ 14875 \text { (Spituk) } & 3 & 64 & 6 & 27\end{array}$

\section{Alchi. Sample 14876}

Sampling point

This sample was collected in Alchi by members of the ACHI Association and handed over by Dr. Christine Bläuer (Fig. 15.4). Constructive use: As reported by conservators, it is used as filling material for cracks. For a detailed description, refer to the remarks given for the use of sample 14875.

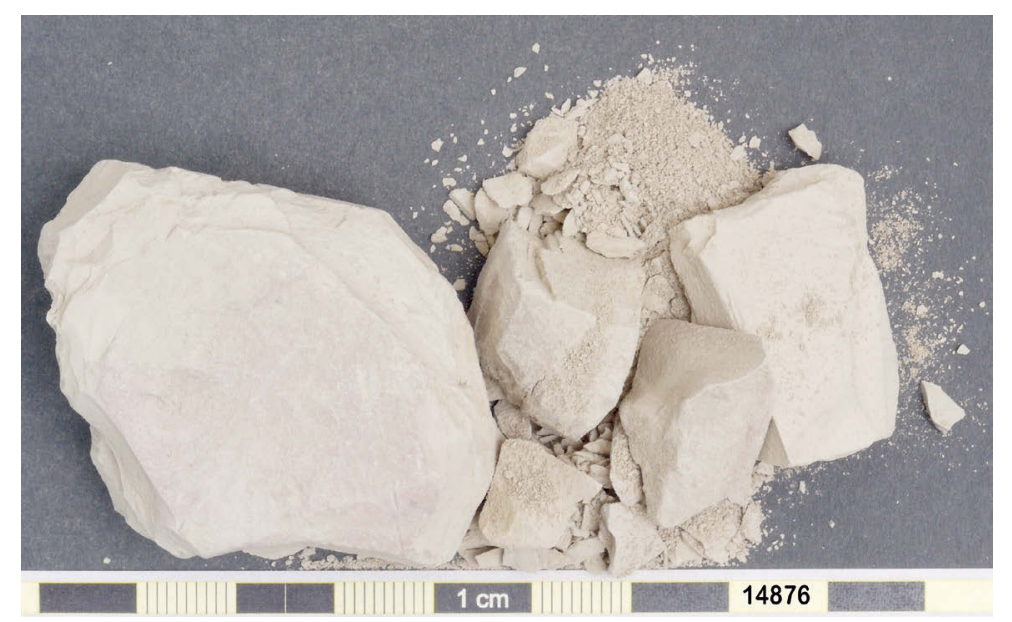

Fig. 15.4 Alchi. Sample 14876. Sample colour (after Munsell): Dry 7.5YR 6/3 light brown. Semi-dry 7.5 YR $5 / 3$ brown. 
Grain size distribution

Generally speaking the grain size distribution of this sample shows strong similarity with sample 11934, which is also from Alchi and collected by Deldan Angmo. The material is very fine. Biggest fraction: fine sand. The median is located at app. $1.2 \mu \mathrm{m}$ (slightly less as at sample 11934); the $<2 \mu \mathrm{m}$ fraction contains app. $77 \%$ of the whole sample (higher than for sample 11934 with $43 \%$ ) and can be described as high. The content of silt and the distribution within the silt and clay fractions is also slightly different to sample 11934. In the distribution curve, no bimodal distribution is evident. A mixture of the material with other substances is excluded since this sample was directly taken from the pit. The grain size distribution curve shows a soft break from fine silt to medium silt and emphasises a clear dominance of clay. A strong similarity to sample 14875 is given.

$\begin{array}{lllll} & \text { Gravel } & \text { Sand } & \text { Silt } & \text { Clay [\%] } \\ 14876 \text { (Alchi) } & 0 & 0.4 & 23.3 & 76.3 \\ 11934 \text { (Alchi) } & 0 & 1.3 & 56.2 & 42.5 \\ 14875 \text { (Spituk) } & 0 & 0.9 & 31.3 & 67.8\end{array}$

Bulk mineral analysis

The BMA shows great similarity to sample 11934 from Alchi and also within the whole range of markalak clay samples collected in Alchi. $14 \AA$ minerals, mica, $7 \AA$ minerals, phyllo silicates, quartz and plagioclase are available in small amounts; only amphiboles and K-feldspar occur as traces. Traces of haematite are visible in the sample colour itself. Dolomite is not available in this sample. The content of calcite at $4 \%$ is below the rate shown for sample 11934 with $14 \%$ but similar to an average available in samples 6052, 8466 and 8481 collected in Spituk. The sample shows evidence of the content of ferric oxides referring to a content of haematite. Similarities are given with samples 8466, 8481 and 14875 (all from Spituk) but not with the colours of samples 8526 and 11934 from Alchi.

Clay mineral analysis

In general the clay mineral distribution is also similar to sample 11934 and the samples collected in Spituk. The following list shows a comparison with samples 6052 and 14875 from Spituk and the examined samples from Alchi. From the first to the fourth chlorite peak, they are continuously increasing which raises the question for the existence of an aluminium chlorite (similar to material to be found e.g. in Waldviertel in Austria) and not ferric magnesium-chlorites.

$\begin{array}{lllll} & \text { Smectite } & \text { Illite } & \text { Kaolinite } & \text { Chlorite [\%] } \\ 14876 \text { (Alchi) } & 7 & 62 & 5 & 26 \\ 11934 \text { (Alchi) } & 7 & 55 & 4 & 33 \\ 6052 \text { (Spituk) } & 6 & 70 & 6 & 18 \\ 14875 \text { (Spituk) } & 3 & 64 & 6 & 27 \\ 8526 \text { (Spituk) } & 6 & 63 & 5 & 26\end{array}$

Regarding the data of this sample, we can state that samples 11934 and 14876 must have been collected in close vicinity to each other. They are not completely identical but equal each other in most parameters. 


\subsection{Lamayuru}

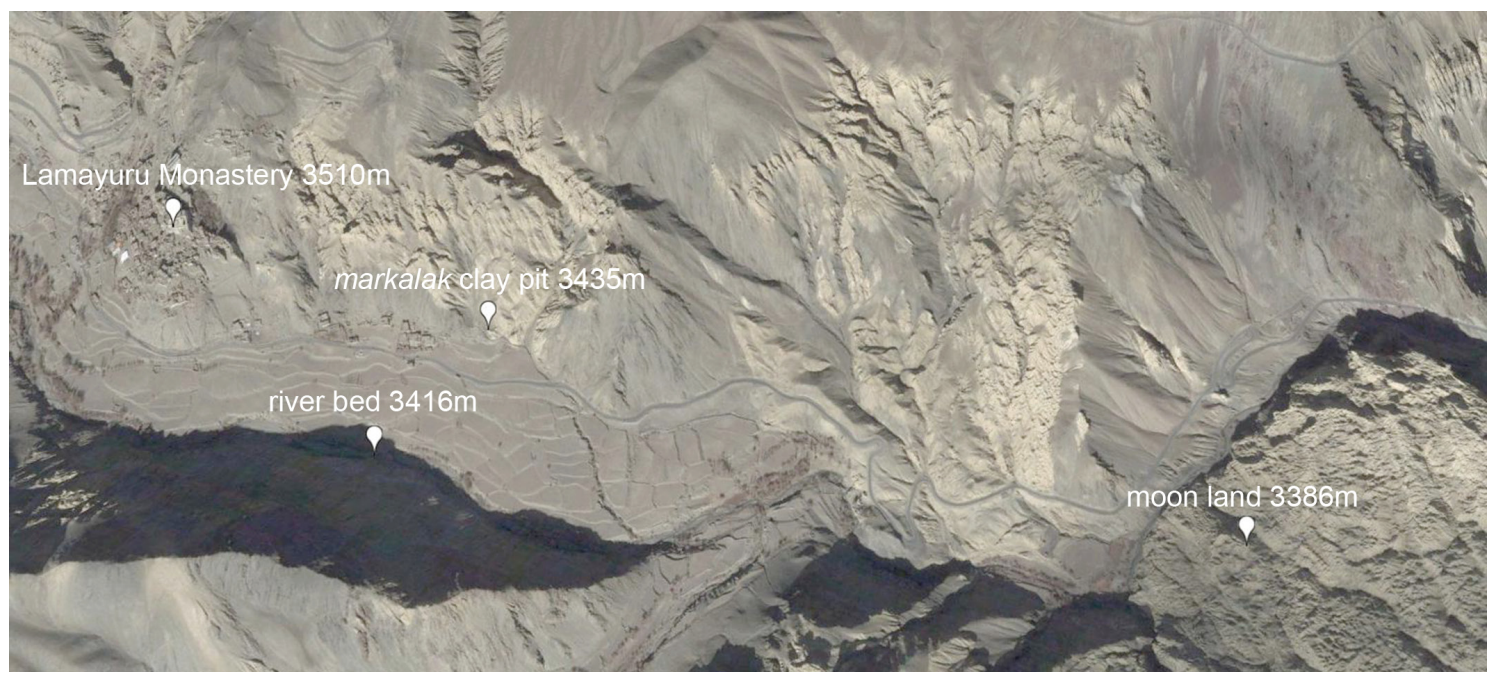

Fig. 16.4 Lamayuru. Ladakh. The level marks show the incline of the cross-country tread from the riverbed to the remains of the lacustrine basin. Source: Google Earth. Image (C) 2015 Digital Globe. Image NASA.

\section{LAmayuru. SAMple 11939}

\section{Sampling point}

Lamayuru is located on a former quaternary palaeolake (Fig. 16.4 and Fig. 17.4). Different layers of sedimentation are visible, in particular in the structure of varve clays (Fig. 18.4). This sample was collected in Lamayuru at the eastern entrance to the village, located at app. $34^{\circ} 16^{\prime} 59.22^{\prime \prime} \mathrm{N}$, $76^{\circ} 46^{\prime} 45.08^{\prime \prime}$ E (Fig. 19.4). The clay pit is located along the road to the right when moving towards Lamayuru and opposite the well-known "moon land". The location of digging for this kind of markalak clay is also locally well known. The area of the clay pits is located at a distance of app. $300 \mathrm{~m}$ from the Lamayuru River and $30 \mathrm{~m}$ above its riverbed at a crossing with another small valley in a northern direction. Along the glacial trough of the river and as a result of the inflow from the north, a lake may have resulted in pounding water and continuous piling up of layer by layer of fine alluvial sediments, similar to the situation at Spituk. Sample number in the field: 65 . Constructive use: Today this material is known for making the upper layer of earth roofs and used for building purposes such as additive for upper plaster layers. It is known for being mixed with sand for the preparation of plasters.

\section{Grain size distribution}

Generally speaking the grain size distribution of this sample shows a similarity with the markalak clay samples that contain a relatively high amount of silt with a maximum peak at the coarse silt fraction. In this relation, sample 6052 from Spituk is comparable. The material is relatively fine. Biggest fraction: fine sand (not counting extremely low contents of fine gravel with $0.5 \%$, coarse sand with $0.5 \%$ and medium sand with $0.4 \%$ ). The median is located at app. $2.3 \mu \mathrm{m}$; the $<2 \mu \mathrm{m}$ fraction contains app. $48 \%$ of the whole sample which can be described as high. Contrary to the 


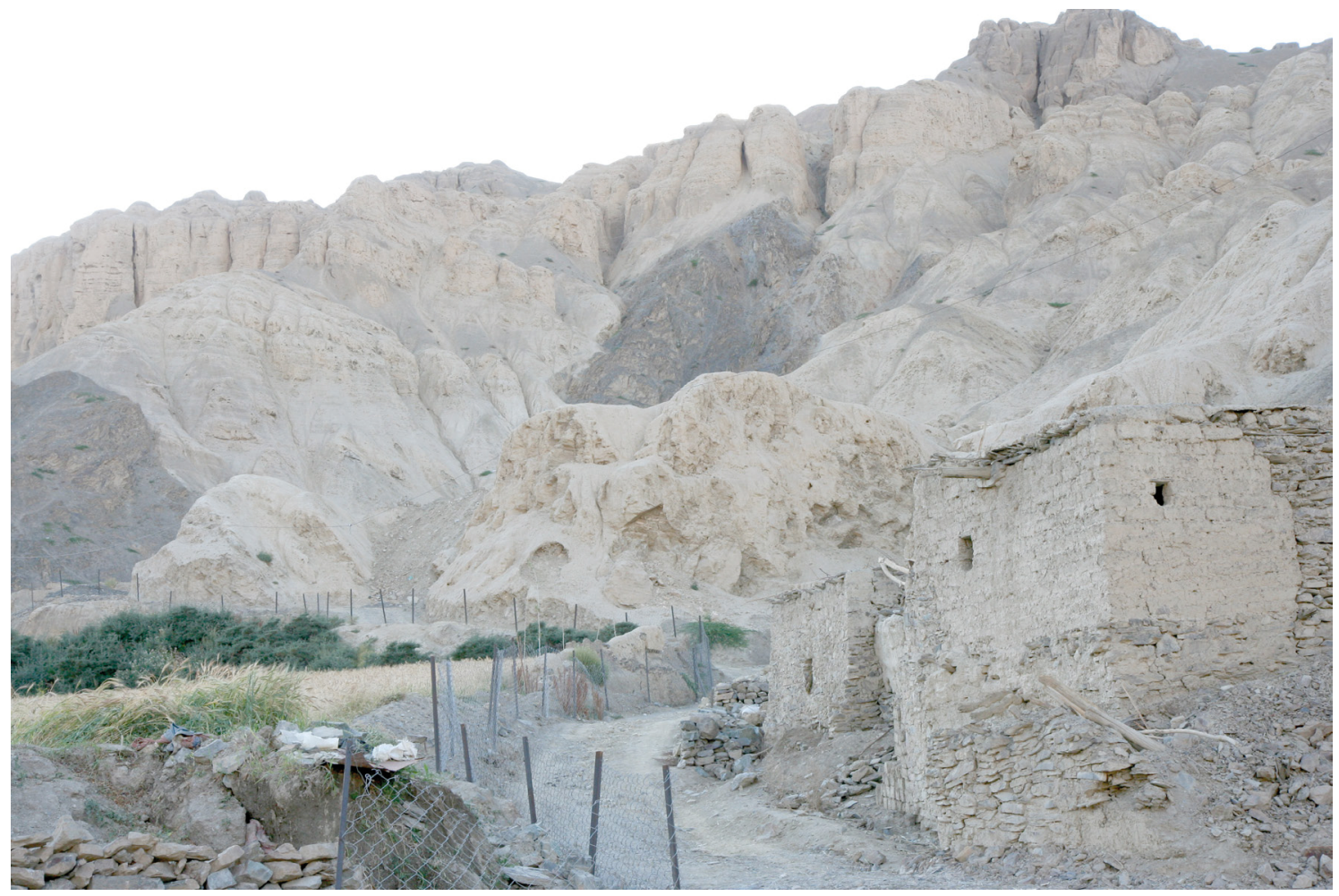

Fig. 17.4 (Top) Lamayuru. Area of clay pits.

Fig. 18.4 (Below) Lamayuru. Striped markalak clay.

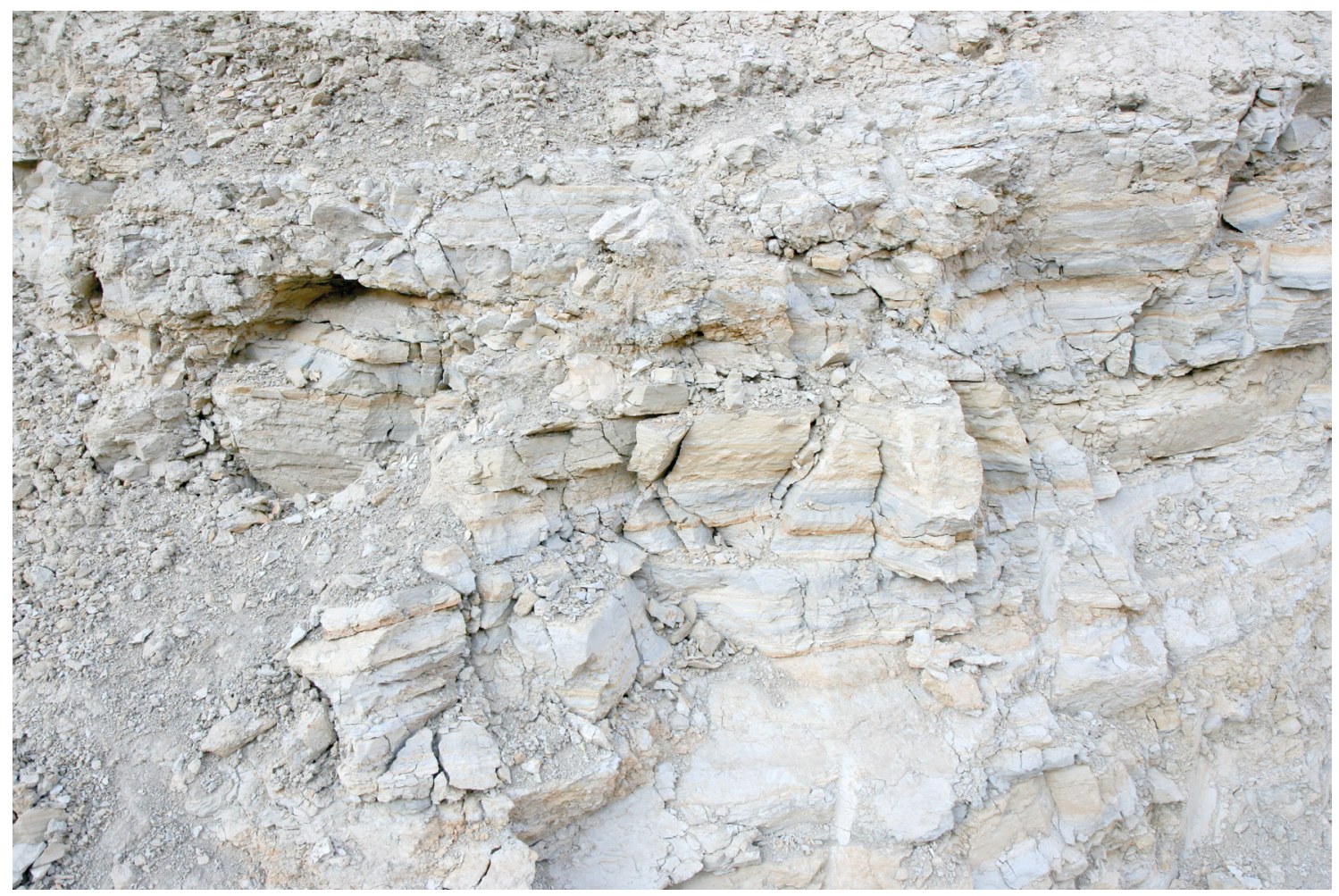




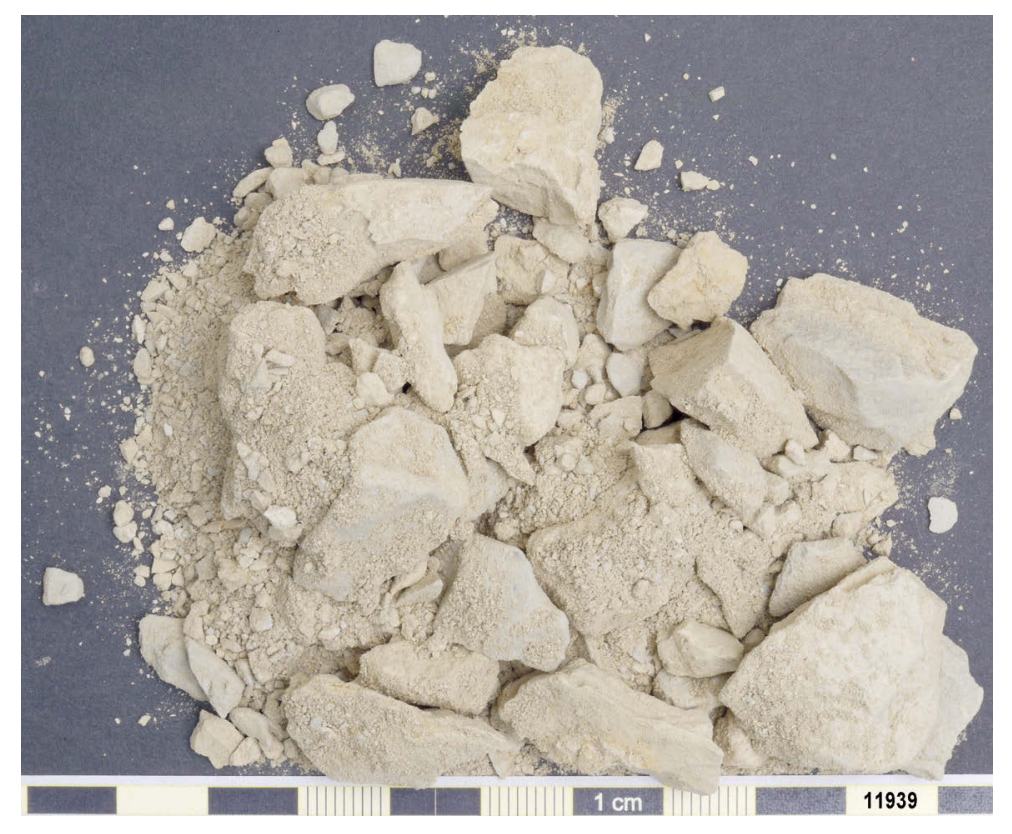

Fig. 19.4 Lamayuru.Sample 11939. Sample colour (after Munsell): Dry 10YR 7/1 light grey.

Semi-dry 10YR 6/2 light brownish grey.

other afore examined samples of markalak clay- except for samples 6052 and 11934 - the highest peak is silt and not of clay fraction. The silt and clay fractions show a similar proportional content within the whole sample. For most of the samples, there is a dominance of the silt fraction. In the distribution curve, no bimodal distribution is evident. A mixture of the material with sand or another type of clay is excluded since this sample was directly taken from the pit. The grain size distribution curve shows no break but a smooth course. For comparison, samples 8466, 8481, 14875 from Spituk and samples 11934 and 14876 from Alchi are listed below:

$\begin{array}{lllll} & \text { Gravel } & \text { Sand } & \text { Silt } & \text { Clay [\%] } \\ 11939 \text { (Lamayuru) } & 0 & 2.1 & 49.7 & 48.2 \\ 6052 \text { (Spituk) } & 0.1 & 0.2 & 84.6 & 15.1 \\ 11934 \text { (Alchi) } & 0 & 1.3 & 56.2 & 42.5\end{array}$

Bulk mineral analysis

In general, the BMA shows great similarity to the other examined markalak clay samples. Mica, quartz and plagioclase are available in small amounts (marked in Table 3.4 with (*)); $14 \AA$ minerals, amphiboles, $7 \AA$ minerals and $\mathrm{K}$-feldspar occur as traces. Traces of haematite are visible in the $\mathrm{X}$-ray diffractogram and also in regard to the sample colour itself. The amount of phyllo silicates is available in a medium amount (marked in the Table 3.4 with $(* *)$ ). Dolomite is not available in this sample. The content of calcite at $16 \%$ is similar to samples 8526,11934 and 14874 , and ranges slightly above an average content of calcite within the markalak clay samples. The sample shows evidence of ferric oxides pointing towards a content of haematite. Similarities are given to samples 8466, 8481 and 14875 (all from Spituk), and 14876 from Alchi. A varve structure on the sample is not clearly evident. 
Clay mineral analysis

In general the clay mineral distribution shows similarities with sample 14876 from Alchi and the samples collected in Spituk. Compared to the examined samples of Spituk and Alchi, no smectite is available while the content of illite is clearly higher. Further, this sample contains a mixed layer (illite-smectite; in the list below mentioned in short as ML).

$\begin{array}{lllll} & \text { Smectite } & \text { Illite } & \text { Kaolinite } & \text { Chlorite [\%] } \\ 11939 \text { (Lamayuru) } & 0(\mathrm{ML}) & 77 & 7 & 16 \\ 14876 \text { (Alchi) } & 7 & 62 & 5 & 26\end{array}$

\section{Lamayuru. Sample 14874}

Sampling point

This sample was collected at Lamayuru by members of the ACHI Association and handed over by Dr. Christine Bläuer (Fig. 20.4). Constructive use: Used as filling material for cracks, as reported by conservators. For a detailed description, refer to the remarks given for the use of sample 14875 .

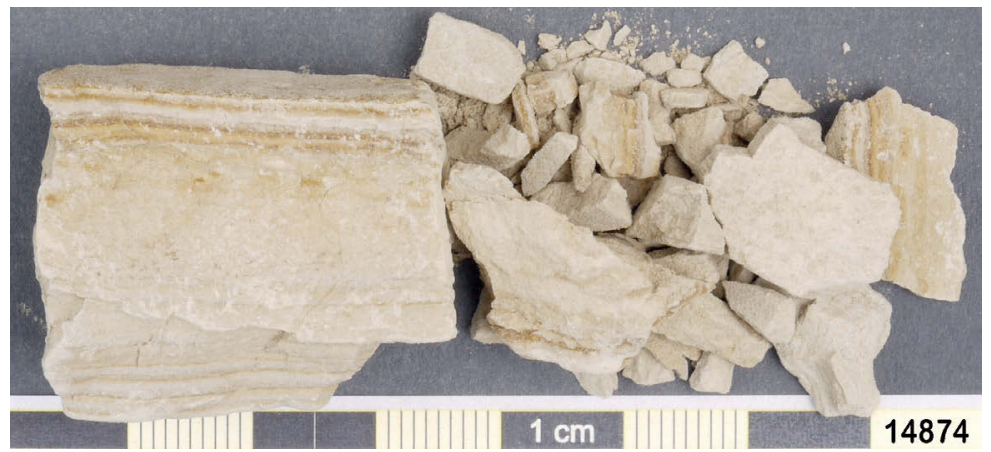

Fig. 20.4 Lamayuru. Sample 14874. Sample colour (after Munsell): Dry 10YR 7/2 light grey. Semi-dry 10YR 5/3 brown.

Grain size distribution

Generally speaking the grain size distribution of this sample shows strong similarity with markalak clay sample 11939. The material is relatively fine. Biggest fraction: coarse gravel (not counting an extremely low content of fine gravel with $0.2 \%$ ). The median is located at app. $2.9 \mu \mathrm{m}$ (vs. $2.3 \mu \mathrm{m}$ at sample 11939 ); the $<2 \mu \mathrm{m}$ fraction contains app. $40 \%$ of the whole sample (vs. $48 \%$ for sample 11939 and $43 \%$ for sample 11934) and can be described as high. Similar to sample 11939 from Lamayuru, the silt and clay fractions show a similar proportional content within the whole sample; for sample 14874 the silt content is slightly higher while sample 11939 shows a slightly higher content of fine sand. A mixture of the material with sand or another type of clay is excluded since this sample was directly taken from the pit. The grain size distribution curve shows no break but a smooth course, which is very close to the course shown at sample 11939. Dark coloured samples are extremely fine regarding the high content of clay.

$\begin{array}{lllll} & \text { Gravel } & \text { Sand } & \text { Silt } & \text { Clay [\%] } \\ 14874 \text { (Lamayuru) } & 0 & 0.1 & 58.8 & 41.1 \\ 11939 \text { (Lamayuru) } & 0 & 2.1 & 49.7 & 48.2 \\ 11934 \text { (Alchi) } & 0 & 1.3 & 56.2 & 42.5\end{array}$


Bulk mineral analysis

With small differences the BMA shows a similar result to that of sample 11939. Mica, $7 \AA$ minerals, phyllo silicates, quartz and plagioclase are available in small amounts (marked in Table 3.4 with $(*)$ ); $14 \AA$ minerals and K-feldspar occur as traces while amphiboles are not available. Dolomite is not available in this sample. Similar to samples 6052,8466 , and 8481 , possible traces of goethite may exist but can not be stated with certainty. The content of calcite at $11 \%$ is slightly smaller than for sample 11939 and slightly below the average range of the markalak clay samples. The sample shows a linear varve structure, which is not similar to sample 11939 from Lamayuru. A possible content of goethite, following traces in the X-ray diffraction, may explain the yellowish coloured stripes.

Clay mineral analysis

In general, the clay mineral distribution is also very similar with sample 11939 . The amount of smectite is also rather low and the content of illite clearly higher than for the other previously tested samples in Spituk and Alchi.

$\begin{array}{lllll} & \text { Smectite } & \text { Illite } & \text { Kaolinite } & \text { Chlorite [\%] } \\ 14874 \text { (Lamayuru) } & 2 & 73 & 7 & 18 \\ 11939 \text { (Lamayuru) } & 0 & 77 & 7 & 16\end{array}$

\subsection{Basgo}

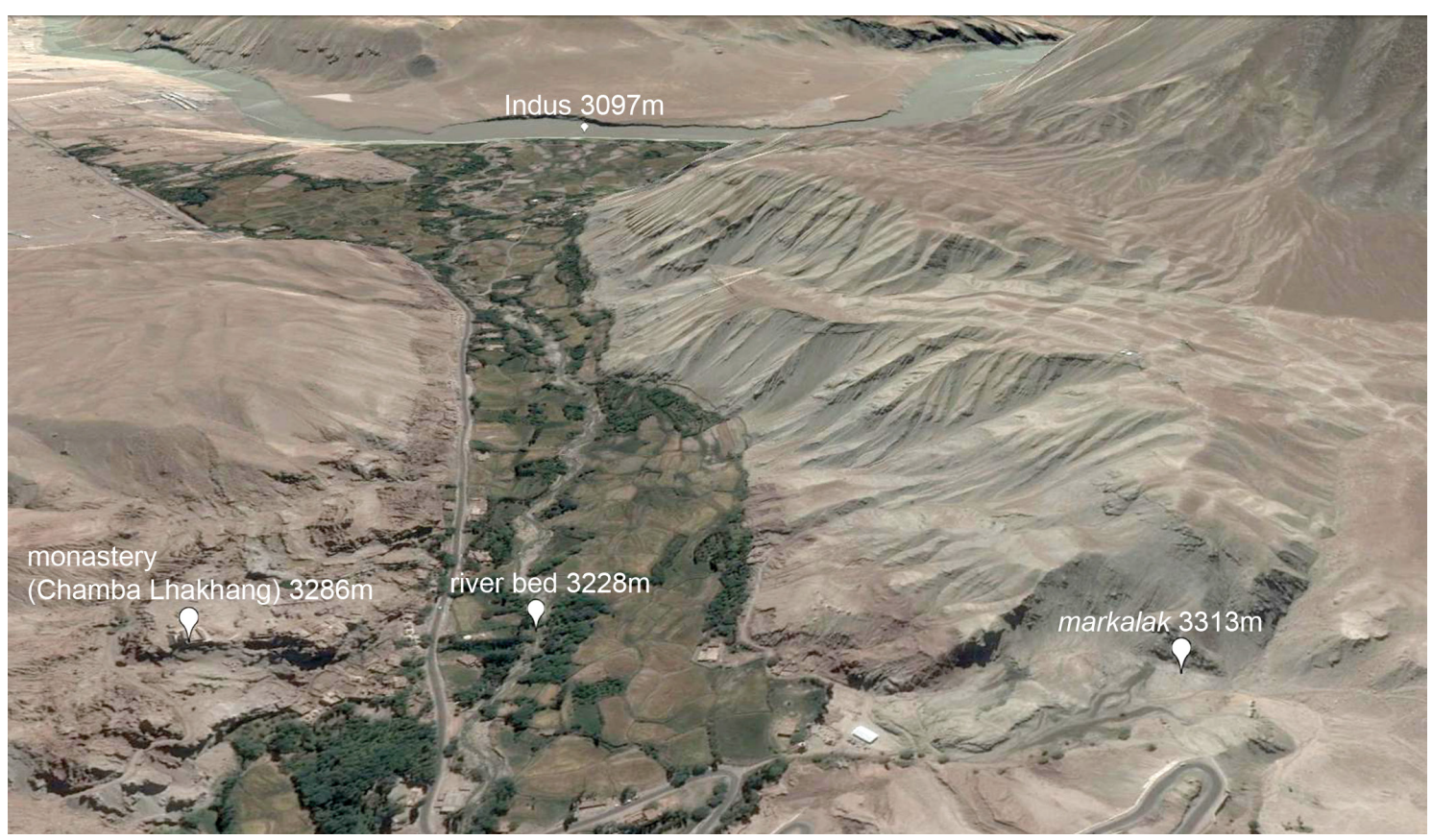

Fig. 21.4 Basgo. The level marks show the incline of the cross-country tread from the riverbed of the Indus to the remains of the lacustrine basin. Source: Google Earth. Image (C) 2015 CNES / Astrium. 


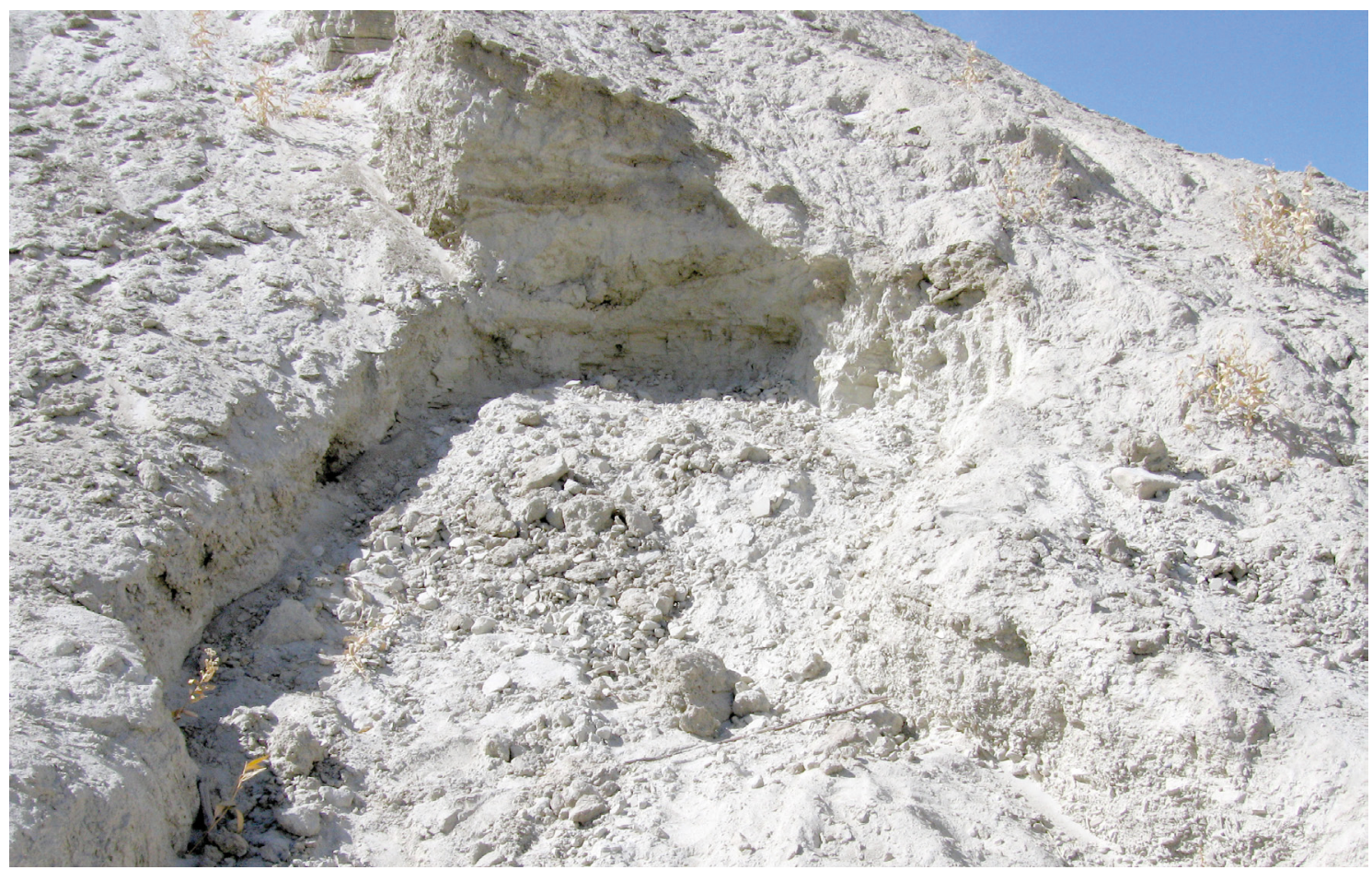

Fig. 22.4 (Top) Basgo. Clay pit.

Fig. 23.4 (Below) Basgo. Markalak clay.

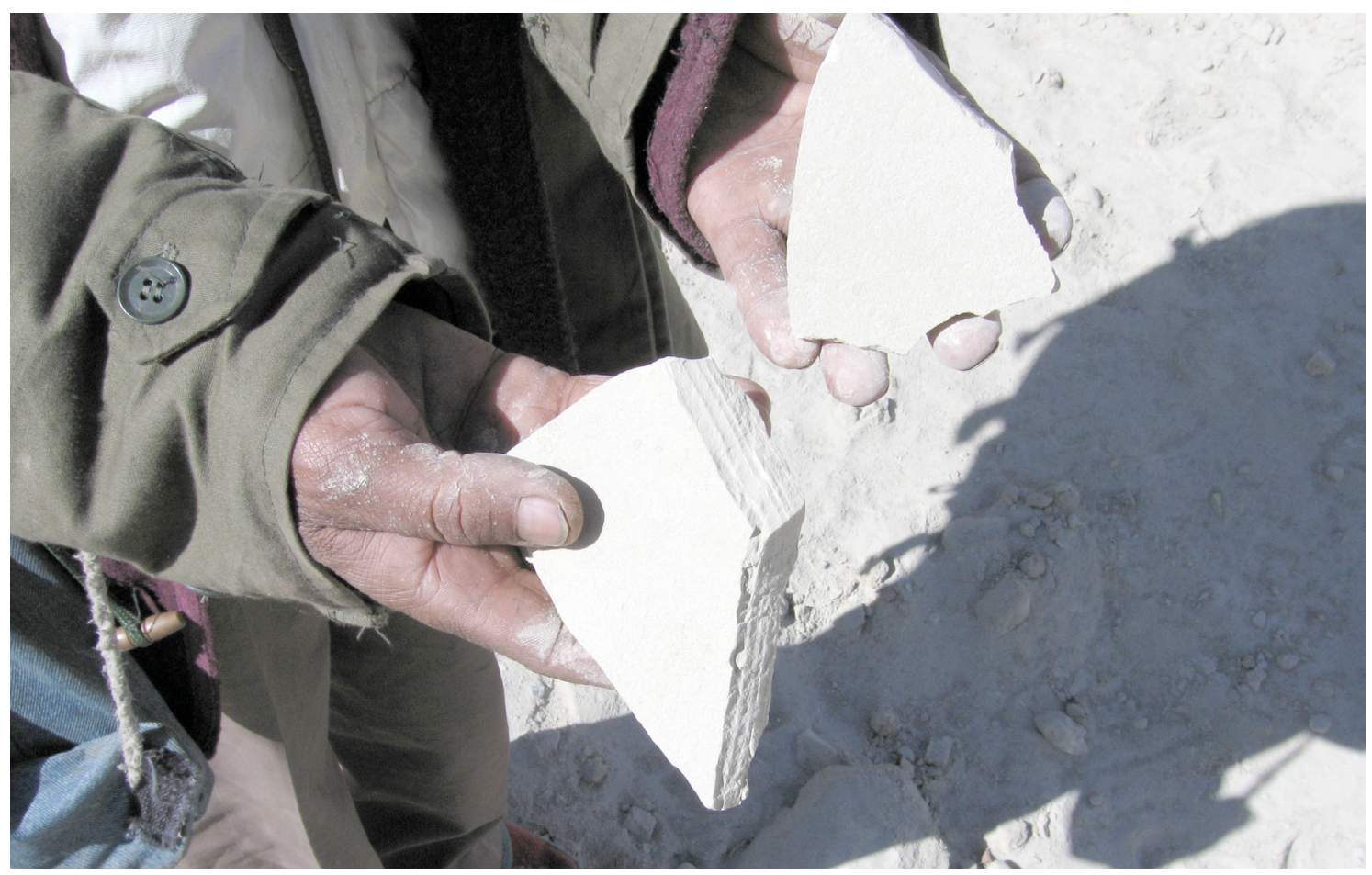




\section{BASGO. SAMPLE 15518}

\section{Sampling point}

This sample was collected in Basgo along a hill not far from the main road. The location of the clay pit is on the left side of the main road in a westerly direction after reaching the high plateau above Basgo when leaving the village along the serpentine road, located at app. $34^{\circ} 13^{\prime} 20.36^{\prime \prime} \mathrm{N}$, 77 16’3.47'E (Fig. 21.4, Fig. 22.4 and Fig. 23.4) (cf. Feiglstorfer 2014: 383). The site can be seen from further away due to its bright and white shiny appearance. The area of the clay pit is located at a distance of app. $2.7 \mathrm{~km}$ from the Indus River and app. $250 \mathrm{~m}$ higher than the riverbed. The next river to the clay pit is embedded in an inflow side valley to the Indus River with a distance of app. $600 \mathrm{~m}$ from the clay pit and app. $70 \mathrm{~m}$ higher than the riverbed. Along the glacial trough of the Basgo River following the high plateau towards the west, pounding water may have resulted in a continuous piling up of layer by layer of fine alluvial sediments, similar to the situation at Spituk. Sample number in the field: 84 BA/MARK. Constructive use: Today this material is known for being used to make the upper layer of earth roofs and for building purposes such as an additive for upper plaster layers (Fig. 24.4).

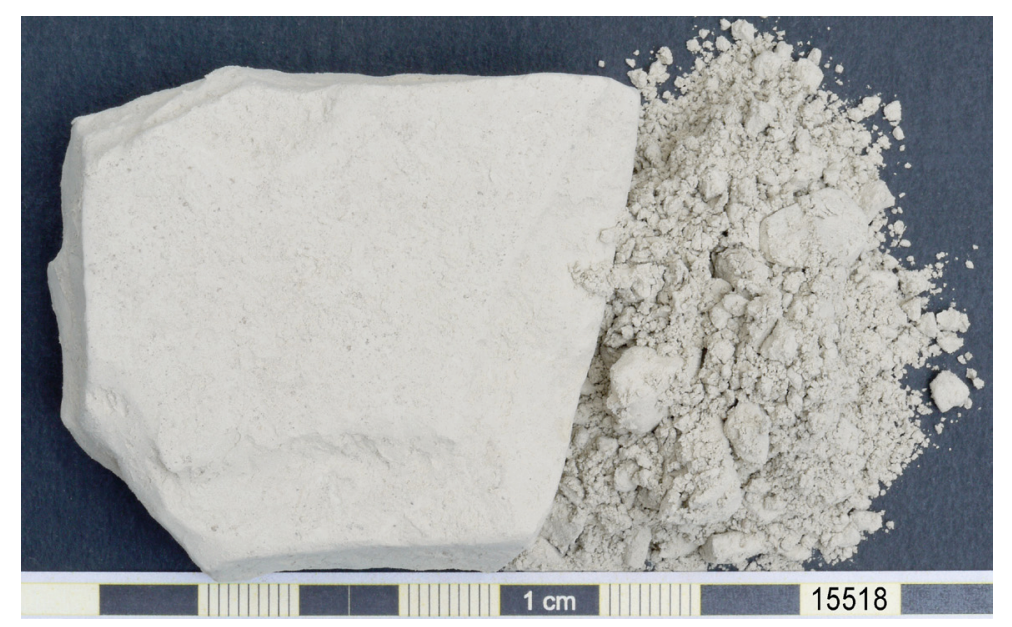

Fig. 24.4 Basgo. Sample 15518. Sample colour (after Munsell): Dry 10 YR (8/1 to $7 / 1)$ light grey. Semi-dry 10 YR $5 / 4$ yellowish brown.

\section{Grain size distribution}

Generally speaking the grain size distribution of this sample shows strong similarity with the markalak clay samples from Lamayuru. The material is relatively fine. Biggest fraction (not counting the small amount at $0.4 \%$ of the fine sand fraction): coarse silt. The median is located at app. $3.6 \mu \mathrm{m}$ (vs. $2.9 \mu \mathrm{m}$ for sample 14874 and $2.3 \mu \mathrm{m}$ for sample 11939); the $<2 \mu \mathrm{m}$ fraction contains app. $32 \%$ of the whole sample (vs. $40 \%$ for sample 14874 and $48 \%$ for sample 11939 , both from Lamayuru) and can be described as high but slightly lower than mentioned samples 14874 and 11939 from Lamayuru. The amount of silt at $68.5 \%$ is clearly higher than the case for the Lamayuru samples 14874 and 11939. A mixture of the material is excluded since this sample was directly taken from the pit. The grain size distribution curve shows a soft break between medium silt and coarse silt, and fine silt and coarse clay. At 35.9\% the maximum peak is fine silt. 


$\begin{array}{lllll} & \text { Gravel } & \text { Sand } & \text { Silt } & \text { Clay [\%] } \\ 15518 \text { (Basgo) } & 0 & 0.1 & 68.5 & 31.4 \\ 11939 \text { (Lamayuru) } & 0 & 2.1 & 49.7 & 48.2 \\ 14874 \text { (Lamayuru) } & 0 & 0.1 & 58.8 & 41.1\end{array}$

Bulk mineral analysis

With small differences the BMA shows a similar result to the BMA of the markalak clay samples. Differences are the phyllo silicates which are available only as traces and the amphiboles which are not available as traces but in small amounts. Mica, amphiboles, $7 \AA$ minerals, quartz and K-feldspar are available in small amounts (marked in Table 3.4 with $(*)$ ); besides the phyllo silicates, the $14 \AA$ minerals also occur as traces. Plagioclase occurs in a medium amount. Dolomite is not available in this sample. At $1 \%$ the content of calcite (measured according to Scheibler) is very small and much below the average rate for calcite within the markalak clay samples. This also seems to be a kind of marker of difference to samples 11939 and 14874, both from Lamayuru. When comparing the colour to the samples from Lamayuru, the similarity is strong, with tendencies of grey towards a yellowish colour; similar to sample 119389, but contrary to sample 14874 , the sample shows no varve structure.

Samples from Lamayuru for comparison of the colour (according to Munsell colour chart):

$\begin{array}{lll}14874 & \text { Dry } & \text { 10YR 7/2 light grey } \\ & \text { Semi-dry } & \text { 10YR 5/3 brown } \\ 11939 & \text { Dry } & \text { 10YR 7/1 light grey } \\ & \text { Semi-dry } & \text { 10YR 6/2 light brownish grey }\end{array}$

Clay mineral analysis

The following list shows comparison of samples 6052 and 14875 from Spituk, and the examined samples from Alchi and from Lamayuru. The similarity of sample 15518 from Basgo to sample 14874 is striking. Besides the samples from Shey (see below), the Lamayuru-Basgo samples show the highest amount of illite while samples from the latter group show a very small content of smectite and a lower content of chlorite.

$\begin{array}{lllll} & \text { Smectite } & \text { Illite } & \text { Kaolinite } & \text { Chlorite [\%] } \\ 15518 \text { (Basgo) } & 3 & 76 & 6 & 15 \\ 6052 \text { (Spituk) } & 6 & 70 & 6 & 18 \\ 14875 \text { (Spituk) } & 3 & 64 & 6 & 27 \\ 14874 \text { (Lamayuru) } & 2 & 73 & 7 & 18\end{array}$




\subsection{Shey}

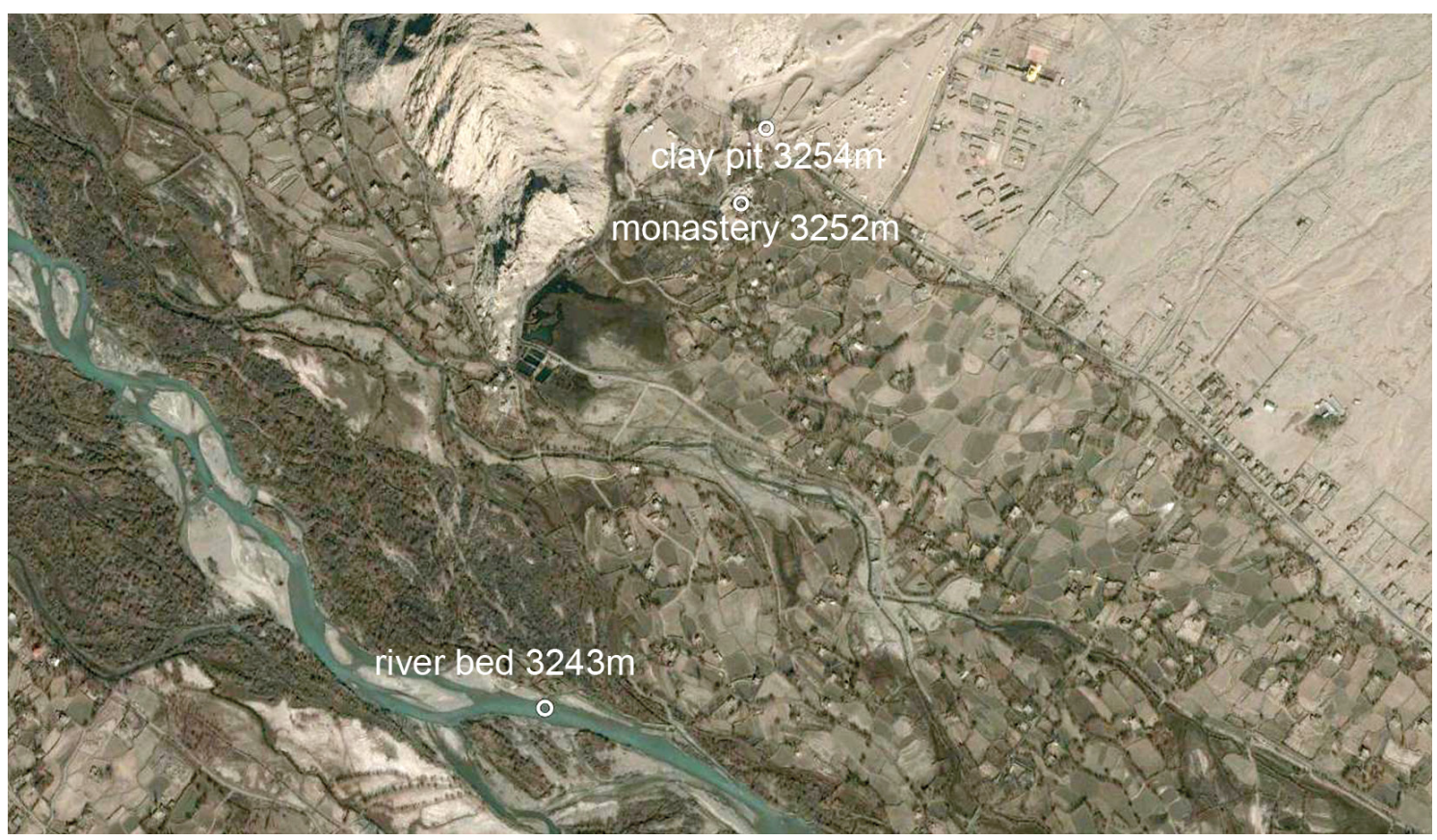

Fig. 25.4 Shey. The level marks show the incline of the cross-country tread from the riverbed of the Indus to the remains of the lacustrine basin.

Source: Google Earth. Image (C) 2015 CNES / Astrium.

Shey. Sample 11913

Sampling point

This sample was collected in Shey in the area of the big field of stupas along the road on the right side when moving towards Leh, located at app. 344'27.89'N, $77^{\circ} 38^{\prime} 21.98^{\prime \prime} \mathrm{E}$. The area of the clay pits is located with a distance of app. $1.3 \mathrm{~km}$ from the Indus and just $10 \mathrm{~m}$ to $15 \mathrm{~m}$ above its riverbed within a wide plain of lateral offsets of the Indus (Fig. 25.4). Towards the west and north, a small mountain belt encompasses the area of the markalak clay pit. Along the glacial trough of the Indus, this small river belt points towards a former naturally formed basin for keeping water that allowed for a continuous piling up of layer by layer of fine alluvial sediments, similar to the situation given at Spituk or Lamayuru (Fig. 26.4 and Fig. 27.4). Sample number in the field: 72. Constructive use: Today this material (Fig. 28.4) is known for making the upper layer of roofs and used for building purposes such as additives for upper plaster layers.

Grain size distribution

Generally speaking, the grain size distribution of this sample shows a strong similarity with the markalak clay samples from Lamayuru and Basgo. The material is relatively fine with a slightly higher content of fine sand than found for samples 15518 (Basgo) and 14874 (Lamayuru), though it is similar to sample 11939 (Lamayuru). Biggest fraction: medium sand with $0.5 \%$. 


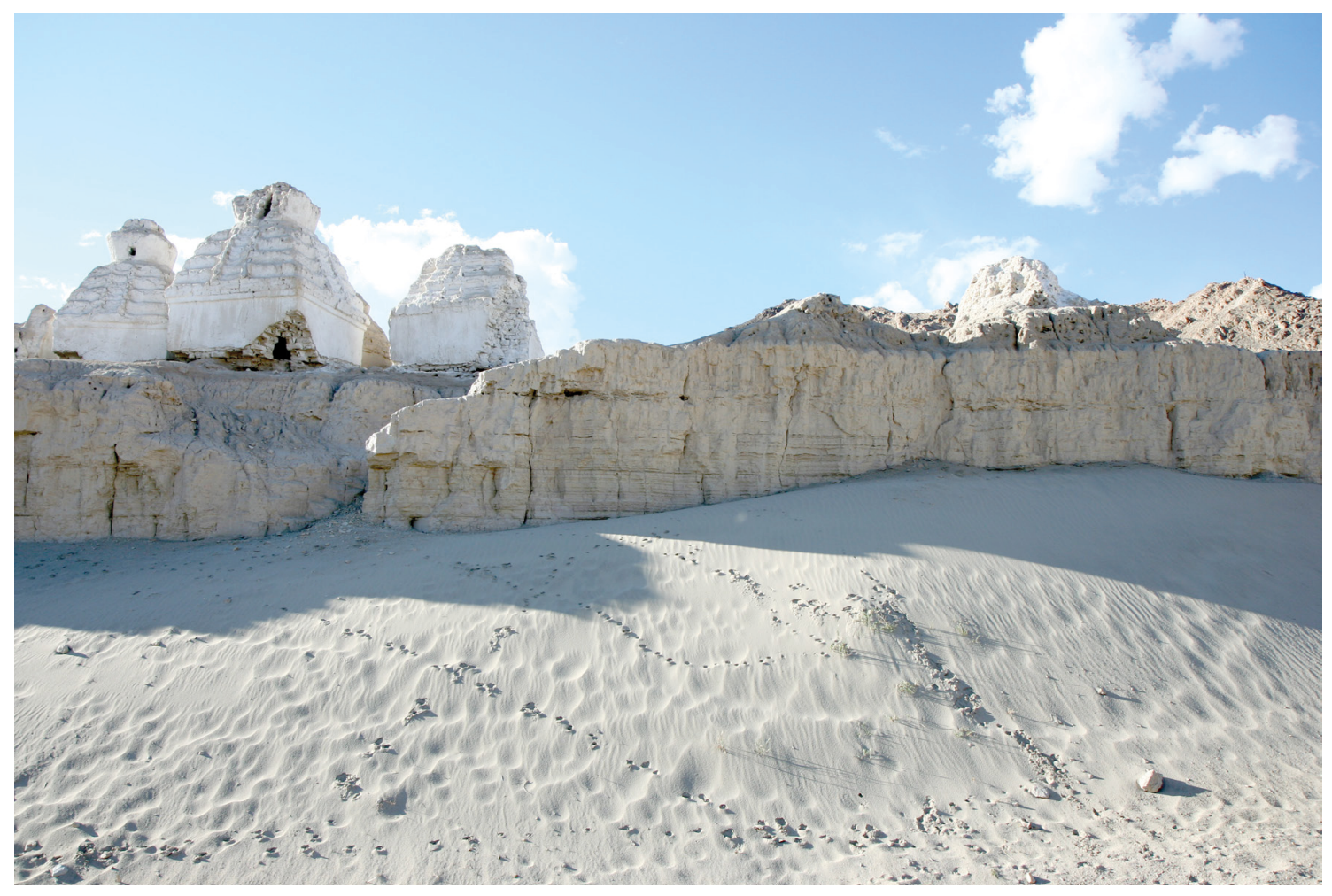

Fig. 26.4 (Top) Shey. Area of clay pits.

Fig. 27.4 (Below) Shey. Markalak clay.

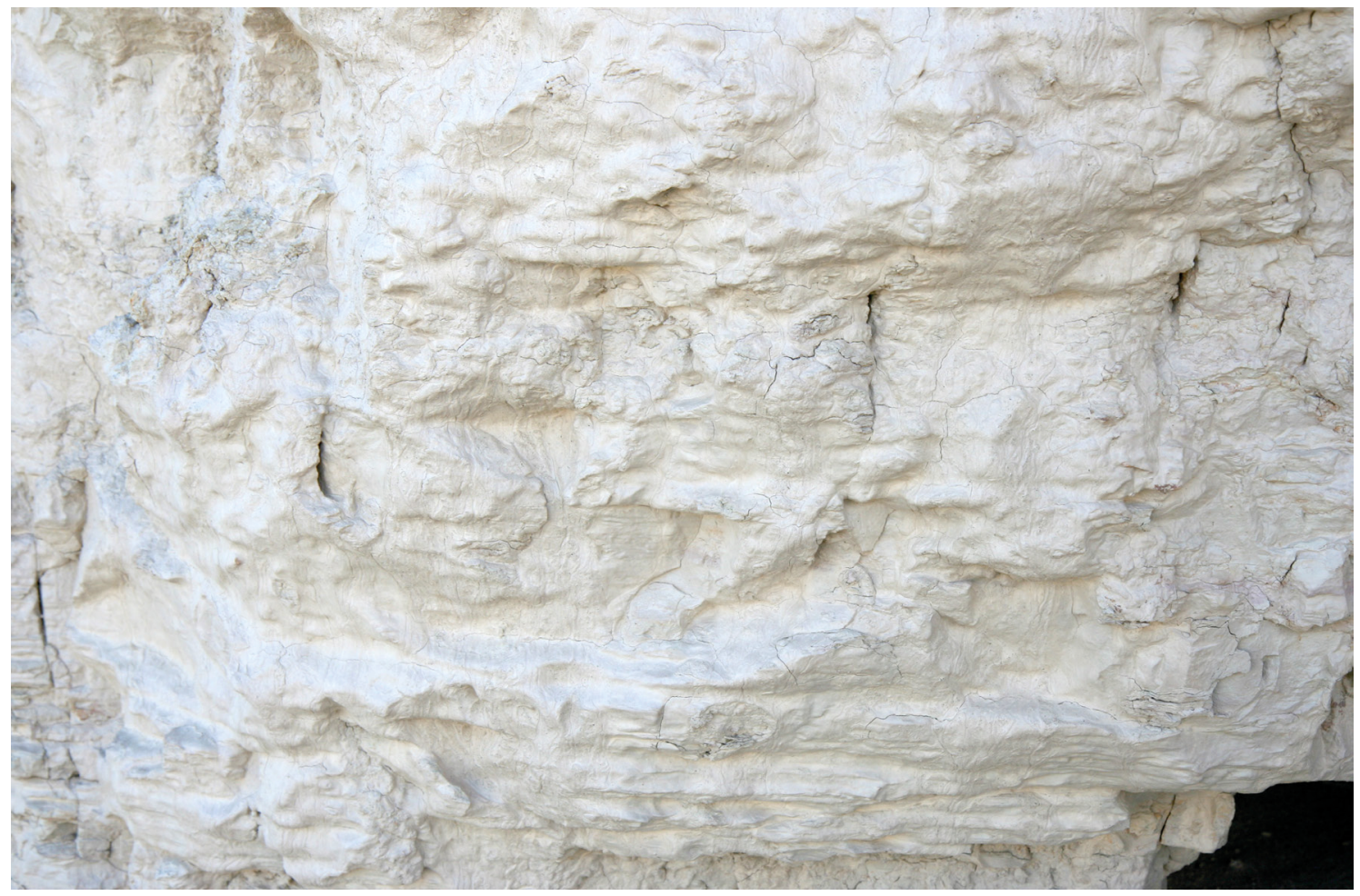




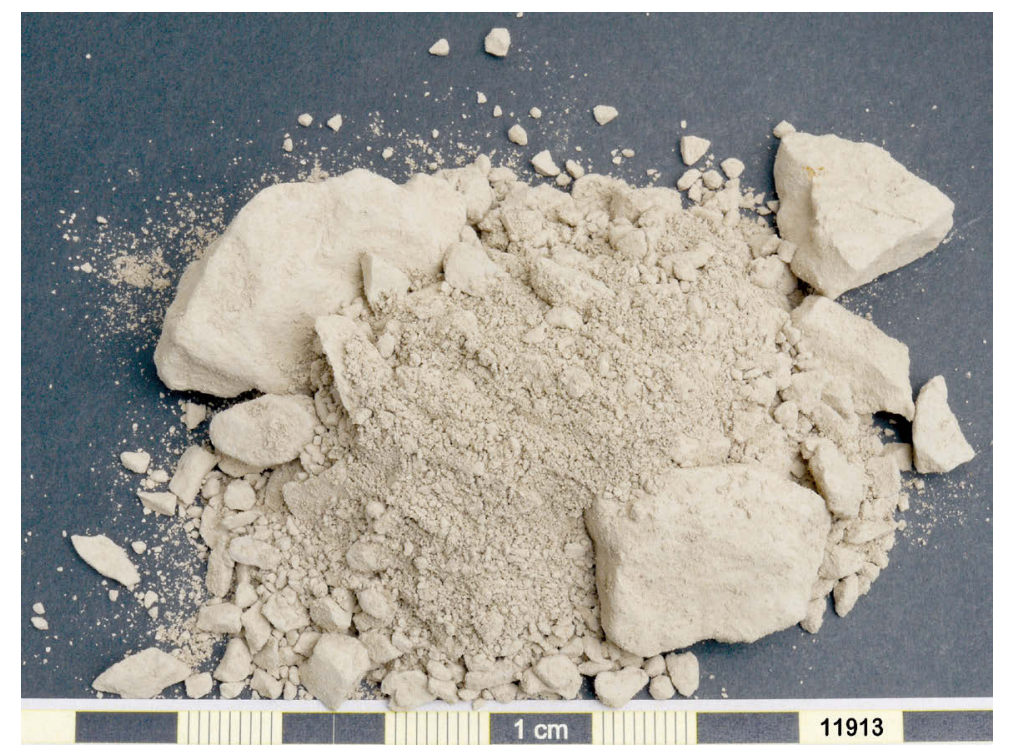

Fig. 28.4 Shey. Sample 11913. Sample colour (after Munsell): Dry 5YR 7/1 light grey. Semi-dry 5YR 5/1 grey.

The median is located at app. $2.8 \mu \mathrm{m}$ (vs. $3.6 \mu \mathrm{m}$ for sample 15518 (Basgo), $2.9 \mu \mathrm{m}$ for sample 14874 and $2.3 \mu \mathrm{m}$ for sample 11939 (both from Lamayuru)); the $<2 \mu \mathrm{m}$ fraction contains app. $43 \%$ of the whole sample (vs. $32 \%$ for sample 15518 (Basgo), $40 \%$ for sample 14874 and $48 \%$ for sample 11939 (both from Lamayuru), and 43\% for sample 11934 (Alchi)) and can be described as high. At $54 \%$ the amount of silt is slightly higher than the amount of clay at $43.7 \%$. Together with samples 15518 from Basgo, 6052 from Spituk and 11934 from Alchi, it is one of the samples in which the amount of silt is higher than the amount of clay. A mixture of the material is excluded since this sample was directly taken from the pit. The grain size distribution curve shows a soft break between medium silt and coarse silt. At $23.4 \%$ the maximum peaks are medium and fine silt. A juxtaposition of the single grain size classes is given in the following list.

$\begin{array}{lllll} & \text { Gravel } & \text { Sand } & \text { Silt } & \text { Clay [\%] } \\ 11913 \text { (Shey) } & 0 & 2.3 & 54 & 43.7 \\ 6052 \text { (Spituk) } & 0.1 & 0.2 & 84.6 & 15.1 \\ 11934 \text { (Alchi) } & 0 & 1.3 & 56.2 & 42.5 \\ 11939 \text { (Lamayuru) } & 0 & 2.1 & 49.7 & 48.2 \\ 14874 \text { (Lamayuru) } & 0 & 0.2 & 58.8 & 41.1 \\ 15518 \text { (Basgo) } & 0 & 0.1 & 68.5 & 31.4\end{array}$

Bulk mineral analysis

With small differences the BMA of this sample shows a similar result to the BMA of the markalak clay samples in general. $14 \AA$ minerals, mica, $7 \AA$ minerals, phyllo silicates, quartz and plagioclase are available in small amounts (marked in Table 3.4 with $(*)$ ); amphiboles and K-feldspar occur as traces. Dolomite is not available in this sample. The content of calcite at $5 \%$ is small and below the average rate for calcite within the markalak clay samples. The grey colour is dominant. No ferric oxides can be traced. 
Clay mineral analysis

The CMA shows differences to most of the previously analysed samples from Spituk, Alchi, Lamayuru and Basgo. Together with samples 11939 and 14874 from Lamayuru, the content of smectite is very small but sample 11913 shows a content of $5 \% 14 \AA$ vermiculite. Together with $1 \%$ smectite, it has an average range of content of swellable clay minerals. The following list shows comparison with samples 6052 and 14875 from Spituk and the examined samples from Alchi, Lamayuru and Basgo. This sample from Shey reaches the highest content of illite within the markalak clay samples. In general it differs in several parameters from the average markalak clay samples. The amount of kaolinite is within an average range but the content of chlorite is comparably low and is the only markalak clay sample containing vermiculite. A hornblende appears in the $2 \mu \mathrm{m}$-fraction. Also a mixed layer was detected, keeping two variations of mixtures open: 1 . chlorite and vermiculite; 2 . chlorite and smectite.

\begin{tabular}{llllll} 
& Smectite & Vermic & Illite & \multicolumn{2}{c}{ Kaolinite Chlorite [\%] } \\
11913 (Shey) & 1 & 5 & 85 & 7 & 2 \\
6052 (Spituk) & 6 & 0 & 70 & 6 & 18 \\
14875 (Spituk) & 3 & 0 & 64 & 6 & 27 \\
11939 (Lamayuru) & 0 & 0 & 77 & 7 & 15
\end{tabular}

\section{Shey. SAMPLe 15404}

\section{Sampling point}

This sample was collected in Shey from a clay pit (Fig. 29.4). The reason for taking this material into consideration although it has nothing to do with a markalak clay is to make its difference clear to another locally used and well known markalak clay. In doing so we can question the unique characters of markalak clay material. Sample number in the field: $78 \mathrm{SH} / \mathrm{ZI}$. Constructive use: The material is well known as a raw material for adobe bricks. At the CIBS (Central Institute of Buddhist Studies) in Choglamsar in Leh in Ladakh, this material is used to build the first form for clay statues around which the model is later sculptured.

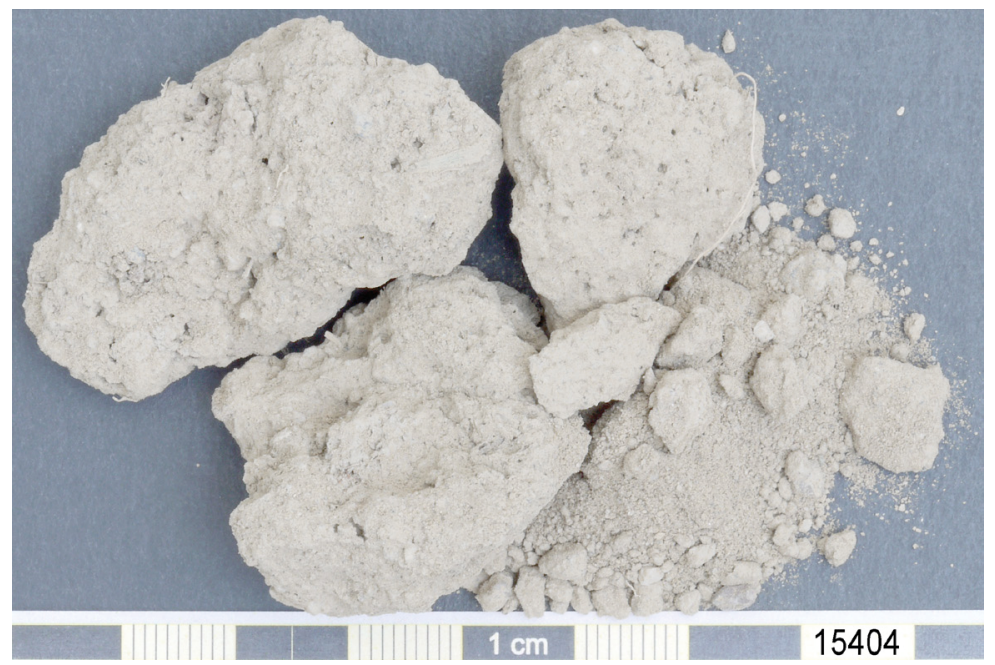

Fig. 29.4 Shey. Sample 15404. Sample colour (after Munsell): Dry 10YR 5/3 brown. Semi-dry 10YR 3/3 dark brown. 
Grain size distribution

Generally speaking the grain size distribution of this sample shows a strong difference to all the afore compared markalak clay samples, except sample 8526 from Alchi which was called markalak clay by Morup Dorje, a local teacher. In this relation we move closer to another kind of markalak clay which bears several specific characteristics, in particular fine fractions of silt and clay. It furthermore has a rather coarse component as a natural mixture. The material is relatively coarse. Biggest fractions: fine gravel. The median is located at app. $180 \mu \mathrm{m}$ (vs. $95 \mu \mathrm{m}$ at sample 8526 from Alchi); the $<2 \mu \mathrm{m}$ fraction contains app. $13 \%$ of the whole sample (same as for sample 8526 from Alchi). The peak lies at the sand fraction with a maximum of $23.4 \%$ of medium sand (vs. a maximum of $32.6 \%$ of fine sand for sample 8526 from Alchi). In the distribution curve, a bimodal distribution with a soft valley between coarse and fine silt is evident. The sample was reported to the author as pure and unmixed. A comparison with the coarse markalak clay of sample 8526 from Alchi, located about $46 \mathrm{~km}$ away, shows its close similarity, while a comparison with the fine markalak clay of sample 14876, also from Alchi, shows its difference. A comparison between these samples shows close similarities with the coarse building material from Alchi given with sample 8526 .

15404 (Shey, coarse building material)

14876 (Alchi, fine markalak clay)

8526 (Alchi, coarse markalak clay)

$\begin{array}{llll}\text { Gravel } & \text { Sand } & \text { Silt } & \text { Clay [in \%] } \\ 8 & 57.9 & 21 & 13.1 \\ 0 & 0.4 & 23.3 & 76.3 \\ 8.1 & 53.7 & 24.4 & 13.8\end{array}$

Bulk mineral analysis

With small differences the BMA shows a similar result to the BMA of the markalak clay samples in general. The medium amount of amphiboles is the highest available rate within the markalak clay samples (marked in Table 3.4 with $\left({ }^{* *}\right)$ ). K-feldspar, mica, $7 \AA$ minerals and quartz are also available in small amounts (marked in Table 3.4 with $(*)$ ); $14 \AA$ minerals and phyllo silicates occur as traces. The content of plagioclase is relatively high (marked in Table 3.4 with (***)). Dolomite is not available. The content of calcite at $1 \%$ is very small and below the average rate for calcite within the markalak clay samples. This samples range within the greyish colours with a slight tendency towards yellowish. Neither in the X-ray diffraction nor with the naked eye could ferric oxides be traced.

Clay mineral analysis

A comparison of the CMA samples 8526 (Alchi, coarse markalak clay), 14876 (Alchi, fine markalak clay) and 11913 (Shey, fine markalak clay) shows strong similarities to the CMA of the samples of Alchi but not to sample 11913 which also has its origin in Shey. The following list shows a comparison with samples 8526 from Alchi (a coarse markalak clay) and 14876 from Alchi (a fine markalak clay).

$\begin{array}{llllll} & \text { Smectite } & \text { Vermic } & \text { Illite } & \text { Kaolinite } & \text { Chlorite [\%] } \\ 15404 \text { (Shey) } & 4 & 0 & 71 & 5 & 20 \\ 11913 \text { (Shey) } & 1 & 5 & 85 & 7 & 2 \\ 14876 \text { (Alchi) } & 7 & 0 & 62 & 5 & 26 \\ 8526 \text { (Alchi) } & 6 & 0 & 63 & 5 & 26\end{array}$




\subsection{Nako}

\section{NAKO. SAMPLe 15516}

\section{Sampling point}

This sample was collected at the Nako temple building site during renovation work in 2006. The exact source was a heap of clay which was collected about $2 \mathrm{~km}$ to the west of Nako, located at Kirsi at app. 78³6'31.32'”, 31 ${ }^{\circ} 52^{\prime} 42.96$ 'N (Gruber 2011: 139). The material is commonly known as tua ${ }^{15}$ clay instead of as markalak clay (Fig. 30.4). Nako is located in Upper Kinnaur in the Indian state Himachal Pradesh south of Ladakh close to Spiti in the west and the Chinese border in the east. The inclusion of this sample into the markalak clay analysis was due to its commonly known fine character and locally mentioned similarity to markalak clay. This material is locally mentioned to be similar to the tua clay from Shelkhar (compared to the following sample 8504 ) and was handed over by locals at the building site. The markalak clay pit is located along a valley which passes Nako to its west leading into the Spiti River. The area of the clay pit is located with a distance of app. $1 \mathrm{~km}$ from the Spiti River and is app. $250 \mathrm{~m}$ higher than the riverbed. Along the glacial trough of this side valley, in the form of an inflow into Spiti Valley, one can find deposits along the trough valley. Such deposits may have resulted from a continuous piling up of layer by layer of fine alluvial sediments. Sample number in the field: $82 \mathrm{NAK} /$ Tua. The fibres shown in the picture may not be part of the original sample but show remains of building material used during the conservation work. Constructive use: Today this material is known for making the upper layer of earth roofs. Additionally Maria Gruber describes its use as binder in mortars (Gruber 2011: 141).

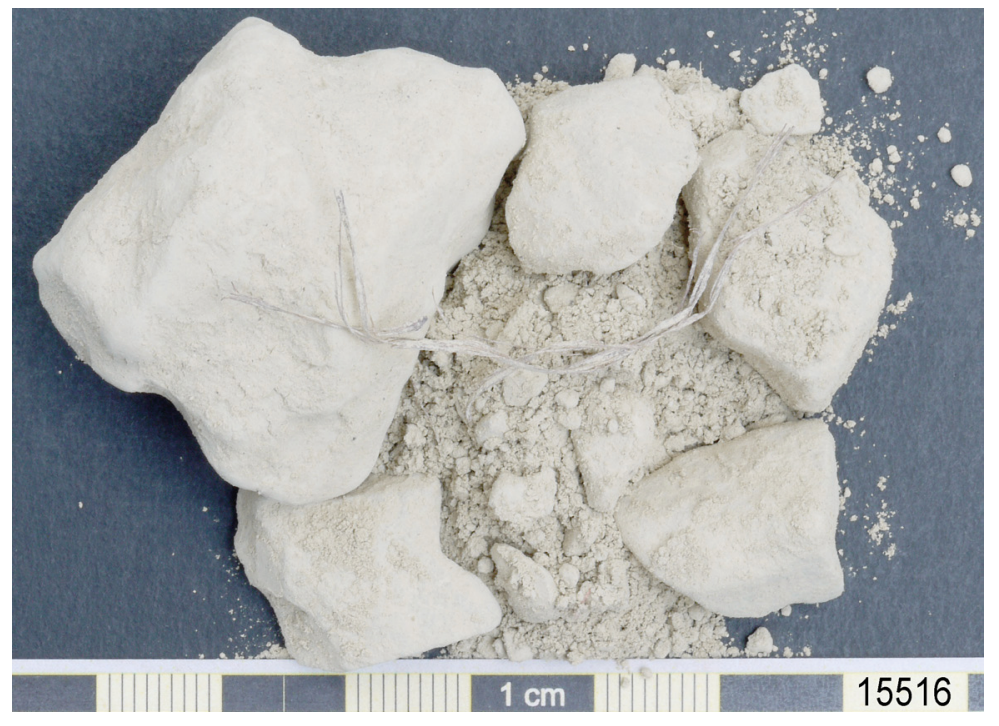

Fig. 30.4 Nako. Sample 15516. Sample colour (after Munsell): Dry 10 YR 7/2 light grey. Semi-dry 10YR 5/4 yellowish brown.

15 Besides thawa and sassa the tua clay is another locally available earth building material. Compare Gruber 2011: 115. The tua clay can be classified as clay-silt (Gruber 2011: 139). 
Grain size distribution

Generally speaking, the grain size distribution of this sample shows a strong similarity to fine Ladakh markalak clays. The median is located at app. $4.5 \mu \mathrm{m}$ (vs. 11934 from Alchi with a median at app. $2.6 \mu \mathrm{m}, 11939$ from Lamayuru with a median at app. $2.3 \mu \mathrm{m}$, and 11913 from Shey with a median at app. $2.8 \mu \mathrm{m}$ ). It is relatively close to sample 15518, a markalak clay from Basgo, with a median at app. $3.6 \mu \mathrm{m}$; the $<2 \mu \mathrm{m}$ fraction contains app. $29 \%$ of the whole sample (vs. 11934 from Alchi with an amount of $<2 \mu \mathrm{m}$ of app. 43\%, 11939 from Lamayuru with an amount of $2 \mu \mathrm{m}$ of app. $48 \%$, and 11913 from Shey with an amount of $2 \mu \mathrm{m}$ of app. $43 \%$ ). At app. 32\% and $2 \mu \mathrm{m}$, sample 15518 from Basgo is again very close to sample 15516. In the distribution curve no bimodal distribution is evident. The grain size distribution curve shows no break with a smooth course. The maximum peak is $30 \%$ fine silt. The proportional relation between silt and clay (silt:clay) is also very similar between these two samples: Sample 15518 (markalak clay from Basgo) with 68.5:31.4 and sample 15516 (tua clay from Nako) with 61.9:29.4. All other fine markalak clay samples show a slightly higher content of fine and medium clay, again with an exception being sample 15518 (markalak clay from Basgo), which shows similar rates. The sample was locally reported to the author as pure and unmixed.

A comparison with other markalak clays shows average rates - except for the slightly increased rates for the content of gravel and sand. The samples Tua* and Tua** have been examined by Maria Gruber (Gruber 2011: 139) and are listed for further comparison. Sample Tua* also shows similarities to sample 15516 from Nako regarding a slightly higher content of sand and a small amount of gravel. In contrast, sample Tua** - in Gruber 2011 referred to as Tua (T3) - shows strong similarities to markalak clay samples, such as sample 15518 from Basgo.

$\begin{array}{lllll} & \text { Gravel } & \text { Sand } & \text { Silt } & \text { Clay [\%] } \\ 15516 \text { (Nako) } & 2.8 & 5.9 & 61.9 & 29.4 \\ \text { Tua* (Nako) } & 0.2 & 2.6 & 71.4 & 25.9 \\ \text { Tua** (Nako) } & 0 & 0.1 & 63.5 & 36.4 \\ 15518 \text { (Basgo) } & 0 & 0.1 & 68.5 & 31.4 \\ 11934 \text { (Alchi) } & 0 & 1.3 & 56.2 & 42.5 \\ 11939 \text { (Lamayuru) } & 0 & 2.1 & 49.7 & 48.2\end{array}$

Bulk mineral analysis

With small differences, the BMA shows a similar result to the BMA of the markalak clay samples. Mica, $7 \AA$ minerals, phyllo silicates, quartz, plagioclase and K-feldspar are available in small amounts (marked in the Table 3.4 with $(*)$ ); $14 \AA$ minerals and amphiboles occur as traces. Dolomite is available at $4 \%$. At $36 \%$ the content of calcite ranges within the highest rates of the markalak clay samples - with this high amount we certainly find a main difference to other markalak clay samples whose average contents of calcite are generally lower. It is similar to 38.4\% (Gruber 2011: 140), i.e. the result given by Maria Gruber measured with STA. Tua clay sample 15516 from Nako ranges within the greyish colours with a slight tendency towards yellowish colouring. Neither in the X-ray diffraction nor with the naked eye is there evidence of ferric oxides. The material appears monochromatic without any varve texture. A comparison of the colour with sample 15518 from Basgo shows similarities with a tendency into yellowish. 


$\begin{array}{llll}15516 & \text { Dry } & \text { 10YR 7/2 } & \text { light grey } \\ & \text { Semi-dry } & \text { 10YR 5/4 } & \text { yellowish brown } \\ 15518 & \text { Dry } & \text { 10YR (8/1)-7/1 } & \text { light grey } \\ & \text { Semi-dry } & \text { 10YR 5/4 } & \text { yellowish brown }\end{array}$

Clay mineral analysis

The following list shows a comparison with markalak clay samples 14875 from Spituk and 14876 from Alchi, both of which show a close similarity to markalak clay sample 15516 from Nako. Sample 15518 from Basgo differs slightly from this pattern.

\begin{tabular}{lllllc} 
& Smectite & Vermic & Illite & \multicolumn{2}{c}{ Kaolinite Chlorite [\%] } \\
15516 (Nako) & 4 & 0 & 69 & 3 & 27 \\
15518 (Basgo) & 3 & 0 & 76 & 6 & 15 \\
14875 (Spituk) & 3 & 0 & 64 & 6 & 27 \\
14876 (Alchi) & 7 & 0 & 62 & 5 & 26
\end{tabular}

\subsection{Shelkhar}

Shelkhar. SAMPle 8504

\section{Sampling point}

This sample was collected at Shelkhar which is about $15 \mathrm{~km}$ to the north-west of Nako located at app. 32॰0'32.81'N, 78³4'14.04'"E (Fig. 31.4, Fig. 32.4 and Fig. 33.4). Same as with sample 15516 , it is commonly known as tua clay instead of markalak clay. The area of the clay pit is located a distance of app. $250 \mathrm{~m}$ from the Spiti River and is app. $70 \mathrm{~m}$ higher than the riverbed. Several small valleys from the west lead towards Shelkhar. Deposits are found along the glacial trough of these side valleys in the form of an inflow into the Spiti River. Specifically located along the trough valley, these deposits may have resulted from continuous piling up of layer by layer of fine alluvial clay, similar to the situation given at the tua clay pit at Kirsi, which is located close to Nako.

In Tabo, for example, this material is also well known as a building material of high quality. In Dhankar, also located in the Spiti Valley, a material called tala is commonly known to be of high quality (Interview Tendup Giacho 2002; Feiglstorfer 2002: 12). Whether this material is similar to a tua or markalak clay is examined in future research. The author took part in digging up the material, thus a mixture of the sample-material with sand or other types of clay is excluded. The location of the relatively small clay pit is along a village road between several hamlets at the upper end of the village and appears as a several metres wide hole in the terrain on the level of the road. Shelkhar is a commonly known place for high quality tua clay. ${ }^{16}$ The material itself becomes relatively hard after drying, similar to other fine markalak clay samples. Sample number in

16 In addition to the statements of Maria Gruber (Gruber 2011: 139) the tua clay is not only available at Kirsi near Nako but the name "tua" indicates a species of a particular quality of clay belonging to the markalak clay type as stated by these tests. 


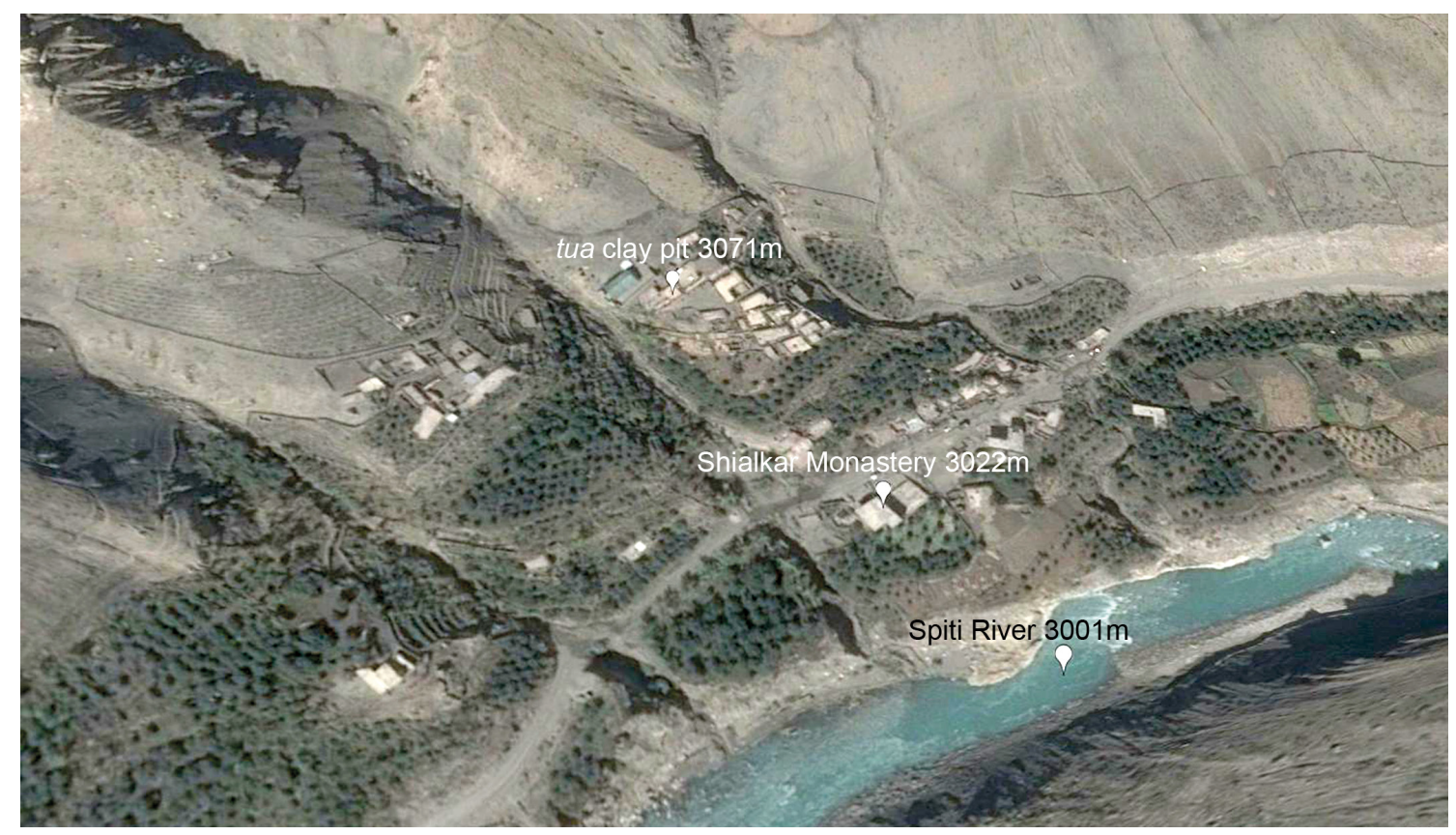

Fig. 31.4 (Top) Shelkhar. The level marks show the incline of the cross-country tread from the riverbed of the Spiti River to the remains of the lacustrine basin. Source: Google Earth. Image (C) 2015 CNES / Astrium.

Fig. 32.4 (Below) Shelkhar. Area of the clay pit.

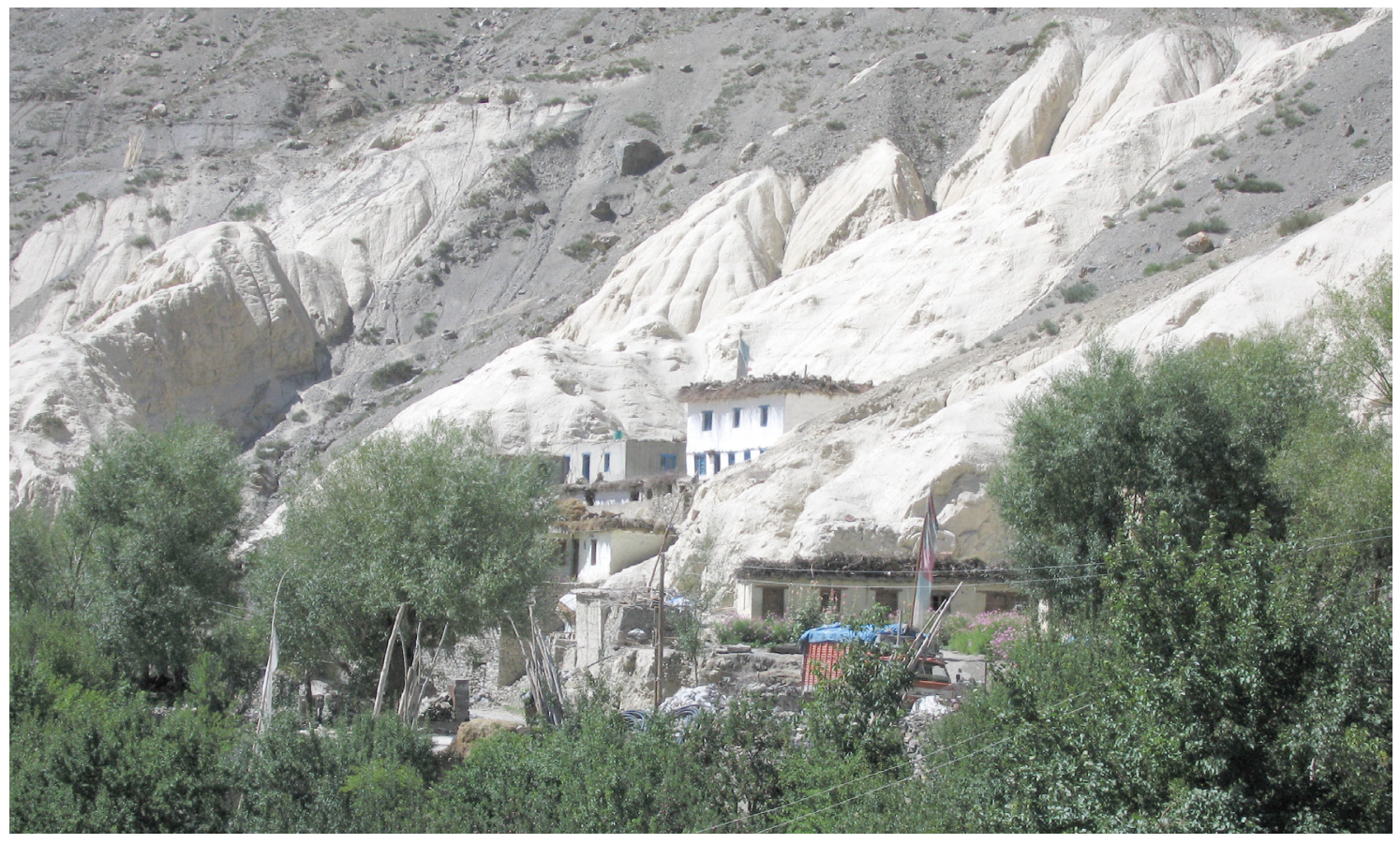




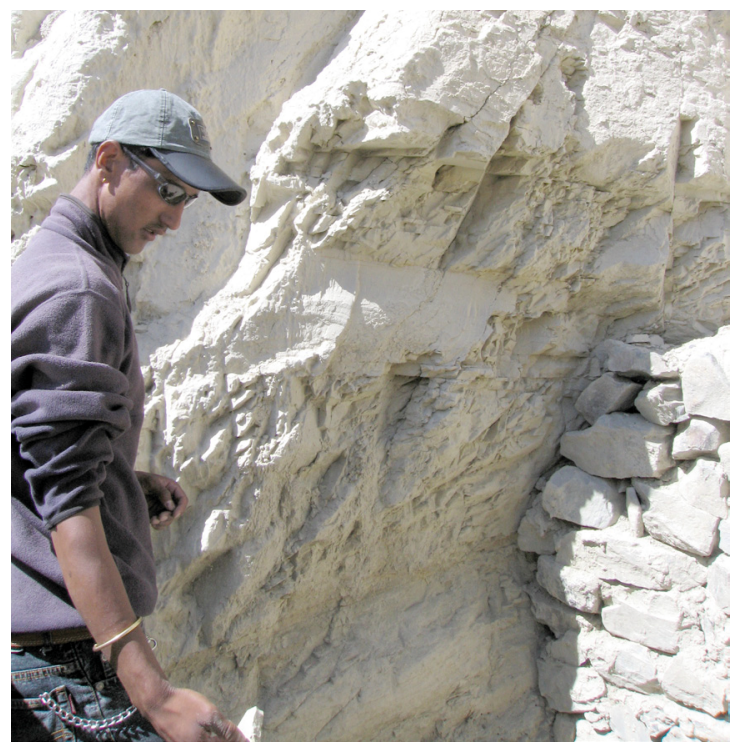

Fig. 33.4 Shelkhar. Tua clay pit.

the field: 51 SH/LG (Fig. 34.4). Constructive use: Today this material is known for making the upper layer of earth roofs. This material is locally also reported for making clay statues. After digging, the material is relatively hard and has to be crushed with a specific tool. ${ }^{17}$

\section{Grain size distribution}

Generally speaking the grain size distribution of this sample shows strong similarity to fine Ladakh markalak clays, in particular to sample 15516 . The material is relatively fine. Biggest fraction: coarse silt. Contrary to sample 15516 from Nako, no coarse material, i.e. gravel or sand, was determined. The median is located at app. $4.3 \mu \mathrm{m}$, similar to $4.5 \mu \mathrm{m}$ for sample 15516 at Nako (vs. 11934

from Alchi with a median of app. $2.6 \mu \mathrm{m}, 11939$ from Lamayuru with a median of app. $2.3 \mu \mathrm{m}$ and 11913 from Shey with of median at app. $2.8 \mu \mathrm{m}$ ). With a median of app. $3.6 \mu \mathrm{m}$, it is relatively close to sample 15518 from Basgo. The $<2 \mu \mathrm{m}$ fraction contains app. $28 \%$ of the whole sample, similar to 29\% for sample 15516 from Nako (vs. 11934 from Alchi with an amount of $<2$ $\mu \mathrm{m}$ of app. 43\%, 11939 from Lamayuru with an amount of $<2 \mu \mathrm{m}$ of app. 48\%, and 11913 from Shey with an amount of $2 \mu \mathrm{m}$ of app. $43 \%$ ). At app. $32 \%$ with $<2 \mu \mathrm{m}$, sample 15518 from Basgo is again very close to tua clay sample 15516 . In the distribution curve no bimodal distribution is evident. The grain size distribution curve shows a soft break between medium silt and coarse silt, and coarse clay and medium clay. At $36.7 \%$ the maximum peak of fine silt is also similar to sample 15516 from Nako. The proportional relation between silt and clay (silt:clay) is also very similar between sample 15518 (markalak clay from Basgo) with 73.3:26.6, and sample 15516 (tua clay from Nako) with 61.9:29.4. All other fine markalak clay samples show a slightly higher content of fine and medium clay, again with an exception being sample 15518 (markalak clay from Basgo) which shows very similar rates. Since the author took part in digging, mixture of this material with sand or another type of clay can be excluded. A comparison to grain size classes of other markalak clay samples shows the close relation of sample 8504 from Shelkhar, primarily to samples 15516 from Nako and 15518 from Basgo.

$\begin{array}{lllll} & \text { Gravel } & \text { Sand } & \text { Silt } & \text { Clay [\%] } \\ \text { 8504 (Shelkhar) } & 0 & 0.1 & 73.3 & 26.6 \\ 15516 \text { (Nako) } & 2.8 & 5.9 & 61.9 & 29.4 \\ 15518 \text { (Basgo) } & 0 & 0.1 & 68.5 & 31.4 \\ 11934 \text { (Alchi) } & 0 & 1.3 & 56.2 & 42.5 \\ 11939 \text { (Lamayuru) } & 0 & 2.1 & 49.7 & 48.2 \\ 11913 \text { (Shey) } & 0 & 2.3 & 54 & 43.7\end{array}$

17 Maria Gruber (2011: 141) describes such a tool as a wooden hammer with a surface of about $10 \times 10 \mathrm{~cm}$ for crushing the material in smaller pieces and thereafter using it as a mortar for grinding into powder. 


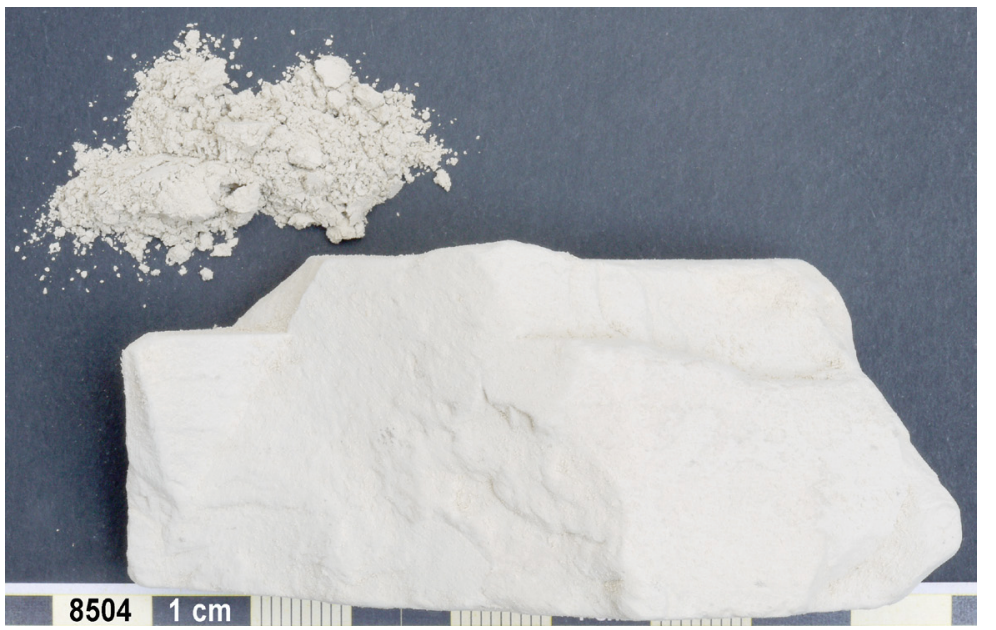

Fig. 34.4 Shelkhar. Sample 8504.

Sample colour (after Munsell): Dry 10YR 7/2 light grey.

Semi-dry 10YR 6/4 light yellowish brown.

Bulk mineral analysis

With small differences, the BMA shows a similar result to the BMA of the markalak clay samples in general and a strong similarity to sample 15516 from Nako. Mica, $7 \AA$ minerals, phyllo silicates, quartz and plagioclase are available in small amounts (marked in the Table 3.4 with (*)); $14 \AA$ minerals, amphiboles and K-feldspar occur as traces. Dolomite is available at $3 \%$. The content of calcite at $27 \%$ is in average range under all markalak clay samples and fits well to the $36 \%$ of calcite for sample 15516 from Nako. The colour is similar to sample 15518 from Basgo.

$\begin{array}{llll}15516(\text { Nako) } & \text { Dry } & \text { 10YR 7/2 } & \text { light grey } \\ & \text { Semi-dry } & \text { 10YR 5/4 } & \text { yellowish brown } \\ 15518 \text { (Basgo) } & \text { Dry } & \text { 10YR (8/1)-7/1 } & \text { light grey } \\ & \text { Semi-dry } & \text { 10YR 5/4 } & \text { yellowish brown }\end{array}$

Clay mineral analysis

The following list shows a comparison with markalak clay sample 14875 from Spituk and 14876 from Alchi. Both are closely similar to markalak clay sample 15516 from Nako. At just 1\% the rate for the content of smectite is comparably low. A comparison with samples 15516 from Nako and 15518 from Basgo shows close similarities.

\begin{tabular}{llllll} 
& Smectite & Vermic & Illite & \multicolumn{2}{l}{ Kaolinite } \\
8504 (Shelkhar) & 1 & 0 & 69 & 3 & 27 \\
15516 (Nako) & 4 & 0 & 69 & 3 & 15 \\
14875 (Spituk) & 3 & 0 & 64 & 6 & 27 \\
14876 (Alchi) & 7 & 0 & 62 & 5 & 27
\end{tabular}




\subsection{Khorchag}

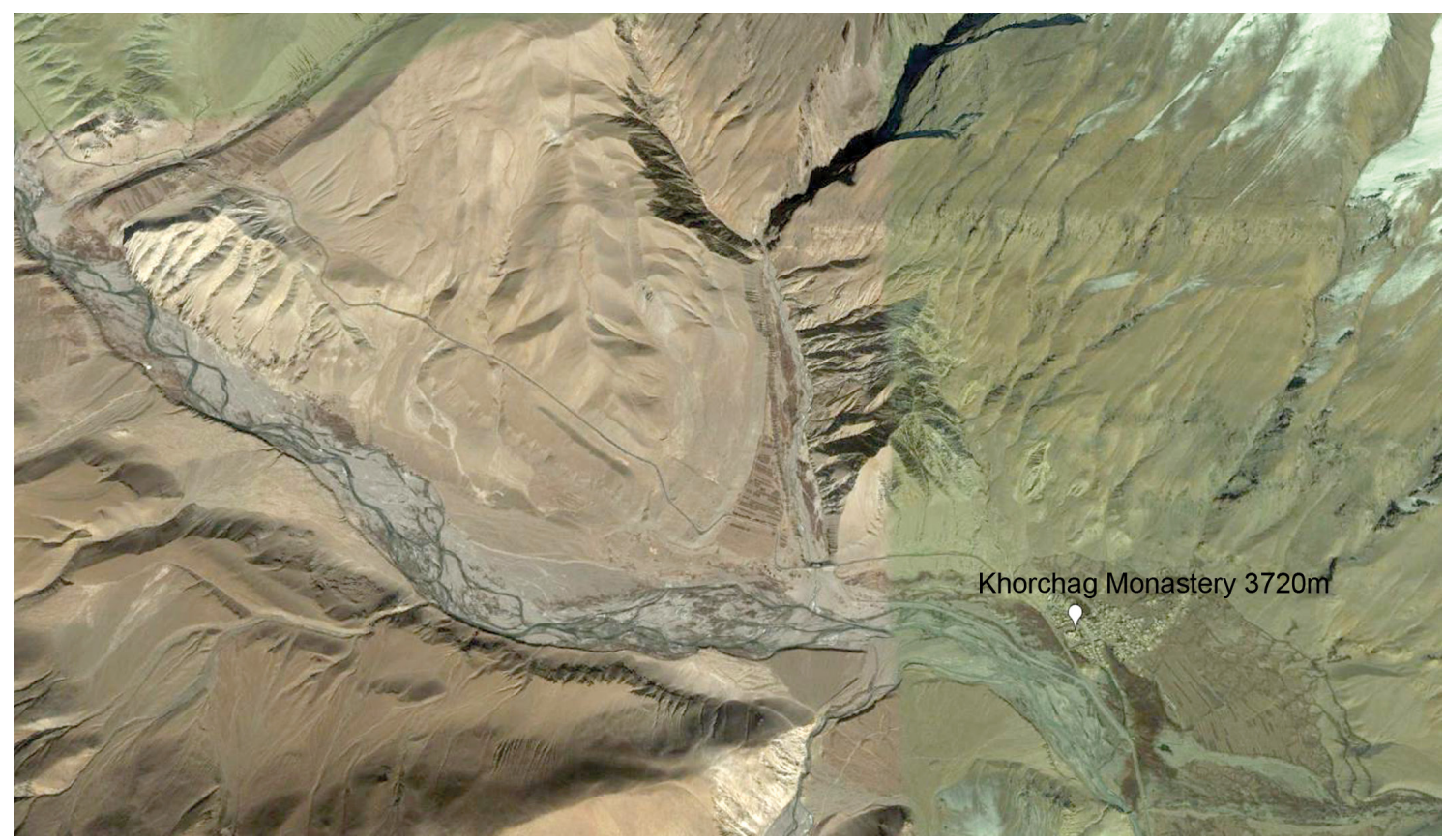

Fig. 35.4 Khorchag Monastery located along the Peacock River.

Source: Google Earth. Image (C) 2015 Digital Globe.

\section{Khorchag. SAMPLE 15377}

\section{Sampling point}

This sample was collected at Khorchag in West Tibet (Ngari) and is commonly known as narkalak clay, not as markalak clay as in Ladakh (Fig. 35.4). The sample was collected by a Lama close to the Khorchag-Purang main road in close vicinity to the monastery and the Peacock River. Khorchag itself is located close to the village of Purang about $100 \mathrm{~km}$ south of Mount Kailas and about $20 \mathrm{~km}$ from the border crossing to Nepal, which is in a southern direction at app. $30^{\circ} 11^{\prime} 45.04$ ' $\mathrm{N}, 81^{\circ} 16^{\prime} 4.23^{\prime \prime}$ E. Khorchag is located both on an alluvial fan, generated by several side valleys, and also opposite of an alluvial fan on the other side of the river. Along the glacial trough of these side valleys, in the form of an inflow into the Peacock River, deposits along the trough valley must have resulted following continuous piling up of layer by layer of fine alluvial clay. Such piling must have specifically occurred in areas of slow flow velocity, like beside rivers such as the Peacock, which transports coarser material due to a higher flow velocity. Sample number in the field: 12 (Fig. 36.4). Constructive use: Today this material is known as a building material of high quality, in particular as ground for wall paintings.

\section{Grain size distribution}

Generally speaking, the grain size distribution of this sample shows a strong similarity to fine markalak clays with a relatively high content of silt and a small amount of coarse material. Despite a still small amount of coarse material, the material is still relatively fine due to a high content of 


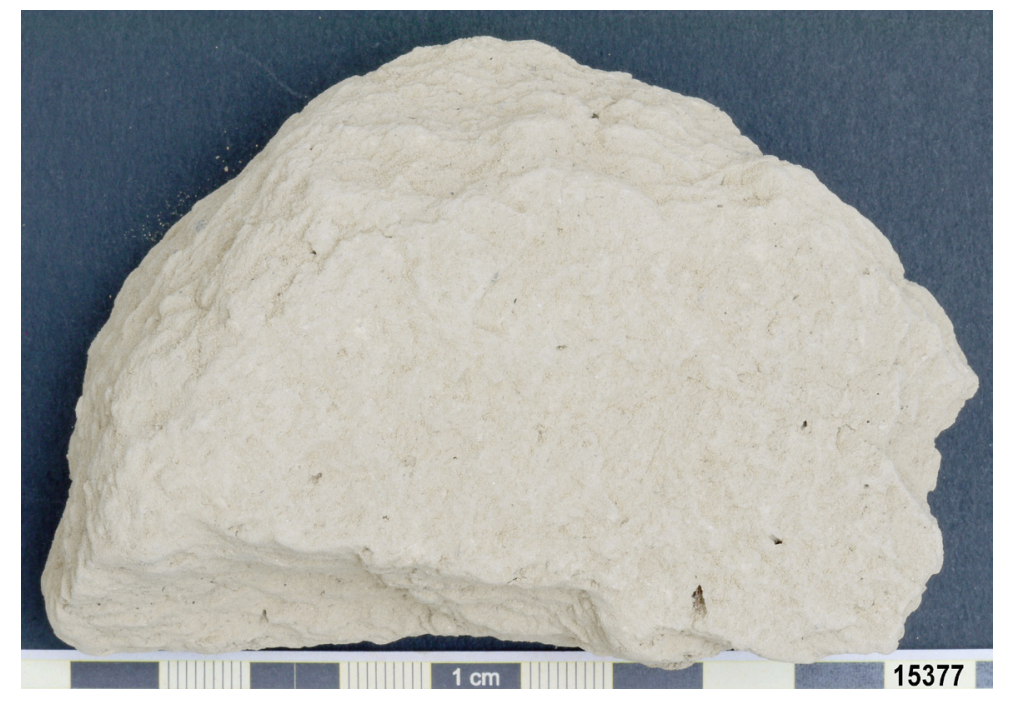

Fig. 36.4 Khorchag. Sample 15377. Sample colour (after Munsell): Dry 10YR 6/3 pale brown. Semi-dry10YR 4/3 brown.

silt. Biggest fraction: medium gravel. Similar to sample 15516 from Nako, coarse material, i.e. gravel or sand, is available in a small amount. The median is located at app. $8.5 \mu \mathrm{m}$, (vs. sample 8504 from Shelkhar with a median of app. $4.3 \mu \mathrm{m}$, sample 15516 from Nako with a median of app. $4.5 \mu \mathrm{m}, 11934$ from Alchi with a median of app. $2.6 \mu \mathrm{m}, 11939$ from Lamayuru with a median of app. $2.3 \mu \mathrm{m}$, and 11913 from Shey with a median of app. $2.8 \mu \mathrm{m})$. It is relatively close to sample 15518 from Basgo with a median of app. $3.6 \mu \mathrm{m}$. The $<2 \mu \mathrm{m}$ fraction contains app. $28 \%$ of the whole sample, same as for sample 8504, i.e. the tua clay from Shelkhar, and similar to $29 \%$ of sample 15516 at Nako (vs. 11934 from Alchi with an amount of $<2 \mu \mathrm{m}$ of app. 43\%, 11939 from Lamayuru with an amount of $<2 \mu \mathrm{m}$ of app. $48 \%$, and 11913 from Shey with an amount of 2 $\mu \mathrm{m}$ of app. $43 \%$ ). With app. $32 \%$ at $2 \mu \mathrm{m}$, sample 15518 from Basgo is again very close to sample 15516. In the distribution curve, no bimodal distribution is evident. The grain size distribution curve shows a soft break between coarse silt and fine sand and also between fine sand and medium sand. The maximum peaks are close to each other in the silt fraction (coarse silt 21.2\%, medium silt $18.4 \%$, and fine silt $17.3 \%$ ).

The proportional relation between silt and clay (silt:clay) is also very similar between sample 15377 with 56.9: 28 and samples 15518 (markalak clay from Basgo) with 73.3:26.6, and in particular with sample 15518 (markalak clay from Basgo) with 61.9:29.4. All the other fine markalak clay samples show a slightly higher content of fine and medium clay. Since this sample has its origin with the longest distance from the other examined samples, the most relevant samples will be juxtaposed in the following list.

$\begin{array}{lllll} & \text { Gravel } & \text { Sand } & \text { Silt } & \text { Clay [\%] } \\ 15377 \text { (Khorchag) } & 1.3 & 13.8 & 56.9 & 28 \\ 8504 \text { (Shelkhar) } & 0 & 0.1 & 73.3 & 26.6 \\ 15516 \text { (Nako) } & 2.8 & 5.9 & 61.9 & 29.4 \\ 15518 \text { (Basgo) } & 0 & 0.1 & 68.5 & 31.4 \\ 11934 \text { (Alchi) } & 0 & 1.3 & 56.2 & 42.5 \\ 11913 \text { (Shey) } & 0 & 2.3 & 54 & 43.7\end{array}$


Bulk mineral analysis

With small differences to the BMA of sample 15377 from Khorchag, the BMA of this sample shows a similar result to the BMA of the markalak clay samples, in particular to samples 15516

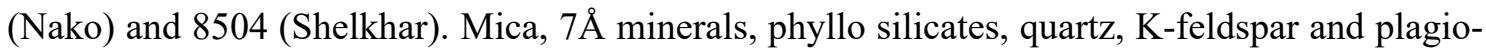
clase are available in small amounts (marked in Table 3.4 with $(*)$ ); $14 \AA$ minerals and amphiboles are not available. At $1 \%$ dolomite is available in a very small amount. The content of calcite at $1 \%$ is very small and differs from the average amount within the markalak clay samples. Compared to samples 15518 from Basgo and 15516 from Nako, the sample 15377 has a tendency towards brown colouring.

$\begin{array}{llll}15518 \text { (Basgo) } & \text { Dry } & \text { 10YR }(8 / 1)-7 / 1 & \text { light grey } \\ & \text { Semi-dry } & \text { 10YR 5/4 } & \text { yellowish brown } \\ 15516(\text { Nako) } & \text { Dry } & \text { 10YR 7/2 } & \text { light grey } \\ & \text { Semi-dry } & \text { 10YR 5/4 } & \text { yellowish brown }\end{array}$

Clay mineral analysis

The following list shows a comparison with markalak clay sample 15518 from Basgo and tua clay sample 15516 from Nako. The grain size distribution and also BMA show similarities. At $3 \%$ of the clay fraction, the content of smectite is similarly low, and the content of illite is less. The striking difference is the absence of chlorite which was available in all the other examined samples.

$\begin{array}{llllll} & \text { Smectite } & \text { Vermic } & \text { Illite } & \text { Kaolinite } & \text { Chlorite [\%] } \\ 15377 \text { (Khorchag) } & 3 & 0 & 53 & 44 & 0 \\ 15518 \text { (Basgo) } & 3 & 0 & 76 & 6 & 15 \\ 15516 \text { (Nako) } & 4 & 0 & 69 & 3 & 15\end{array}$




\subsection{Results of mineral analysis given in tables}

Table 2.4 Grain size classes.

\begin{tabular}{|c|c|c|c|c|c|c|}
\hline Sample & $\begin{array}{c}\text { Gravel } \\
{[\%]}\end{array}$ & $\begin{array}{c}\text { Sand } \\
{[\%]}\end{array}$ & $\begin{array}{l}\text { Silt } \\
{[\%]}\end{array}$ & $\begin{array}{l}\text { Clay } \\
{[\%]}\end{array}$ & $\begin{array}{c}\text { Median } \\
{[\mu \mathrm{m} \text { at } 50 \%]}\end{array}$ & $\begin{array}{c}<2 \mu \mathrm{m} \\
{[\%]}\end{array}$ \\
\hline \multicolumn{7}{|c|}{ Spituk } \\
\hline 6052 & 0.1 & 0.2 & 84.6 & 15.1 & 7.5 & 16 \\
\hline 8466 & 0 & 0.3 & 20 & 79.7 & 0.9 & 80 \\
\hline 8481 & 0 & 1 & 17.5 & 81.5 & 0.6 & 82 \\
\hline 14875 & 0 & 0.9 & 31.3 & 67.8 & 0.8 & 70 \\
\hline \multicolumn{7}{|c|}{ Alchi } \\
\hline 8526 & 8.1 & 53.7 & 24.4 & 13.8 & 95 & 13 \\
\hline 11934 & 0 & 1.3 & 56.2 & 42.5 & 2.6 & 43 \\
\hline 14876 & 0 & 0.4 & 23.3 & 76.3 & 1.2 & 77 \\
\hline \multicolumn{7}{|c|}{ Lamayuru - Basgo } \\
\hline 11939 & 0 & 2.1 & 49.7 & 48.2 & 2.3 & 48 \\
\hline 14874 & 0 & 0.1 & 58.8 & 41.1 & 2.9 & 40 \\
\hline 15518 & 0 & 0.1 & 68.5 & 31.4 & 3.6 & 32 \\
\hline \multicolumn{7}{|c|}{ Shey } \\
\hline 11913 & 0 & 2.3 & 54 & 43.7 & 2.8 & 43 \\
\hline 15404 & 8 & 57.9 & 21 & 13.1 & 180 & 13 \\
\hline \multicolumn{7}{|c|}{ Nako - Shelkhar } \\
\hline 15516 & 2.8 & 5.9 & 61.9 & 29.4 & 4.5 & 29 \\
\hline 8504 & 0 & 0.1 & 73.3 & 26.6 & 4.3 & 28 \\
\hline \multicolumn{7}{|c|}{ Khorchag } \\
\hline 15377 & 1.3 & 13.8 & 56.9 & 28 & 8.5 & 28 \\
\hline
\end{tabular}


Table 3.4 Bulk mineral analysis.

\begin{tabular}{|c|c|c|c|c|c|c|c|c|c|c|c|c|c|c|}
\hline Sample & $14 \AA$ & Mica & Amph & $7 \AA$ & Phy sil & Quar & Goeth & K-fsp & Plagio & Calc & Dol & Haem & Gyps & Pyr \\
\hline \multicolumn{15}{|c|}{ Spituk } \\
\hline 6052 & . & $*$ & --- & . & $*$ & $*$ & ? & . & $*$ & $69 \%$ & $5 \%$ & --- & --- & -- \\
\hline 8466 & $*$ & $*$ & . & $*$ & $* *$ & $*$ & ? & . & $*$ & $5 \%$ & --- & . & --- & . \\
\hline 8481 & . & $*$ & . & $*$ & $* *$ & $*$ & ? & . & $*$ & $3 \%$ & --- & . & --- & --- \\
\hline 14875 & . & $*$ & . & $*$ & $*$ & $*$ & --- & . & $*$ & $42 \%$ & $6 \%$ & . & --- & --- \\
\hline \multicolumn{15}{|c|}{ Alchi } \\
\hline 8526 & . & $*$ & . & $*$ & $*$ & $* *$ & --- & $*$ & $* *$ & $15 \%$ & $3 \%$ & --- & --- & --- \\
\hline 11934 & $*$ & $*$ & . & $*$ & $*$ & $*$ & --- & . & $*$ & $14 \%$ & . & --- & --- & -- \\
\hline 14876 & $*$ & $*$ & . & * & $*$ & $*$ & --- & . & $*$ & $4 \%$ & --- & . & --- & . \\
\hline \multicolumn{15}{|c|}{ Lamayuru - Basgo } \\
\hline 11939 & . & $*$ & . & . & $* *$ & $*$ & --- & . & $*$ & $16 \%$ & --- & . & --- & -- \\
\hline 14874 & . & $*$ & -- & $*$ & $*$ & $*$ & ? & . & $*$ & $11 \%$ & --- & --- & --- & --- \\
\hline 15518 & . & $*$ & $*$ & $*$ & . & $*$ & --- & $*$ & $* *$ & $1 \%$ & --- & --- & --- & -- \\
\hline \multicolumn{15}{|c|}{ Shey } \\
\hline 11913 & $*$ & $*$ & . & $*$ & $*$ & $*$ & --- & . & $*$ & $5 \%$ & --- & --- & --- & . \\
\hline 15404 & . & $*$ & $* *$ & $*$ & . & $*$ & --- & $* *$ & $* * *$ & $1 \%$ & . & --- & --- & . \\
\hline \multicolumn{15}{|c|}{ Nako - Shelkhar } \\
\hline 15516 & . & $*$ & . & $*$ & $*$ & $*$ & --- & $*$ & $*$ & $36 \%$ & $4 \%$ & --- & --- & . \\
\hline 8504 & . & $*$ & . & $*$ & $*$ & $*$ & --- & . & $*$ & $27 \%$ & $3 \%$ & & --- & \\
\hline \multicolumn{15}{|c|}{ Khorchag } \\
\hline 15377 & --- & $*$ & --- & $*$ & $*$ & $*$ & --- & $*$ & $*$ & $1 \%$ & $1 \%$ & --- & --- & --- \\
\hline
\end{tabular}


Table 4.4 Clay mineral analysis.

\begin{tabular}{|c|c|c|c|c|c|c|}
\hline Sample & Smectite & $\begin{array}{c}\text { Vermiculite } \\
14 \AA / 18 \AA\end{array}$ & Illite & Kaolinite & Chlorite & Mixed layer \\
\hline \multicolumn{7}{|c|}{ Spituk } \\
\hline 6052 & 6 & & 70 & 6 & 18 & \\
\hline 8466 & 8 & & 65 & 4 & 23 & \\
\hline 8481 & 12 & & 64 & 5 & 19 & \\
\hline 14875 & 3 & & 64 & 6 & 27 & \\
\hline \multicolumn{7}{|c|}{ Alchi } \\
\hline 8526 & 6 & & 63 & 5 & 26 & \\
\hline 11934 & 7 & & 55 & 4 & 33 & \\
\hline 14876 & 7 & & 62 & 5 & 26 & \\
\hline \multicolumn{7}{|c|}{ Lamayuru - Basgo } \\
\hline 11939 & & & 77 & 7 & 16 & ML Illit+Smect \\
\hline 14874 & 2 & & 73 & 7 & 18 & \\
\hline 15518 & 3 & & 76 & 6 & 15 & \\
\hline \multicolumn{7}{|c|}{ Shey } \\
\hline $11913^{*}$ & 1 & 5 & 85 & 7 & 2 & ML \\
\hline 15404 & 4 & & 71 & 5 & 20 & \\
\hline \multicolumn{7}{|c|}{ Nako - Shelkhar } \\
\hline 15516 & 4 & & 67 & 3 & 26 & \\
\hline 8504 & 1 & & 69 & 3 & 27 & \\
\hline \multicolumn{7}{|c|}{ Khorchag } \\
\hline 15377 & 3 & & 53 & 44 & & \\
\hline
\end{tabular}




\section{MARKALAK CLAYS AND MARINE CLAYS}

The stratigraphic layer sequence of markalak clay pits at Lamayuru or Spituk shows a continuous change between bright and dark layers (Fig. 37.4 and Fig. 38.4) (cf. Feiglstorfer 2014: picture 16.5). The layer thickness within the samples varies between app. $5 \mathrm{~mm}$ and $20 \mathrm{~mm}$ for small stripes. This variation was measured in sample 8481 while markalak clay sample 6052 shows no stripes at all. Further, the markalak clay sample 8466 shows a layering of app. $15 \mathrm{~mm}$ of the reddish dark part and $15 \mathrm{~mm}$ of the greyish part. The dimension of the layers is not continuously the same but changing. Samples that appear without stripes from Spituk were part of higher stripes measuring roughly up to one metre. Their colours vary due to different mineral deposits.

Markalak clays can be mentioned as marine clays - marine clays in general have glaciolimnic or glacilacustrine sediments (Wimmer-Frey, Schwaighofer 2002: 264). In the case of marine clays, the stratification results from material transport either by flooding or by a continuous inlet, possibly a mixture of both. The coarser and heavier particles are deposited closer to the water stream in the areas of a more rapid flow while the finer material, in particular clay and silt, are deposited in areas of slower water movement (Brady, Weil 2000: 38). Dependent on the speed and amount of the water, the content of coarse as well as fine material varies along the layers of the floodplain.

The change between bright and dark layers within one pit can be explained - comparable to annual rings of trees but in this case semiannual - by a different water seasonal transport. Due to a higher amount of water during snowmelt, more and slightly coarser material is transported than in the dry season. By this the colour and the content proportion between different grain fractions

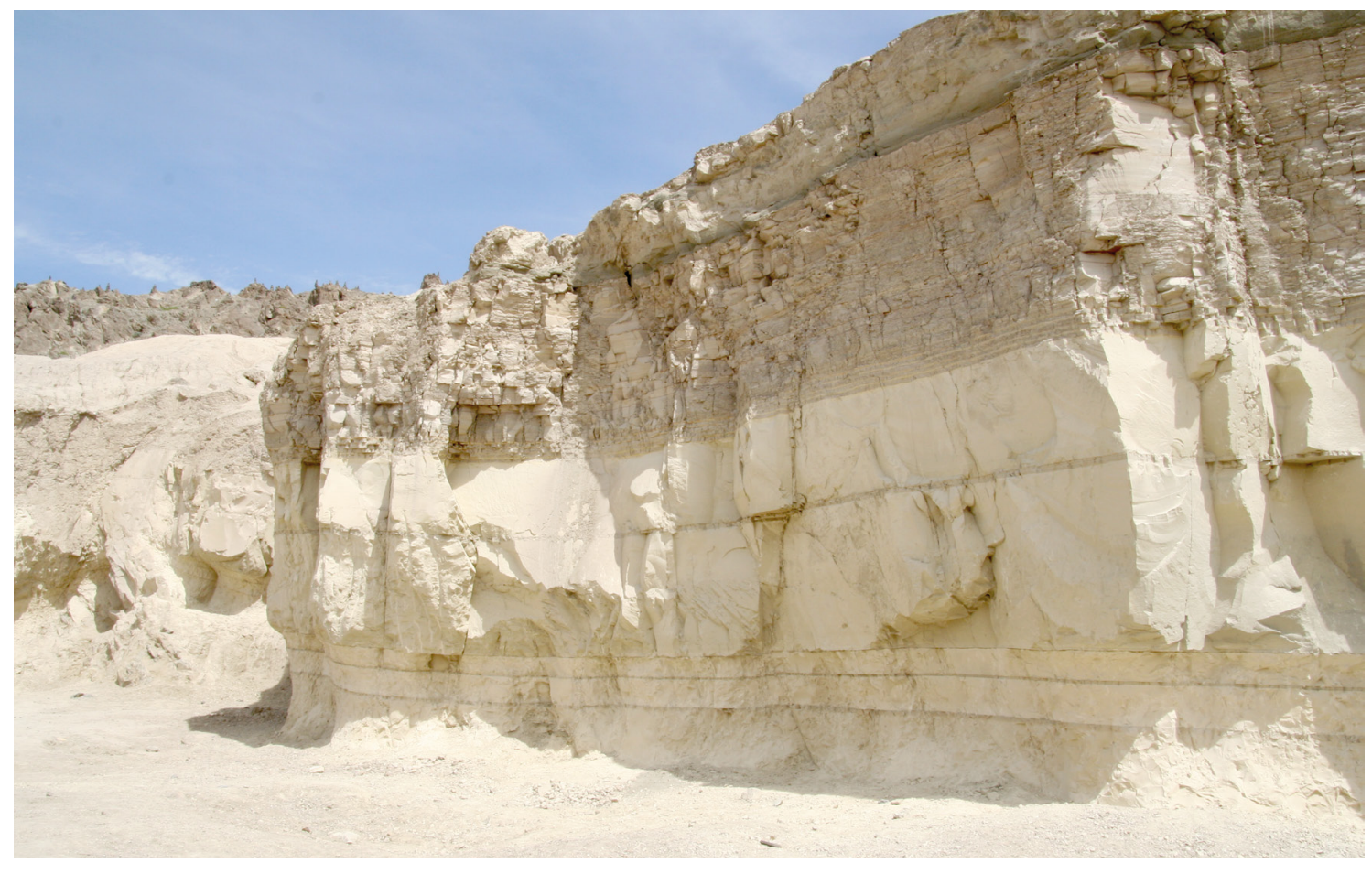

Fig. 37.4 Spituk clay pit. 

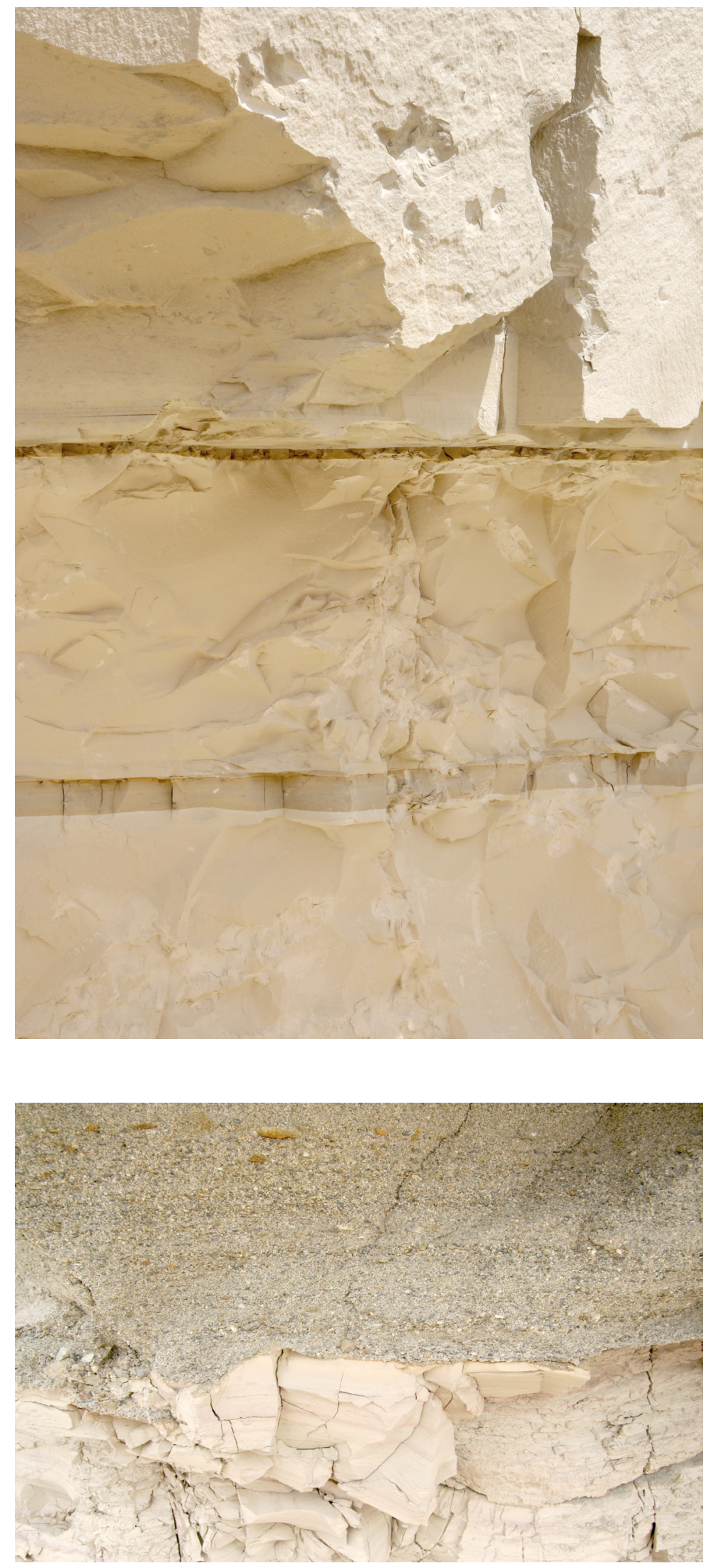

Fig. 38.4 Spituk. Lacustrine sedimentation.

Fig. 39.4 Spituk clay pit. Sandy upper layer. 
changes - in this case between the layers with a dominance of silt and of clay. After snowmelt, the water content decreases and transport is reduced to smaller particles (that means: more water increasing speed of transport - transport of coarser grains; see Introduction 6.3.4 "Palaeolakes"). For practical use as a building material, these changes are marginal, but regarding the content proportion of silt:clay, this can be enough to change the colour slightly and cause it to appear brighter or darker. One bright and one dark layer together would mark the course of one year regarding the changes of the amount of water transport, including strong and less strong seasons of transport. The slight and layer wise continuous change in colour is shown by the result of the colour analysis. This observation is valid within the sequence of layers at one particular geological profile, which may change between different profiles as shown in the comparison of samples 8466 and 8481. Both samples show a similar high content of clay but according to the Munsell colour chart, sample 8466 appears as grey (10YR 5/1) while sample 8481 appears as greyish brown (10YR 5/2).

At Spituk the horizontal distance between the Indus River (altitude app. $3190 \mathrm{~m}$ ) and the markalak clay pit (altitude app. $3226 \mathrm{~m}$ ) is app. $960 \mathrm{~m}$ and the difference in altitude is app. $36 \mathrm{~m}$ (see Fig. 3.4). The pit is located at the foot of a side valley which runs in a northern direction. Possibilities for the influx of fine material is either from this valley - from here the fine material is desludged (washed out) - or from the side of the Indus River - where the water level allowed for debris, possibly at a narrower passage of the river. The difference in altitude of app. $36 \mathrm{~m}$ between the river and the pit is minimal regarding Himalayan situations and allows for such a scenario. A kind of narrowing and/or detaching of parts of the river and the formation of a lake - possibly covering the area of today's clay pit and at this location depositing the fine desludged material - is reasonable. Also a mixture of both scenarios can be an option for the explanation of the development of this markalak clay pit. As a consequence of continuous depositing of desludged material in dependence of seasonal differences in the amount of seasonally flowing water, the striped colouring of the layers within the clay pit can be explained. The upper most layer of markalak clay in Spituk is covered by relative sandy sediments (Fig. 39.4).

The striped appearance of the markalak clay pits at Spituk or Lamayuru corresponds to what we know from varves (Ger. Bändertone) which are dependent on a cold climate with proglacial lakes or small lakes along the ice. One varve is a pair of two layers which change from a coarse and bright lower layer to a darker and finer layer (Press, Siever 1995: 582). In the warmer season at the time when the lakes are free of ice, sediments transported by melt water are brighter and coarser with a higher content of silt, while in the cold season when the lakes are frozen and the water stands still, clay appears in the form of brighter suspended solid sediments (Press, Siever 1995: 343; see Introduction 6.3.4 "Palaeolakes"). Varve clays are commonly known as raw material suitable for ceramics and various uses as building material.

As comparison, in Austria's western states of Tyrol, Vorarlberg, Salzburg and parts of Carinthia, they are the prime source of raw material for the brick industry. According to Winkler's (1954) "triangle for the limits of use", exceeding a maximum of 50\% of silt (in particular fine and medium silt) makes the raw material improper for its use for thin-walled hollow fired material. (Wimmer-Frey, Schwaighofer 2002: 264) This approach will not be further treated in the present research since firing of brick or ceramics is a secondary issue within the Himalayas. Concerning 
building material in this wide mountainous and relatively arid region, fuel for firing is sparse and we are primarily dealing with air-dried and not fired earth building material.

Primarily their content of silt and clay varies and the prime material can be classified as silts, siltclays (or clay-silts) with a small amount of sand. For the production of bricks the used marine clays have to be improved with further clay materials (Wimmer-Frey, Schwaighofer 2002: 264). This fact again emphasises its extremely fine material characteristic, which is also a reason why even in unfired use in the Himalayas their usage for building purposes in a primary-statically stressed manner (e.g. adobe bricks) and also for subconstructions for plasters is not of importance.

\subsection{Comparative material}

On the basis of results from the Himalayas, a question is raised for the comparability to local Austrian clay. In Wollanig in Carinthia, for example, we know of the existence of marine clays which were deposited during the ice ages. This smooth material with high plasticity is still used for the production of bricks. Another Austrian material, sample 7880 from Stierschweiffeld in Lower Austria, which can in a simplified form be defined as marl (Ger. Tegel) with a high content of silt, will be compared with sample 8466 from Spituk, which is a varve clay containing a relatively high amount of silt.

Sample 7697 from Wollanig contains $39.1 \%$ of clay with no swellable clay minerals and a linear shrinkage of 5.6\% (Kruzik 2008: 96). Sample 7880 from Stierschweiffeld shows a content of clay of $15 \%$ with $34 \%$ swellable material and a linear shrinkage of $1.6 \%$ (Ottner 2006: 7, 15). In comparison, at $84.7 \%$ the content of clay in sample 8466 from Spituk is much higher with a content of swellable clay minerals of $8 \%$. The measured linear shrinkage with a value of $7 \%$ in sample 8466 from Spituk also exceeds the values of sample 7697 from Wollanig and sample 7880 from Stierschweiffeld. The values of sample 7697 from Wollanig are very similar to those of sample 8466 from Spituk. On the contrary, the values of sample 7880 from Stierschweiffeld differ widely.

Sample 7697 from Wollanig shows a liquid limit $\left(\mathrm{W}_{\mathrm{L}}\right)$ of $31.2 \%$, a plasticity limit $\left(\mathrm{W}_{\mathrm{P}}\right)$ of $18.5 \%$ and plasticity $\left(\mathrm{I}_{\mathrm{P}}\right)$ of $12.6 \%$; sample 7880 from Stierschweiffeld shows a liquid limit $\left(\mathrm{W}_{\mathrm{L}}\right)$ of $28.7 \%$, a plasticity limit $\left(\mathrm{W}_{\mathrm{p}}\right)$ of $21.9 \%$ and plasticity $\left(\mathrm{I}_{\mathrm{p}}\right)$ of $6.7 \%$ (Kruzik 2008: 80). Sample 7880 from Stierschweiffeld in comparison contains 34\% of smectite (Ottner 2006: 15). In comparison, sample 8466 from Spituk shows a liquid limit $\left(\mathrm{W}_{\mathrm{L}}\right)$ of $33.2 \%$, a plasticity limit $\left(\mathrm{W}_{\mathrm{p}}\right)$ of $21 \%$ and plasticity $\left(\mathrm{I}_{\mathrm{P}}\right)$ of $12.75 \%$ which is relatively close to the values of sample 7697 from Wollanig and also of sample 7880 from Stierschweiffeld. The sample from Wollanig shows a grain size distribution (Kruzik 2008: 47) of 1\% gravel, $4 \%$ sand, $56 \%$ silt and $39 \%$ clay. Sample 7880 from Stierschweiffeld shows a grain size distribution (Ottner 2006: 7) with 0\% gravel, 28\% sand, $57.3 \%$ silt and $14.7 \%$ clay. Sample 8466 from Spituk shows the following grain size distribution: $0 \%$ gravel, $0.3 \%$ sand, $20 \%$ silt and $79.7 \%$ clay.

A comparison of these samples shows for the sample from Spituk a higher content of clay containing $8 \%$ swellable material (versus $0 \%$ for the material from Wollanig and 5\% for the material from Stierschweiffeld) and otherwise a much smaller content of silt which is relatively similar 
for samples 7697 from Wollanig and 7880 from Stierschweiffeld. The content of calcite was measured at 28\% for sample 7697 from Wollanig, and 7\% for sample 7880 from Stierschweiffeld (Kruzik 2008: 71). On the other hand, at $8 \%$ sample 8466 from Spituk shows a much lower content than sample 7697 from Wollanig but a similar value to sample 7880 from Stierschweiffeld. For the markalak clay samples from the Himalayas, characteristically their content is of calcite.

\section{CONCLUSION}

\section{Research question 1: Are there any particular material qualities to categorise a particular clay as markalak?}

Starting with haptic qualities, a markalak clay can be described as fine. When touching a dry sample, it bleeds and fine layers remain on one's fingers. The core of the samples appears hard and difficult to break. The period of moisture penetration takes longer, as is the case with coarse material, which soaks up water much quicker. As soon as the humidity reaches the core of the sample, it turns into a sticky slurry. The oral test states fineness when the material 'melts' on one's tongue and does not create significant noise when chewing. As soon as some content of sand is available, the sound changes into a cracking between the teeth.

At first glance, small markalak clay samples appear as monochromatic but already the pit itself is layered in stripes of different colours and intensities, pointing towards its natural origin as varve clay. The large-scale layering at the pit is also visible for the small samples on a smaller scale. Reddish and yellowish colours give evidence of the content of ferric oxides. Following a distinction according to Munsell, in a dry state the colours show tendencies towards brownish, grey and yellowish, and are primarily bright. In a semi-dry state they appear as brown, yellowish and grey, are partially bright with some turning dark.

A further aspect in defining the material's properties is mineral composition. The shape of the grains can be described as "angular" which points towards a short distance of transport and further towards a relatively young material. An analysis of the grain size classes shows no gravel in most samples, or just a small amount. An exception is the sample found in Alchi (sample 8526) which turned out to be basically similar to the fine properties of markalak clays in general but already naturally contained some coarse material. Similar is the appearance of samples 15377 from Khorchag and 15516 from Nako, while for the latter an anthropogenic addition of coarse material can not be excluded. The content of sand ranges for the fine samples between $0.1 \%$ and $2.3 \%$. Exceptions can again be mentioned and include samples 8526 from Alchi, 15516 from Nako and 15377 from Khorchag. Excluding coarse sample 8526 from Alchi, a median can be stated between $0.6 \mu \mathrm{m}$ and $8.5 \mu \mathrm{m}$ and a content of minerals $<2 \mu \mathrm{m}$ was available up to $82 \%$.

Regarding the content of silt, the samples can be divided in two categories. Those with a low content range between app. $18 \%$ and $31 \%$, and those with a high content range between app. $50 \%$ and $85 \%$. In contrast to the content of silt, we find the content of clay, meaning, in the case of a high amount of silt, the amount of clay is low, and vice versa. Dependent on use, one has to choose 
between the silt or clay dominated material. Regarding local terminology, no further differentiation regarding this difference in content of clay or silt could be observed.

The bulk mineral analysis showed similarities over all the samples, with only a few variances. The average content of $14 \AA \AA$ minerals ranges between traces and a small amount, the content of mica in general occurs in a small amount, the content of amphiboles on average occurs as traces, the content of $7 \AA$ minerals in general is seen in a small amount, the content of phyllo silicates is on average a small amount, the content of quartz in general is a small amount, the content of $\mathrm{K}$-feldspar on average occurs in traces and small amount, and the content of plagioclase occurs in a small amount. Partially dolomite could be observed in traces or small amount. Seemingly specific for most of the markalak clay samples is a content of calcite varying between a very small amount and $69 \%$. In several samples, traces of haematite were found.

Distinctive for the markalak clay samples from all examined regions is their high content of illite, ranging between $53 \%$ and $85 \%$ of the clay fraction. Also kaolinite, with a content of $3 \%$ to $7 \%$, is similar and rather small, though there is one exception: Sample 15377 from Khorchag shows a content of $44 \%$ of kaolinite. Also the content of chlorite at $15 \%$ to $33 \%$ has a similar range, with two exceptions: Sample 11913 from Shey at just 2\% and sample 15377 which show no content of chlorite. For markalak clays, their small content of swellable clay minerals - which turns out to range between $1 \%$ and $12 \%$ with an average $4.8 \%$ - is important for the behaviour of minimal shrinkage after moistening. In general this is a result of the smectite with only one exception, i.e. in the case of sample 11913 from Shey, the swellable mineral is also vermiculite with a content of $5 \%$.

Observing material properties of sample 8466 from Spituk - which has a content of $80 \%$ of clay, median grain size classes at $0.9 \mu \mathrm{m}$ and a content of $8 \%$ of smectite - the water content to reach a standard stiffness was measured at $121 \%$. The liquid limit $\left(\mathrm{W}_{\mathrm{L}}\right)$ was measured according to Casagrande with a water content of $133.75 \%$, a plasticity limit $\left(\mathrm{W}_{\mathrm{p}}\right)$ according to DIN 18122-1 with a water content of $121 \%$, and a plasticity coefficient $\left(\mathrm{I}_{\mathrm{p}}\right)$ according to Voth of $12.75 \%$, which again ranges around "very clayey" with a tendency towards "very silty". According to the result of the shrinkage test according to DIN 18952, this sample can be classified as a "very soft clay" with a shrinkage of 7\%. The coefficient for the activity according to Houben and Guillaud (1984) was measured at $0.15 \%$ which points towards a classification of "very little activity". The hardness of the surface was measured according to Vickers at $1.39 \mathrm{~kg} / \mathrm{mm}^{2}$ which is not to compare with the compressive strength.

\section{Research question 2: Are the particular material qualities related to specific regions?}

As specified for the answer to research question 1, we can state distinct material properties for markalak clays. In this aspect, a further differentiation between the different regions - i.e. Ladakh, Upper Kinnaur and Khorchag with a maximum distance between Ladakh and Upper Kinnaur of app. $260 \mathrm{~km}$ and between Upper Kinnaur and Khorchag again app. $310 \mathrm{~km}$, in total app. $570 \mathrm{~km}$ - is of interest. 
A comparison between the colours of the samples of the different regions shows the following result. One range of markalak clay colours includes those with a light grey appearance in a dry state and brown/yellowish brown colour in a semi-dry state. Of course, we have to consider that the final colour depends on the content of particular minerals which are relatively similar over all the examined samples. A crucial result of this research is that over this distance one particular feature of the markalak clay is its colour, if not changed by certain local mineral influences. This given colour (light grey/pale brown in a dry state and brown/yellowish brown in a semi-dry state) can be stated for the sample from Khorchag (sample 15377) in the far east in the west of Tibet, for the samples from Nako (sample 15516) and Shelkhar (sample 8504) in Upper Kinnaur and also for the samples from Ladakh, for example from Basgo (sample 15518).

The different mineral compositions related to these three regions were also examined. Regarding the different grain size classes in Khorchag (sample 15377), we find a markalak clay with a relatively high content of silt at $56.9 \%$ and a content of clay reaching $28 \%$. This proportion is similar to what we find in Upper Kinnaur for sample 15516 from Nako, which has a content of silt of $61.9 \%$ and a content of clay of $29.4 \%$. This is also the case for sample 8504 from Shelkhar, which has a content of silt of $73.3 \%$ and a content of clay of $26.6 \%$. These two grain size fractions seem to be decisive for the grain size relation of markalak clays. Also in Ladakh various samples, for example from Basgo and Lamayuru (samples 11939, 14874 and 15518), are very close to the mentioned proportion. A slightly higher or lower content of sand does not seem to disturb its basic determination as a markalak clay but influences the particular use as building material. In Spituk and Alchi we find varieties of markalak clays which deviate from this pattern of a high content of silt and a lower content of clay by changing this proportion into a lower content of silt and a higher content of clay. Locally, they still range as markalak clays and can generally be described as extremely fine clays. Dependant on the particular needs, the choice is for one of these variations. Interestingly, it is again not the "one specific type of clay" but a particular variety traditionally known as markalak clay.

Regarding the bulk mineral analysis (BMA), we can state that all samples show at least traces of calcite but even within the single regions of examination, the content varies. The content of calcite of the samples of Spituk ranges between $3 \%$ and $5 \%$ and also between $42 \%$ and $69 \%$, at Alchi the range is between $4 \%$ and $15 \%$, at Lamayuru between $11 \%$ and $16 \%$, at Basgo at $1 \%$, at Shey at 5\%, in Upper Kinnaur between $27 \%$ and $36 \%$ and at Khorchag 1\%. All the other bulk mineral components show no abnormalities.

Regarding the clay mineral content, the content of smectite is relatively balanced between the single regions. The content of illite is on average at $68 \%$, and at Khorchag drops to the lowest rate at $53 \%$. At Shey it reaches the highest rate at $85 \%$. The content of kaolinite ranges on average between $3 \%$ and $7 \%$ but increases up to $44 \%$ for the sample from Khorchag. All samples show a content of chlorite with an average of app. $15 \%$ to $33 \%$. Just as for sample 11913 from Shey, this value drops to $2 \%$, and at Khorchag no chlorite could be traced.

Concerning the tua clays from Nako, data of different types from TARA and Maria Gruber (2011) were juxtaposed. For the restoration at the monastery in Nako, the company TARA tested various samples of local clay to determine its physical properties as building material (Interview Khosla 
2002; Feiglstorfer 2002: 12). Chemical observations have been in preparation. Sujoy Chaudhury (TARA) explained the consistency of different kinds of clay and handed a list of results of analysis over to the author. The analysis included a sample of $t u a^{\mathrm{A}}$, explained as a fine material used for the thinner and most upper layer of the earth roof with a sealing aspect. Also included was locally available clay ${ }^{\mathrm{B}}$, which is in general used for roofing, and an adobe brick ${ }^{\mathrm{C}}$, which is used for the construction of walls (Interview with Sujoy Chaudhury 2002; Feiglstorfer 2002: 12). The data on the list of TARA (see Table 5.4 in Appendix of Chapter IV) were summarised and given below.

List of TARA. Summarised by the author:

$\begin{array}{lllll} & \text { Tua }^{\mathrm{A}} & \text { Clay }^{\mathrm{B}} & \text { Adobe brick }^{\mathrm{C}}[\%] \\ \text { Gravel } & 1.20 & 4.44 & 8.43 & \\ \text { Sand } & 27.80 & 63.56 & 46.57 & \\ \text { Silt } & 43.00 & 17.00 & 26.00 & \\ \text { Clay } & 28.00 & 15.00 & 19.00 & \\ & & & & \\ & \text { Gravel } & \text { Sand } & \text { Silt } & \text { Clay [\%] } \\ 15516 & 2.8 & 5.9 & 61.9 & 29.4 \\ \text { Tua } \text { (TARA) } & 1.2 & 27.8 & 43 & 28 \\ \text { Tua }{ }^{*} \text { (M. Gruber) } & 0.2 & 2.6 & 71.4 & 25.9 \\ \text { Tua** (M. Gruber) } & 0 & 0.1 & 63.5 & 36.4\end{array}$

In general the tua clay sample examined by TARA shows, similar to the tua clay sample 15516 from Nako, a very small content of gravel, which appears only in these two samples. Compared to the other tua clay sampes, the content of sand is very high, the content of silt slightly lower than the average of all the examined markalak clay samples, and the content of clay ranges in the lower area. Concerning the content of clay in particular, a similarity to sample 15516 is given. The examined clay sample is rather coarse and the adobe sample appears as a mixture of the $t u a^{A}$ - and the clay ${ }^{\mathrm{B}}$ sample.

\section{Research question 3: What are the material qualities which support the markalak clay's use for the mentioned building purposes?}

Stitching of cracks on roofs and walls, on the fine upper layer of a plaster or on a sculpture has specific requirements such as

- a proper binding within the material itself

- a proper adhesion to the adjoining layer of clay

- a reduced shrinkage

- an appropriate smoothness

Binding within the markalak clay is achieved by a certain amount of clay minerals, in particular of swellable material. Generally speaking, the mixture of this material, in particular of swellable and non swellable clay minerals and the amount of silt, are ideal for the mentioned purpose. 
In this regard we have to divide the results of research into two categories: those with a high content of clay (up to app. 82\%) and those with a high content of silt (up to app. 85\%). Both species find their appropriate practical use. Regarding the first group with a high content of clay, they are certainly rather smooth with a high inner binding and higher tendency to crack than is the case for the second group. Adhesion to adjoining layers of clay depends on the grain size classes, the binding of the adjoining material and the proper content of water for processing the markalak clay. With a too dry consistency, adhesion is too low, and with a too wet consistency, shrinkage increases and the duration of drying is extended for a rather long time.

Additionally, the thicker the layer of a markalak clay is, the higher the absolute shrinkage of the infill and the higher the risk of a reduced adhesion. In a further course, this results in cracks, primarily between the markalak clay infill and the adjoining portions of clay but also in hair cracks within the markalak clay itself. These are reasons that may explain Martina Oeter's description of the markalak clay's mixture with sand containing grains of up to $2 \mathrm{~mm}$ in the case of stitching deeper cracks (see sample 14875).

The higher the content of clay and the thicker the layers of markalak clay, the more importance the application of coarse material. The small content of swellable clay minerals (in average 6\%) and the slight content of calcite still mean reduced shrinkage and no cracks or just fine hair cracks within the markalak clay (see shrinkage tests), even when the content of clay is high. In this regard the treatment of markalak clay with a high content of clay with a possible need for mixing with coarse material may be different to the treatment of markalak clay with a high content of silt. Its shrinkage is smaller and the content of clay is still enough for proper binding - an ideal material for stitching cracks in walls.

Martina Oeter also mentions that for the un-mixed application, the oatmeal material is well suitable and the yellowish and greyish materials show a tendency to shrink and crack after compression. Particularly in Spituk and also in Alchi, we find varieties of markalak clay with a relatively high content of clay. For samples from Lamayuru, Basgo, Shey, Nako, Shelkhar or Khorchag, we can not state such a high content of clay since their content of silt was always higher than for clay. Their colour has a primary tendency towards light greyish in a dry state. Due to a slightly different mineral composition at Spituk, this assignability to colours changes where the grey colours point towards a rather high content of clay (app. $80 \%$ for sample 8466 and $82 \%$ for sample 8481 ). On the other hand, the yellowish sample 6052 shows an extremely high content of silt at $84.6 \%$, while the oatmeal (brownish grey in a dry state) markalak clay (sample 14875) seems proper with a content of $31.3 \%$ of silt and $67.8 \%$ of clay. Martina Oeter's description answers the question of the greyish material with a high content of clay, which shows improper behaviour when shrinking.

Due to the high content of clay minerals and the low content of silt - which does not show an internal relocatability of the molecules due to the behaviour of phyllo silicates - it is more difficult to compress which may also result in cracks. This effect can also be seen when burnishing a surface of markalak clay with a high content of clay minerals. It continuously loses its internal adhesion and when it is compressed the silicate layers move aside and do not remain stable. We see a similar effect for the behaviour of too fine plasters (shown in Chapter II). With increasing pressure, phyllo silicates detach from the layers below. 
When stitching cracks in a roof following the explained method of Mr. Dawa - which involved just scattering pieces of markalak clay onto the cracks in the upper layer of the earth roof - the drying process is not of much relevance since this method works with a full saturation of the clay by making it fluid.

\subsection{Research question 4: Regarding places of finding, are there regional peculi- arities for places where to find markalak clay?}

The places of finding are directly connected to the genesis of the raw material. Most of the samples show a relatively high content of fine and in particular silt material, which may have been transported by wind and water. The material settled in lakes cut off from a main stream of water, thus layer wise segments were deposited. This consideration emphasises the finding that the markalak clay material was in all cases in a particular local manner related to the occurrence of water transport and in that relation to a specific geomorphology. The Indus River flows close to the clay pits in Spituk, and the trough of a valley passes from the north; the Indus with the Basgo River as its side arm flows close to the clay pit in Basgo, which is located just below a plateau; the Indus River passes Achi village; Lamayuru is flanked by a water transporting valley; Shey is also flanked by the Indus River; the clay pit in Nako is located along a trough leading into the Spiti River; Shelkhar is also located along the Spiti River; and Khorchag is flanked by the Peacock River. These troughs may have been channels for the transport of material during the ice age, and fine clay was deposited along its sides. A thick layer of ice may also be the reason why the place of deposit is much higher than today's level of the mentioned riverbeds, for example at Basgo or at Nako. This kind of evolution can be seen as not necessarily dependent on Himalayan regions, but just as the individual geomorphology of each trough having a local particularity. Regarding these kinds of precondition, we can not exclude that in the examined regions (Ladakh, Spiti, Kinnaur and Ngari) it is possible to find many more pits with markalak-like clay, and thus a great number of variations within the range given in this chapter could be possible.

\subsection{Research question 5: In which way can knowledge transfer concerning markalak clay be related to specific locally conventional terms?}

Within this study a knowledge transfer over a wide region over a distance of about $600 \mathrm{~km}$, in particular between Ladakh, Upper Kinnaur and Purang in West Tibet was traced. This transfer was certainly related to both specific local terms and particular properties of the clay. The term "markalak" (Tib. mar ka lag) is well known over a wide area, particularly in Ladakh, and describes a fine butter like clay. Regarding the results of this research, we can state that, over this wide area from Ladakh to Purang, particular material qualities and usage are clearly defined with the terms "markalak", "tua" and "narkalak". When talking about a terminological transfer, the material component is the basis to understand the context. That is to say that during the use of one of these terms in the course of a conversation with locals, traders, workers, et alii, it must have been clear what one was talking about when using terms like "markalak", "narkalak" or "tua", particularly over such a wide distance. The key for this understanding must have been given by the knowledge about specific properties of the material, including colour, haptic and visual 
appearance, and possibly also its taste and also characteristics of the places where the material can be found. Further, also technical features like the behaviour of a particular clay during precipitation (contact with water), wind, pressure, etc. may have been characteristics for the identification and description of particular types of clay. These matters were treated afore in a scientific approach on a material research level. An important factor for communicating on various types of clays seems to be knowledge about the particular clay's use, for example as an upper plaster layer, as proper material for stitching cracks in roofs and walls, or as the upper layer of sculptures etc. The interest of the local user may primarily be the material quality for a particular usage in a complete practical and empirical approach.

In this context, a hypothesis - which has to be treated in an anthropological discourse - is that an essential basis for creating knowledge is experience. It is experience which covers the knowledge on material and cultural aspects. The regional terms of materials cover these aspects and can be seen as vehicles being necessary for an efficient knowledge transfer. Examining the essence of experience lies beyond this study and the given results offer valuable data for further examinations on this topic.

\subsection{Research question 6: What are the geological parametres of markalak clays?}

Markalak clays can be identified as lacustrine sediments, in particular as varve clays. The formation of lakes along water run offs seems to have been responsible for the deposit of this rather fine material. The bright layers point towards a higher content of silt, which was deposited during the warmer season, while the darker layers show a higher content of clay, which were deposited during the colder season. Several Austrian examples were given as comparison. Lacustrine sediments play an important role as raw material for the production of fired bricks. The mineral composition of the given Austrian examples show close similarities to some of the Himalayan samples with the following basic features: small content of swellable minerals, in particular smectite, a rather high content of silt and less clay, a dominance of illite, some metamorphic chlorite as the second strongest clay mineral, and some kaolinite. Both dominant minerals, i.e. illite and chlorite, can be traced back to grinding due to activities of glaciers and moraines. Smectite and kaolinite originate from young weathering and can be described as relatively fresh and post-glacial. Smectite originates from light weathering, while kaolinite is the result of strong weathering. Illite also originates from light glacial weathering, e.g. of mica - starting with a mechanical/physical weathering, followed by chemical weathering.

We can partially find a content of vermiculite, which is a "weak" product of weathering. Mixed layers can be traced back to the interglacial period, but are available in the amount of $1 \%$, as found in sample 11939, which is from a building technical point of view negligible. Vermiculite $14 \AA$ found in sample 11913 is less swellable than vermiculite $18 \AA$. From a constructive point of view, the high amount of non-swellable clay minerals, i.e. illite, chlorite and kaolinite, can be seen as positive. The small content of smectite indicates only minor weathering and heredity. A content of mica throughout indicates physical weathering during the ice age. Weathered chlorite and mica are products of friction from a physical weathering process with - in the Himalayan samples - a varying and always available content of calcite. The amount of feldspar is low and the rock of the catchment area is metamorphic, which is shown by its content of hornblende and mica. 
The high content of clay at app. $80 \%$ in sample 8466 and app. $82 \%$ in sample 8481 is a result of lacustrine sedimentation in the winter season, when fine sediments sink to the ground. The fineness of the sediments leaves an open question concerning genesis. A reason could be a mechanical crushing of fine sediments (incl. illite and chlorite), e.g. by weathering related to a glacier and glacial milk. Lacustrine chalk built up by nanoplankton can be excluded as an explanation due to a too small content of calcite. The content of smectite is also too small to be useful as an explanation. 
